OPEN ACCESS

Edited by:

Guido Moll,

Charité - Universitätsmedizin Berlin,

Germany

Reviewed by:

Mohammad Bayat,

Shahid Beheshti University of Medical

Sciences, Iran

Francisco Avila,

Mayo Clinic Florida, United States

Marco Patruno,

University of Padua, Italy

*Correspondence:

Álvaro Sierra-Sánchez

alvarosisan@gmail.com;

alvarosisan@correo.ugr.es

Specialty section:

This article was submitted to

Stem Cell Research,

a section of the journal

Frontiers in Cell and Developmental

Biology

Received: 15 January 2021

Accepted: 21 June 2021

Published: 23 July 2021

Citation:

Montero-Vilchez T,

Sierra-Sánchez Á, Sanchez-Diaz M,

Quiñones-Vico MI,

Sanabria-de-la-Torre $R$,

Martinez-Lopez $A$ and

Arias-Santiago S (2021)

Mesenchymal Stromal

Cell-Conditioned Medium for Skin

Diseases: A Systematic Review.

Front. Cell Dev. Biol. 9:654210.

doi: 10.3389/fcell.2021.654210

\section{Mesenchymal Stromal Cell-Conditioned Medium for Skin Diseases: A Systematic Review}

\author{
Trinidad Montero-Vilchez ${ }^{1,2}$, Álvaro Sierra-Sánchez ${ }^{2,3 *}$, Manuel Sanchez-Diaz ${ }^{1,2}$, \\ Maria Isabel Quiñones-Vico 2,3,4, Raquel Sanabria-de-la-Torre ${ }^{2,3,4}$, \\ Antonio Martinez-Lopez ${ }^{1,2}$ and Salvador Arias-Santiago $0^{1,2,3,4}$
}

${ }^{1}$ Department of Dermatology, Virgen de las Nieves University Hospital, Granada, Spain, ${ }^{2}$ Biosanitary Institute of Granada (ibs.GRANADA), Granada, Spain, ${ }^{3}$ Cell Production and Tissue Engineering Unit, Virgen de las Nieves University Hospital, Andalusian Network of Design and Translation of Advanced Therapies, Granada, Spain, ${ }^{4}$ Department of Dermatology, Faculty of Medicine, University of Granada, Granada, Spain

The skin is the largest organ of the human body, and its dysfunction is related to many diseases. There is a need to find new potential effective therapies for some skin conditions such as inflammatory diseases, wound healing, or hair restoration. Mesenchymal stromal cell (MSC)-conditioned medium (CM) provides a potential opportunity in the treatment of skin disease. Thus, the objective of this review is to evaluate the uses of MSC-CM for treating skin diseases in both animal and human models. A systematic review was conducted regarding the use of MSC-CM for treating skin conditions. One hundred one studies were analyzed. MSC-CM was evaluated in wound healing (55), hypertrophic scars (9), flap reperfusion (4), hair restoration (15), skin rejuvenation (15), and inflammatory skin diseases (3). MSC-CM was obtained from different MSC sources, mainly adipose tissue, bone marrow, and umbilical cord blood. MSC-CM was tested intravenously, intraperitoneally, subcutaneously, intradermally or intralesionally injected or topically applied. MSC-CM was used in both animals and humans. MSC-CM improved wound healing, hair restoration, skin rejuvenation, atopic dermatitis, and psoriasis in both animals and humans. MSC-CM also decreased hypertrophic scars and flap ischemia in animal models. In conclusion, MSC-CM is a promising therapy for skin conditions. Further studies are needed to corroborate safety and effectiveness and to standardize CM manufacturing.

Keywords: advanced therapy, conditioned medium, dermatology, mesenchymal stem cells, stem cells

\footnotetext{
Abbreviations: $\mathrm{AD}$, atopic dermatitis; $\mathrm{AGA}$, androgenetic alopecia; $\mathrm{AT}$, adipose tissue; $\mathrm{BM}$, bone marrow; Botox, botulinum toxin type A; CM, conditioned medium; DMEM, Dulbecco's modified Eagle medium; ECM, extracellular matrix; EV, extracellular vesicles; Exos, exosomes; HB-EGF, heparin binding-epidermal growth factor-like growth factor; HDFs, human dermal fibroblasts; HGF, hepatocyte growth factor; IGF, insulin-like growth factor; IL, interleukin; Men, menstrual blood; MSCs, mesenchymal stromal cells; PBS, phosphate-buffered saline; PSSI, Psoriasis Scalp Severity Index; qRT-PCR, real-time quantitative polymerase chain reaction; SCH, stratum corneum hydration $(\mathrm{SCH})$; SCORAD, SCORing Atopic Dermatitis Index; SHSs, Haliclona sp. spicules; SDF-1, stromal cell-derived factor 1; TEWL, transepidermal water loss; TGF- $\beta$, transforming growth factor $\beta$; Th2, lymphocyte T helper type 2; TNF- $\alpha$, tumor necrosis factor $\alpha$; UC, umbilical cord; VEGF, vascular endothelial growth factor.
} 


\section{INTRODUCTION}

Mesenchymal stromal cells (MSCs) are a type of multipotent adult stem cells that have the potential to proliferate, selfregenerate, and differentiate into multiple cell lineages (Dominici et al., 2006). They can be isolated from several sources such as bone marrow (BM-MSCs), adipose tissue (AT-MSCs), umbilical cord (UC-MSCs), amnion, placenta, or dental pulp (Bogatcheva and Coleman, 2019). MSCs are considered to be one of the most promising therapeutic options in cell therapy and tissue engineering, as they can be used for treating skin, cardiovascular, hematological, neurological, bone, and cartilage diseases (Wong et al., 2015; Kim et al., 2017; Hu et al., 2018; Martinez-Lopez et al., 2020).

It has been observed that the beneficial effects of MSCs are due not only to their multipotent ability but also to their secreted cytokines and growth factors (Caplan, 2017). Cell-free preparations have several advantages over cell therapy, as they can be obtained more easily and more economically and can be manufactured, packaged, and transported straightforwardly (Yang et al., 2021). Moreover, cellfree preparations do not have adverse events associated with cell administration such as rejection, tumorigenic, thrombogenic, ossification, or calcification risk (Bogatcheva and Coleman, 2019; Yang et al., 2021). The risk of malignant transformation of MSCs is a great concern, as MSCs therapy involves ex vivo production and expansion of cell lines, although the spontaneous malignant transformation of human MSCs has not been completely proved and there are many studies that have demonstrated that MSCs, even after physical and chemical stress, undergo senescence rather than become tumorigenic (Caplan et al., 2019). MSCs activate the host innate immune systems and the coagulation, increasing the expression of procoagulant tissue factor and demonstrating a procoagulant effect after MSC contact with blood in in vitro investigations. Infusion reactions and thromboembolism have been reported when using intravascular MSC products. A possible proposed solution to this problem is diluting or treating the MSCs with tissue factor pathwayblocking reagents. Moreover, hemocompatibility testing and optimal product delivery are important for designing safer MSC therapies. Other experimental intravascular therapies, such as islets, hepatocytes, and products derived from MSCs, could also improve MSC safety (Moll et al., 2019). The activation of the immune response could also lead to rejection. There are many investigations that focus on strategies to evade immune recognition, such as human leukocyte antigen (HLA)-matched cells or pharmaceutical immunosuppression (Moll et al., 2019, 2020). Cell-free preparation could help to reduce this risk of malignant transformation, thrombogenic risk, and rejection.

The molecules secreted by stromal cells are referred to the stromal cell secretome and include proteins, microRNA, growth factors, antioxidants, proteasomes, and exosomes (Maguire, 2013). The stromal cell culture media that comprise the secretome are known as the conditioned media (CM), and they are considered to be an abundant resource of paracrine factors (Pawitan, 2014; Mizukami and Yagihashi, 2016). The paracrine factors secreted in vitro include vascular endothelial growth factor (VEGF), hepatocyte growth factor (HGF), insulinlike growth factor-1 (IGF-1), IGF-2, and stromal cell-derived factor 1 (SDF-1) (Ratajczak et al., 2012; Deng et al., 2018). The administration of these factors to the site of an injured organ increases its metabolic activity and oxygen supply and remodels the extracellular matrix (Ratajczak et al., 2012).

The skin is the largest organ of the human body, and its dysfunction is linked to several diseases (Montero-Vilchez et al., 2021). MSCs provide a supply of new cells for epidermal homeostasis, hair cycling, and repairing injured tissue (Kim et al., 2017; Guo et al., 2020). MSCs-CM also provide a potential opportunity in the treatment of skin disease, and there is increased evidence justifying its use for the treatment of cutaneous conditions such as wound healing, hair growth, inflammatory skin diseases, or skin rejuvenation. Thus, the objective of this review is to evaluate the use of MSC-CM for treating skin diseases in both in animals and humans.

\section{MATERIALS AND METHODS}

\section{Search Strategy}

A literature search was performed using Medline, Scopus, Embase, and ClinicalTrials.gov from conception to October 2020, following PRISMA Guidelines (Supplementary Material). The following search terms were used: [(MSC) OR (Mesenchymal Stem Cell) OR (Mesenchymal Stromal Cell) OR (Multipotent Stem Cell) OR (Multipotent Stromal Cell) OR (Stem Cell)] AND [(Conditioned Medium) OR (Conditioned Culture Media)] AND [(skin) OR (dermatology)].

\section{Inclusion and Exclusion Criteria}

The search was limited to (i) human or animal data, (ii) in vivo studies, (iii) using MSC-CM for skin conditions, and (iv) articles written in English or Spanish.

All types of epidemiological studies (clinical trials, cohort studies, case-control studies, and cross-sectional studies) regarding MSC-CM use for skin conditions were included and analyzed. Reviews, guidelines, protocols, and conference abstracts were excluded.

\section{Study Selection}

Two researchers (TMV and AML) independently reviewed the titles and abstracts of the articles obtained in the first search to assess relevant studies. The full texts of all articles meeting the inclusion criteria were reviewed, and their bibliographic references were checked for additional sources. The articles considered relevant by both researchers were included in the analysis. Disagreements about inclusion or exclusion of articles were discussed until a consensus was reached. If no consensus was reached, resolution was achieved by discussion with a third researcher (SAS).

\section{Variables}

The variables assessed were MSC source, passage number and percentage of confluence, model tested, treatment group, 


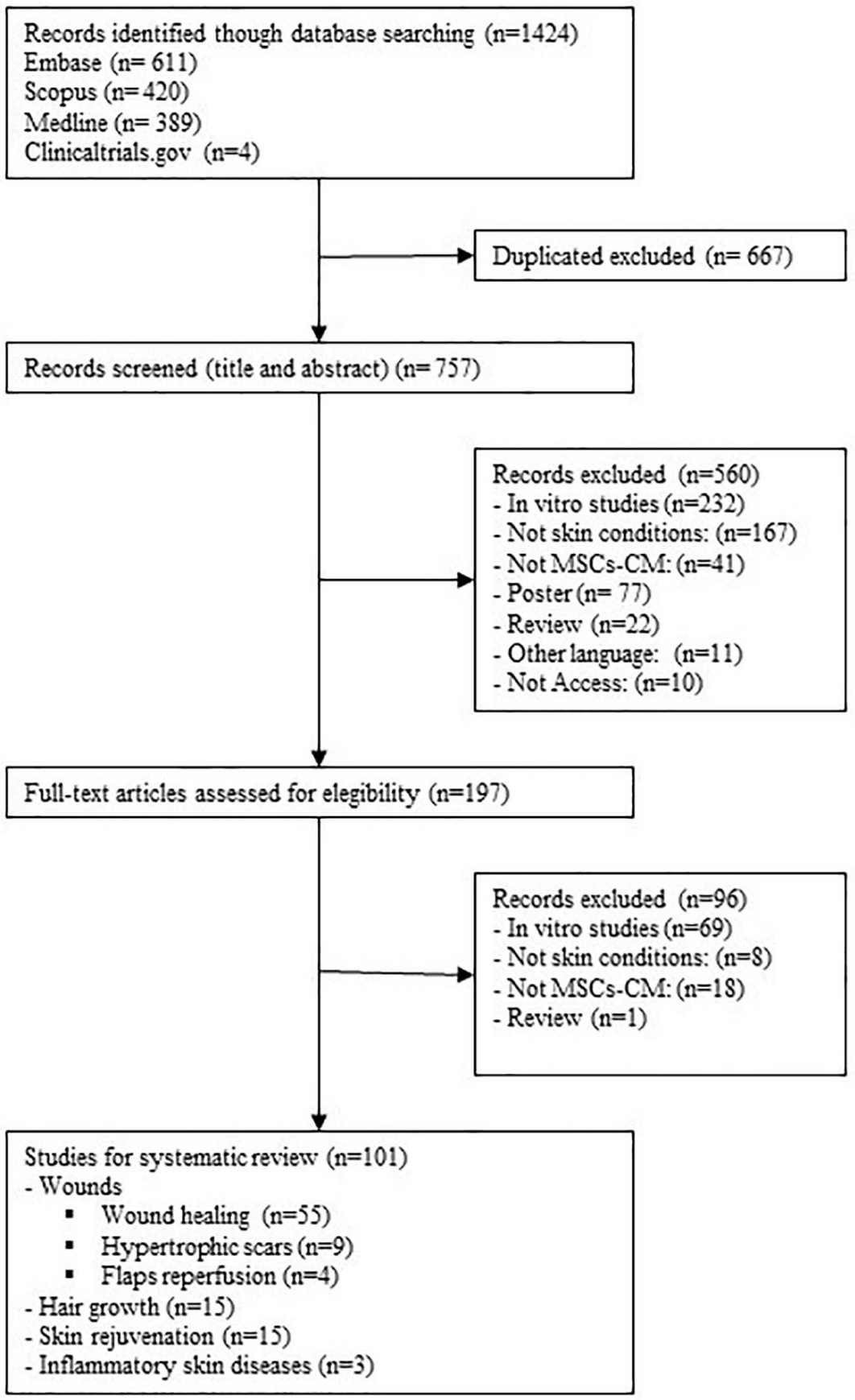

FIGURE 1 | Flow diagram of the study selection process.

route of administration, sample size, assessment, outcomes, and adverse events.

\section{RESULTS}

Our literature search identified 1,422 references, 757

after removing duplicates. After the title and abstract were screened, 197 records underwent full-text review. A total of 96 records were excluded because they did not investigate MSC-CM treatment in vivo skin conditions. Other reasons for exclusion along with the flowchart are shown in Figure 1. Ultimately, 101 studies met the eligible criteria.

Mesenchymal stromal cell-CM has been tested in several skin conditions: wound healing, hypertrophic scars, flap and 
TABLE 1 | Studies regarding mesenchymal stromal cell-conditioned medium for treating wounds in animal models.

\begin{tabular}{|c|c|c|c|c|c|c|c|c|c|c|}
\hline & MSC source & $\begin{array}{l}\text { Method of } \\
\text { tissue } \\
\text { extraction }\end{array}$ & $\begin{array}{l}\text { MSC } \\
\text { characterization }\end{array}$ & $\begin{array}{l}\text { Preparation of } \\
\text { MSC-CM }\end{array}$ & Model & $\begin{array}{l}\text { Groups of } \\
\text { treatments and } \\
\text { via of } \\
\text { administration }\end{array}$ & $\begin{array}{l}\text { Follow-up } \\
\text { (days) }\end{array}$ & Assessment & Main outcome & Other outcomes \\
\hline $\begin{array}{l}\text { Chen et al., } \\
2021\end{array}$ & $\begin{array}{l}\text { Human } \\
\text { subcutaneous } \\
\text { adipose tissue } \\
\text { samples }\end{array}$ & Liposuction & $\begin{array}{l}\text { Flow cytometry } \\
\text { (CD29+, CD90+, } \\
\text { CD105+, CD31-, } \\
\text { CD34-, CD45-). } \\
\text { Osteogenic and } \\
\text { adipogenic } \\
\text { differentiation }\end{array}$ & $\begin{array}{l}\text { MSCs of passage } \\
3 \text { at } 90 \% \\
\text { confluence were } \\
\text { used. CMs at } \\
\text { different dilutions } \\
\text { (100, 50, and } \\
25 \% \text { ) were } \\
\text { collected. } \\
\text { Electrospun } \\
\text { fibrous scaffolds } \\
\text { formed by } \\
\text { emulsion } \\
\text { electrospinning; } \\
\text { an ADSC-CM } \\
\text { loaded } \\
\text { micro-nano } \\
\text { polylactic acid } \\
\text { (PLA) electrospun } \\
\text { fiber (MPF) was } \\
\text { developed }\end{array}$ & $\begin{array}{l}\text { Murine. } \\
\text { Full-thickness } \\
\text { excisional } \\
\text { wounds, } \\
15 \mathrm{~mm} \times 15 \mathrm{~mm} \text {, } \\
\text { on dorsal surface }\end{array}$ & $\begin{array}{l}\text { Wounds were } \\
\text { covered with an } \\
\text { electrospun } \\
\text { membrane } \\
\text { - Control } \\
\text { - MPF alone } \\
\text { - MPF loaded } \\
\text { with 100\% } \\
\text { AT-MSC-CM } \\
\text { - MPF loaded } \\
\text { with 50\% } \\
\text { AT-MSC-CM } \\
\text { - MPF loaded } \\
\text { with 25\% } \\
\text { ATMSC-CM } \\
\text { ( } n=3 / \text { group) }\end{array}$ & 15 & $\begin{array}{l}\text { Macroscopic } \\
\text { appearance } \\
\text { (photography), } \\
\text { histology (HE, } \\
\text { MT), IHC, } \\
\text { qRT-PCR }\end{array}$ & $\begin{array}{l}\text { MPF loaded with } \\
\text { MSC-CM } \\
\text { accelerated } \\
\text { wound healing } \\
\text { and prevented } \\
\text { abnormal scar } \\
\text { formation, } \\
\text { promoting } \\
\text { angiogenesis } \\
\text { without adversely } \\
\text { affecting } \\
\text { epidermal cells }\end{array}$ & $\begin{array}{l}\text { MPF loaded with } \\
\text { MSC-CM inhibited } \\
\text { ECM deposition, } \\
\text { including Col I and } \\
\text { Col III, and } \\
\text { decreased } \alpha \text {-SMA } \\
\text { expression, } \\
\text { showing an } \\
\text { inhibitory effect on } \\
\text { fibroblast } \\
\text { differentiation. } \\
\text { Groups with less } \\
\text { collagen deposition } \\
\text { and smaller scar } \\
\text { area showed more } \\
\text { VEGF expression } \\
\text { and a faster healing } \\
\text { rate. The wound } \\
\text { area of MPF loaded } \\
\text { with } 100 \% \\
\text { AT-MSC-CM was } \\
\text { only } 34.9 \% \text { of that } \\
\text { of the control group }\end{array}$ \\
\hline $\begin{array}{l}\text { Zhou et al., } \\
2020\end{array}$ & $\begin{array}{l}\text { Human dental } \\
\text { pulp isolated } \\
\text { from } \\
\text { periodontally } \\
\text { compromised } \\
\text { teeth } \\
\text { (P-DP-MSCs) } \\
\text { and healthy } \\
\text { teeth } \\
\text { (H-DP-MSCs) }\end{array}$ & Teeth extracting & $\begin{array}{l}\text { Flow cytometry } \\
\text { (CD90+, CD105+, } \\
\text { CD146+, CD31-, } \\
\text { CD34-, CD45-). } \\
\text { Osteogenic, } \\
\text { adipogenic, and } \\
\text { chondrogenic } \\
\text { differentiation }\end{array}$ & $\begin{array}{l}\text { MSCs of passage } \\
4 \text { at } 90 \% \\
\text { confluence were } \\
\text { used. CM was } \\
\text { collected and, it } \\
\text { was used to } \\
\text { obtain EVs }\end{array}$ & $\begin{array}{l}\text { Murine. } \\
\text { Full-thickness } \\
\text { excisional } \\
\text { wounds, on the } \\
\text { dorsal surface }\end{array}$ & $\begin{array}{l}100 \mu l \\
\text { subcutaneously } \\
\text { injected at } 4 \text { sites } \\
\text { around the } \\
\text { wound ( } 25 \mu \text { l per } \\
\text { site) } \\
\text { - Control } \\
\text { - P-DP-MSC-CM } \\
\text { EVs } \\
\text { - H-DP-MSC- } \\
\text { CM EVs } \\
\text { ( } n=10 / \text { group) }\end{array}$ & 14 & $\begin{array}{l}\text { Macroscopic } \\
\text { appearance } \\
\text { (photography), } \\
\text { microscopic } \\
\text { appearance } \\
\text { (newly formed } \\
\text { vessels), } \\
\text { histology (HE), } \\
\text { IHC (VEGF, } \\
\text { CD31) }\end{array}$ & $\begin{array}{l}\text { Wound closure } \\
\text { was markedly } \\
\text { accelerated by } \\
\text { DP-MSC-CM } \\
\text { EVs and } \\
\text { P-DP-MSC-CM } \\
\text { EVs. } \\
\text { P-DP-MSC-CM } \\
\text { EV group closed } \\
\text { faster than } \\
\text { H-DP-MSC-CM } \\
\text { EV group } \\
\text { (p<0.05) }\end{array}$ & $\begin{array}{l}\text { DP-MSC-CM } \\
\text { extracellular } \\
\text { vesicle-treated } \\
\text { wounds had a } \\
\text { lower level of scar } \\
\text { formation and } \\
\text { enhanced vessel } \\
\text { formation in the } \\
\text { wound sites. No } \\
\text { adverse events } \\
\text { were observed }\end{array}$ \\
\hline
\end{tabular}


TABLE 1 | Continued

\begin{tabular}{|c|c|c|c|c|c|c|c|c|c|c|}
\hline & MSC source & $\begin{array}{l}\text { Method of } \\
\text { tissue } \\
\text { extraction }\end{array}$ & $\begin{array}{l}\text { MSC } \\
\text { characterization }\end{array}$ & $\begin{array}{l}\text { Preparation of } \\
\text { MSC-CM }\end{array}$ & Model & $\begin{array}{l}\text { Groups of } \\
\text { treatments and } \\
\text { via of } \\
\text { administration }\end{array}$ & $\begin{array}{l}\text { Follow-up } \\
\text { (days) }\end{array}$ & Assessment & Main outcome & Other outcomes \\
\hline $\begin{array}{l}\text { Sabzevari et al., } \\
2020\end{array}$ & $\begin{array}{l}\text { Wharton's jelly } \\
\text { from human } \\
\text { umbilical cords }\end{array}$ & $\begin{array}{l}\text { Cesarean } \\
\text { section }\end{array}$ & $\begin{array}{l}\text { Flow cytometry } \\
\text { (CD44+, CD73+, } \\
\text { CD90+, CD105+, } \\
\text { CD14-, CD31-, } \\
\text { CD34-, CD45-, } \\
\text { HLA-DR-). } \\
\text { Osteogenic, } \\
\text { adipogenic, and } \\
\text { chondrogenic } \\
\text { differentiation }\end{array}$ & $\begin{array}{l}\text { MSC of passages } \\
4-6 \text { at } 70 \% \\
\text { confluence were } \\
\text { used. WJ-MSCs } \\
\text { were transfected } \\
\text { with a } \\
\text { recombinant } \\
\text { construct } \\
\text { encoding } \\
\text { hCAP-18/LL-37 } \\
\text { gene. Next, the } \\
\text { CM of the } \\
\text { transfected cells } \\
\text { (LL-37-MSCs) } \\
\text { was harvested, } \\
\text { and its } \\
\text { concentrate was } \\
\text { formulated in a } \\
\text { sodium alginate } \\
\text { (SA)/gelatine (G) } \\
\text { hydrogel }\end{array}$ & $\begin{array}{l}\text { Murine. } \\
\text { Full-thickness } \\
\text { circular excision } \\
\text { wound, } 20 \mathrm{~mm} \text {, } \\
\text { below the skull }\end{array}$ & $\begin{array}{l}\text { The hydrogel was } \\
\text { placed on the } \\
\text { wound and } \\
\text { covered by a } \\
\text { wound dressing } \\
\text { - PBS (control) } \\
\text { - SA/G-PBS } \\
\text { group (the } \\
\text { SA/G-2/8 } \\
\text { hydrogel } \\
\text { contained only } \\
\text { PBS) } \\
\text { - SA/G-V-CM } \\
\text { group (the } \\
\text { SA/G-2/8 } \\
\text { hydrogel } \\
\text { contained only } \\
\text { CM vehicle) } \\
\text { - SA/G-LL-37- } \\
\text { CM group (the } \\
\text { SA/G-2/8 } \\
\text { hydrogel } \\
\text { contained } \\
\text { LL-37-CM) } \\
\text { (n=3/group) }\end{array}$ & 21 & $\begin{array}{l}\text { Macroscopic } \\
\text { appearance } \\
\text { (photography), } \\
\text { histology (HE, } \\
\text { MT), qRT-PCR }\end{array}$ & $\begin{array}{l}\text { WJ-MSC-CM } \\
\text { hydrogel } \\
\text { effectively } \\
\text { accelerated } \\
\text { wound } \\
\text { contraction and } \\
\text { promoted wound } \\
\text { healing, even } \\
\text { more in the } \\
\text { SA/G-LL-37-CM } \\
\text { group }\end{array}$ & $\begin{array}{l}\text { Blood vessels were } \\
\text { higher in } \\
\text { SA/G-LL-37-CM } \\
\text { group, showing the } \\
\text { early angiogenesis } \\
\text { profile with higher } \\
\text { VEGF-A levels. This } \\
\text { group also showed } \\
\text { the best collagen } \\
\text { arrangement, } \\
\text { thickness, and } \\
\text { density }\end{array}$ \\
\hline $\begin{array}{l}\text { Joseph et al., } \\
2020\end{array}$ & $\begin{array}{l}\text { Caprine, } \\
\text { canine, and } \\
\text { guinea pig } \\
\text { bone marrow }\end{array}$ & $\begin{array}{l}\text { Aspiration } \\
\text { needle from the } \\
\text { iliac crest }\end{array}$ & $\begin{array}{l}\text { Flow cytometry (CD } \\
73+, \text { CD90+, CD } \\
\text { 105+, CD34-). } \\
\text { Chondrogenic, } \\
\text { osteogenic, and } \\
\text { adipogenic } \\
\text { differentiation }\end{array}$ & $\begin{array}{l}\text { MSCs of passage } \\
3 \text { at } 80 \% \\
\text { confluence were } \\
\text { used. CM was } \\
\text { collected and } \\
\text { then lyophilized } \\
\text { by the } \\
\text { freeze-drying } \\
\text { method and was } \\
\text { vacuum sealed } \\
\text { and stored at } \\
4^{\circ} \mathrm{C} \text {. } \\
\text { A serum-free } \\
\text { DMEM medium } \\
\text { was processed } \\
\text { for use as a } \\
\text { control }\end{array}$ & $\begin{array}{l}\text { Guinea pig. } \\
\text { Full-thickness } \\
\text { excisional skin } \\
\text { wounds, } \\
20 \mathrm{~mm} \times 20 \mathrm{~mm} \text {, } \\
\text { on the dorsum on } \\
\text { either side of the } \\
\text { midline }\end{array}$ & $\begin{array}{l}100 \mu \text { l of } \\
\text { formulated } \\
\text { respective CM } \\
\text { was applied } \\
\text { topically with } \\
\text { sterile applicator } \\
\text { over the wounds } \\
\text { one per week } \\
\text { - Control (laminin } \\
\text { gel+DMEM) } \\
\text { - Canine CM } \\
\text { (laminin } \\
\text { gel+canine } \\
\text { MSC-CM) } \\
\text { - Caprine CM } \\
\text { (laminin } \\
\text { gel+caprine } \\
\text { MSC-CM) }\end{array}$ & 28 & $\begin{array}{l}\text { Macroscopic } \\
\text { appearance } \\
\text { (photography), } \\
\text { histology (HE) }\end{array}$ & $\begin{array}{l}\text { MSC-CM } \\
\text { accelerates } \\
\text { excision wound } \\
\text { healing } \\
\text { compared with } \\
\text { control }(p<0.05)\end{array}$ & $\begin{array}{l}\text { Surface epithelium, } \\
\text { neovascularization, } \\
\text { and collagen } \\
\text { depositions } \\
\text { improved more in } \\
\text { MSC-CM-treated } \\
\text { group than in } \\
\text { controls ( } p<0.05) \text {. } \\
\text { Allogeneic and } \\
\text { xenogenic } \\
\text { application of CM } \\
\text { significantly } \\
\text { improved wound } \\
\text { healing quality, with } \\
\text { minimal scar } \\
\text { formation. Better } \\
\text { healing rate was } \\
\text { observed in the } \\
\text { allogeneic group }\end{array}$ \\
\hline
\end{tabular}


TABLE 1 | Continued

\begin{tabular}{|c|c|c|c|c|c|c|c|c|c|c|}
\hline & MSC source & $\begin{array}{l}\text { Method of } \\
\text { tissue } \\
\text { extraction }\end{array}$ & $\begin{array}{l}\text { MSC } \\
\text { characterization }\end{array}$ & $\begin{array}{l}\text { Preparation of } \\
\text { MSC-CM }\end{array}$ & Model & $\begin{array}{l}\text { Groups of } \\
\text { treatments and } \\
\text { via of } \\
\text { administration }\end{array}$ & $\begin{array}{l}\text { Follow-up } \\
\text { (days) }\end{array}$ & Assessment & Main outcome & Other outcomes \\
\hline & & & & & & $\begin{array}{l}\text { - Guinea pig CM } \\
\text { (laminin } \\
\text { gel+guinea pig } \\
\text { MSC-CM) } \\
\text { ( } n=6 / \text { group) }\end{array}$ & & & & \\
\hline He et al., 2020 & Human amnion & Amniocentesis & $\begin{array}{l}\text { Flow cytometry } \\
\text { (CD73, CD45, } \\
\text { CD31, CD105, } \\
\text { CD44, CD34, } \\
\text { CD90, CD29, } \\
\text { SSEA-3, SSEA-4, } \\
\text { EP-CAM, HLA-DR). } \\
\text { Chondrogenic, } \\
\text { osteogenic, and } \\
\text { adipogenic } \\
\text { differentiation }\end{array}$ & $\begin{array}{l}\text { MSCs of passage } \\
2 \text { at } 90 \% \\
\text { confluence were } \\
\text { used. CM was } \\
\text { collected }\end{array}$ & $\begin{array}{l}\text { Murine. } \\
\text { Full-thickness } \\
\text { excisional skin } \\
\text { wounds, } 10 \mathrm{~mm} \text {, } \\
\text { on the dorsum }\end{array}$ & $\begin{array}{l}50 \mu \mathrm{l} \\
\text { subcutaneous } \\
\text { injected into the } \\
\text { surrounding } \\
\text { tissues of the } \\
\text { wound bed at } \\
\text { four sites } \\
\text { - PBS (control) } \\
\text { - MSC-CM } \\
\text { - Murine LOXL2 } \\
\text { ( } 5 \mu \mathrm{g}, \text { Sino } \\
\text { Biologicals, } \\
\text { China) } \\
\text { ( } n=4 / \text { group) }\end{array}$ & 12 & $\begin{array}{l}\text { Macroscopic } \\
\text { appearance } \\
\text { (photography), } \\
\text { histology (HE, TC) }\end{array}$ & $\begin{array}{l}\text { Wound sizes } \\
\text { were significantly } \\
\text { reduced in the } \\
\text { LOXL2 and } \\
\text { MSC-CM groups } \\
\text { compared with } \\
\text { controls } \\
(p<0.05)\end{array}$ & $\begin{array}{l}\text { MSC-CM and } \\
\text { LOXL2 enhanced } \\
\text { wound healing. } \\
\text { Epidermis of the } \\
\text { MSC-CM and } \\
\text { LOXL2 group mice } \\
\text { resembled normal } \\
\text { skin and the } \\
\text { keratinocytes were } \\
\text { well organized and } \\
\text { tightly arranged. } \\
\text { These treatments } \\
\text { also significantly } \\
\text { reduced fibrosis } \\
\text { and improved } \\
\text { keratinocyte } \\
\text { proliferation. No } \\
\text { adverse events } \\
\text { were reported }\end{array}$ \\
\hline $\begin{array}{l}\text { Ahangar et al., } \\
2020\end{array}$ & $\begin{array}{l}\text { Human bone } \\
\text { marrow }\end{array}$ & Aspiration & - & $\begin{array}{l}\text { MSCs of passage } \\
1 \text { at } 70 \% \\
\text { confluence were } \\
\text { used. CM was } \\
\text { collected }\end{array}$ & $\begin{array}{l}\text { Murine. } \\
\text { Full-thickness } \\
\text { excisional skin } \\
\text { wounds, } 6 \mathrm{~mm}^{2} \text {, } \\
\text { on dorsal surface }\end{array}$ & $\begin{array}{l}100 \mu \mathrm{I} \text { was } \\
\text { injected at four } \\
\text { sites into the } \\
\text { margins of each } \\
\text { wound MSC-CM } \\
\text { - DMEM } \\
\text { ( } n=8 / \text { group) }\end{array}$ & 14 & $\begin{array}{l}\text { Macroscopic } \\
\text { appearance } \\
\text { (photography), } \\
\text { histology (HE, } \\
\text { TC), IHC, } \\
\text { qRT-PCR }\end{array}$ & $\begin{array}{l}\text { MSC-CM } \\
\text { improved wound } \\
\text { healing, showing } \\
\text { a significant } \\
\text { reduction in } \\
\text { average wound } \\
\text { area and wound } \\
\text { width compared } \\
\text { with } \\
\text { DMEM-treated } \\
\text { group }(p<0.05)\end{array}$ & $\begin{array}{l}\text { At day } 7 \\
\text { post-wounding, } \\
\text { wounds in } \\
\text { MSC-CM-treated } \\
\text { mice were } 90 \% \\
\text { re-epithelialized } \\
\text { compared with } \\
78 \% \text { in control } \\
\text { group. MSC-CM } \\
\text { also decreased } \\
\text { inflammatory } \\
\text { response, } \\
\text { increased } \\
\text { endothelial cell } \\
\text { number and } \\
\text { angiogenesis } \\
\text { (showed in an } \\
\text { increased numbers } \\
\text { of CD31-positive }\end{array}$ \\
\hline
\end{tabular}


TABLE 1 | Continued

\begin{tabular}{|c|c|c|c|c|c|c|c|c|c|c|}
\hline & MSC source & $\begin{array}{l}\text { Method of } \\
\text { tissue } \\
\text { extraction }\end{array}$ & $\begin{array}{l}\text { MSC } \\
\text { characterization }\end{array}$ & $\begin{array}{l}\text { Preparation of } \\
\text { MSC-CM }\end{array}$ & Model & $\begin{array}{l}\text { Groups of } \\
\text { treatments and } \\
\text { via of } \\
\text { administration }\end{array}$ & $\begin{array}{l}\text { Follow-up } \\
\text { (days) }\end{array}$ & Assessment & Main outcome & Other outcomes \\
\hline & & & & & & & & & & $\begin{array}{l}\text { endothelial cells), } \\
\text { and increased both } \\
\text { collagen I and III } \\
\text { expression }\end{array}$ \\
\hline $\begin{array}{l}\text { Rong et al., } \\
2019\end{array}$ & $\begin{array}{l}\text { ASC: sticks of } \\
\text { antlers from } \\
\text { sika deer } \\
\text { hU-MSC: } \\
\text { human } \\
\text { umbilical cords }\end{array}$ & $\begin{array}{l}\text { hU-MSC: } \\
\text { Cesarean } \\
\text { sections }\end{array}$ & - & $\begin{array}{l}\text { MSCs of passage } \\
3 \text { at } 80 \% \\
\text { confluence were } \\
\text { used. CM was } \\
\text { collected }\end{array}$ & $\begin{array}{l}\text { Murine. } \\
\text { Full-thickness } \\
\text { skin excisional } \\
\text { wounds, } 8 \mathrm{~mm} \text { in } \\
\text { diameter, on the } \\
\text { dorsal surface }\end{array}$ & $\begin{array}{l}\text { MSC-CM was } \\
\text { mixed with the } \\
\text { hydrogel. } 200 \mu \text { I } \\
\text { of each group } \\
\text { was pipetted } \\
\text { onto the wound } \\
\text { every } 2 \text { days } \\
\text { - DMEM } \\
\text { - EGF } \\
\text { - MSC-CM } \\
\text { - ASC-CM } \\
\text { ( } n=8 \text { /group) }\end{array}$ & 16 & $\begin{array}{l}\text { Photography, } \\
\text { histology (HE), } \\
{ }^{H C C}\end{array}$ & $\begin{array}{l}\text { ASC-CM group } \\
\text { accelerated } \\
\text { wound healing } \\
\text { compared with } \\
\text { other treatments. } \\
\text { At } 16 \text { days, } \\
\text { wounds in } \\
\text { ASC-CM group } \\
\text { were completely } \\
\text { closed, while } \\
\text { other groups } \\
\text { showed different } \\
\text { sizes of unhealed } \\
\text { wounds (DMEM, } \\
6.14 \pm 4.1 \mathrm{~mm}^{2} ; \\
\text { EGF, } \\
1.79 \pm 3.2 \mathrm{~mm}^{2} ; \\
\text { hU-MSC-CM, } \\
0.61 \pm 2.3 \mathrm{~mm}^{2} \text {, } \\
p<0.05 \text { ) }\end{array}$ & $\begin{array}{l}\text { ASC-CM group } \\
\text { had the thickest } \\
\text { dermis containing } \\
\text { the highest number } \\
\text { of cutaneous } \\
\text { appendages and } \\
\text { the highest vessel } \\
\text { numbers. The } \\
\text { ASC-CM treatment } \\
\text { significantly } \\
\text { upregulated the } \\
\text { expression ratios of } \\
\text { Col3A1/Col1A2, } \\
\text { TGF- } \beta 3 / T G F-\beta 1 \text {, } \\
\text { MMP1/TIMP1 and } \\
\text { MMP3/TIMP1 }\end{array}$ \\
\hline $\begin{array}{l}\text { Robert et al., } \\
2019\end{array}$ & Human skin & Face-lifting & - & $\begin{array}{l}\text { MSCs of passage } \\
6 \text { at } 90 \% \\
\text { confluence were } \\
\text { used. CM was } \\
\text { collected }\end{array}$ & $\begin{array}{l}\text { Murine. } \\
\text { Full-thickness } \\
\text { excisional wound, } \\
6 \mathrm{~mm} \text { in } \\
\text { diameter, on } \\
\text { dorsum surface }\end{array}$ & $\begin{array}{l}\text { CM was directly } \\
\text { applied to the } \\
\text { wounds or } \\
\text { embedded within } \\
\text { hydrogels } \\
\text { - Control, no } \\
\text { treatment }(n=12) \\
\text { - Carrageenan } \\
\text { hydrogel }(n=9) \\
\text { - Carrageenan } \\
\text { hydrogel } \\
\text { embedded with } \\
\text { MSC-CM }(n=10) \\
\text { - Polyvinyl alcohol } \\
\text { hydrogel }(n=10) \\
\text { - Polyvinyl alcohol } \\
\text { hydrogel- } \\
\text { embedded with } \\
\text { MSC-CM }(n=11) \\
\text { - Only MSC-CM } \\
(n=8)\end{array}$ & 14 & $\begin{array}{l}\text { Macroscopic } \\
\text { appearance } \\
\text { (photography), } \\
\text { histology (HE) }\end{array}$ & $\begin{array}{l}\text { All groups } \\
\text { showed } \\
\text { successfully } \\
\text { repaired and } \\
\text { closed wounds, } \\
\text { although the } \\
\text { animals treated } \\
\text { with CM } \\
\text { embedded in } \\
\text { PVA (or only with } \\
\text { PVA) displayed } \\
\text { slightly larger } \\
\text { wounds } \\
(p>0.05)\end{array}$ & $\begin{array}{l}\text { Improvements in } \\
\text { wound closure } \\
\text { were not observed, } \\
\text { but MSC-CM } \\
\text { increased } \\
\text { angiogenesis, } \\
\text { independently of } \\
\text { the hydrogel used }\end{array}$ \\
\hline
\end{tabular}


TABLE 1 | Continued

\begin{tabular}{|c|c|c|c|c|c|c|c|c|c|c|}
\hline & MSC source & $\begin{array}{l}\text { Method of } \\
\text { tissue } \\
\text { extraction }\end{array}$ & $\begin{array}{l}\text { MSC } \\
\text { characterization }\end{array}$ & $\begin{array}{l}\text { Preparation of } \\
\text { MSC-CM }\end{array}$ & Model & $\begin{array}{l}\text { Groups of } \\
\text { treatments and } \\
\text { via of } \\
\text { administration }\end{array}$ & $\begin{array}{l}\text { Follow-up } \\
\text { (days) }\end{array}$ & Assessment & Main outcome & Other outcomes \\
\hline Raj et al., 2019 & $\begin{array}{l}\text { Human } \\
\text { umbilical cord }\end{array}$ & $\begin{array}{l}\text { Umbilical cord } \\
\text { dissection }\end{array}$ & $\begin{array}{l}\text { Flow cytometry } \\
\text { (CD13+, CD29+, } \\
\text { CD44+, CD90+, } \\
\text { CD10-, CD14-, } \\
\text { CD34-, CD117-) }\end{array}$ & $\begin{array}{l}\text { MSCs were } \\
\text { transduced with a } \\
\text { lentiviral vector } \\
\text { (green } \\
\text { fluorescence } \\
\text { protein tagged). } \\
\text { MSCs of passage } \\
\text { 3-4 were used. } \\
\text { CM was } \\
\text { collected. Wound } \\
\text { dressing patches: } \\
\text { impregnated of } \\
\text { aloe } \\
\text { verapolycaprolactone } \\
\text { (AV/PCL) } \\
\text { nanoscaffolds } \\
\text { with hWJSCs or } \\
\text { hWJSC-CM } \\
\text { were also created }\end{array}$ & $\begin{array}{l}\text { Murine. } \\
\text { Full-thickness } \\
\text { excisional wound, } \\
8 \mathrm{~mm} \text {, on the } \\
\text { back }\end{array}$ & $\begin{array}{l}100 \mu \text { l of: } \\
- \text { PBS with } \\
1 \times 10^{6} \mathrm{MSCs} \\
\text { - MSC-CM } \\
- \text { PBS with } \\
1 \times 10^{6} \text { fibroblast } \\
\text { - Fibroblast-CM } \\
- \text { UCM } \\
- \text { PBS with } \\
1 \times 10^{6} \\
\text { MSCs+AV/PCL } \\
- \text { MSC- } \\
\text { CM+AV/PCL } \\
- \text { PBS with } \\
1 \times 10^{6} \text { fibroblast } \\
+ \text { AV/PCL } \\
- \text { Fibroblast- } \\
\text { CM+AV/PCL } \\
- \text { PBS+AV/PCL } \\
- \text { Untreated group } \\
\text { ( } n=9 / \text { group) }\end{array}$ & 28 & $\begin{array}{l}\text { Macroscopic } \\
\text { appearance } \\
\text { (photography), } \\
\text { histology (HE), } \\
\text { IHC, qRT-PCR }\end{array}$ & $\begin{array}{l}\text { The dermal } \\
\text { thickness of both } \\
\text { MSCs+AV/PCL } \\
(290.55 \mu \mathrm{m}) \text { and } \\
\text { MSC-CM+AV/PCL } \\
(338.3 \mu \mathrm{m}) \\
\text { treatment groups } \\
\text { was significantly } \\
\text { greater than that } \\
\text { of the controls } \\
\text { (PBS+AV/PCL, } \\
\text { 193.51 } \mu \mathrm{m} \text {; } \\
\text { UCM, } \\
266.55 \mu \mathrm{m} \text {; } \\
\text { fibroblast+AV/PCL, } \\
235.29 \mu \mathrm{m} \text {; } \\
\text { fibroblast-CM+ } \\
\text { AV/PCL, } \\
\text { 227.31 } \mu \mathrm{m})\end{array}$ & $\begin{array}{l}\text { CD31 marker } \\
\text { showed strong } \\
\text { positive signals in } \\
\text { the MSC-CM group } \\
\text { and in the MSCs } \\
\text { group compared } \\
\text { with untreated } \\
\text { controls }\end{array}$ \\
\hline Im et al., 2019 & $\begin{array}{l}\text { Human (type is } \\
\text { not specified) }\end{array}$ & $\begin{array}{l}\text { Purchased from } \\
\text { Lonza (Basel, } \\
\text { Switzerland) }\end{array}$ & - & $\begin{array}{l}\text { MSCs of } \\
\text { passages 6-12 } \\
\text { were used. CM } \\
\text { from the MSCs } \\
\text { treated with or } \\
\text { without gold-iron } \\
\text { nanoparticles } \\
\text { was collected }\end{array}$ & $\begin{array}{l}\text { Murine. } \\
\text { Full-thickness } \\
\text { excisional wound, } \\
20 \mathrm{~mm} \times 20 \mathrm{~mm} \text {, } \\
\text { on the back }\end{array}$ & $\begin{array}{l}\text { Daily injection of } \\
\text { CM } \\
(200 \mu / / \text { wound) } \\
\text { was for } 4 \text { days } \\
\text { - MSC-CM } \\
\text { passage } 6 \\
\text { - MSC-CM } \\
\text { passage } 12 \\
\text { - MSC-CM } \\
\text { passage } 12 \text { with } \\
\text { gold-iron } \\
\text { nanoparticles } \\
\text { ( } n=4 \text { /group) }\end{array}$ & 14 & $\begin{array}{l}\text { Macroscopic } \\
\text { appearance } \\
\text { (photography), } \\
\text { histology (HE), } \\
\text { IHC, qRT-PCR }\end{array}$ & $\begin{array}{l}\text { All wounds were } \\
\text { almost closed } \\
\text { with similar } \\
\text { appearance in all } \\
\text { groups }\end{array}$ & $\begin{array}{l}\text { Increased CD31 } \\
\text { expression was } \\
\text { observed in MSC- } \\
\text { CM passage } 12 \\
\text { with gold-iron } \\
\text { nanoparticles group } \\
\text { compared with the } \\
\text { passage } 12 \text { without } \\
\text { gold-iron nano- } \\
\text { particles. SM- } \alpha \\
\text { expression did not } \\
\text { exhibit differences } \\
\text { between groups. } \\
\text { The relative amount } \\
\text { of involucrin and } \\
\text { laminin was higher } \\
\text { in MSC-CM } \\
\text { passage } 6 \text { and } \\
\text { MSC-CM passage } \\
12 \text { with gold-iron } \\
\text { nanoparticles } \\
\text { compared with } \\
\text { MSC-CM passage } \\
12\end{array}$ \\
\hline
\end{tabular}


TABLE 1 | Continued

\begin{tabular}{|c|c|c|c|c|c|c|c|c|c|c|}
\hline & MSC source & $\begin{array}{l}\text { Method of } \\
\text { tissue } \\
\text { extraction }\end{array}$ & $\begin{array}{l}\text { MSC } \\
\text { characterization }\end{array}$ & $\begin{array}{l}\text { Preparation of } \\
\text { MSC-CM }\end{array}$ & Model & $\begin{array}{l}\text { Groups of } \\
\text { treatments and } \\
\text { via of } \\
\text { administration }\end{array}$ & $\begin{array}{l}\text { Follow-up } \\
\text { (days) }\end{array}$ & Assessment & Main outcome & Other outcomes \\
\hline $\begin{array}{l}\text { Yuan et al., } \\
2018\end{array}$ & $\begin{array}{l}\text { Human adipose } \\
\text { tissue }\end{array}$ & - & $\begin{array}{l}\text { Flow cytometry } \\
\text { (CD49+, CD73+, } \\
\text { CD90+, CD105+, } \\
\text { CD34-). } \\
\text { Adipogenic and } \\
\text { chondrogenic } \\
\text { differentiation }\end{array}$ & $\begin{array}{l}\text { MSCs of } \\
\text { passages } 2-5 \\
\text { were used. Cells } \\
\text { were cultured in } \\
\text { the presence of } \\
\text { the profibrogenic } \\
\text { cytokine TGF- } \beta 1 \text {. } \\
\text { CM was collected }\end{array}$ & $\begin{array}{l}\text { Murine. } \\
\text { Full-thickness } \\
\text { skin wounds, } \\
6 \mathrm{~mm} \text { punch, on } \\
\text { the back }\end{array}$ & $\begin{array}{l}\text { Wounds were } \\
\text { applied with 0, } \\
10,50 \text {, and } \\
100 \% \text { MSC-CM }{ }^{*} \\
\text { or left untreated } \\
\text { ( } n=7 / \text { group) }\end{array}$ & 14 & $\begin{array}{l}\text { Macroscopic } \\
\text { appearance } \\
\text { (photography) }\end{array}$ & $\begin{array}{l}\text { MSC-CM } \\
\text { treatment } \\
\text { significantly } \\
\text { accelerated } \\
\text { wound healing } \\
(p<0.05)\end{array}$ & $\begin{array}{l}\text { Compared with the } \\
\text { non-treated } \\
\text { wounds and 0\% } \\
\text { MSC-CM group, } \\
100 \% \text { MSC-CM } \\
\text { treatment } \\
\text { accelerated wound } \\
\text { healing on the } \\
\text { seventh day after } \\
\text { wounding (ratio of } \\
\text { untreated wound } \\
\text { area: } 100 \% \text { in } \\
\text { untreated group, } \\
100 \% \text { in 0\% } \\
\text { MSC-CM, and } 50 \% \\
\text { in 100\% MSC-CM) }\end{array}$ \\
\hline $\begin{array}{l}\text { Payushina } \\
\text { et al., } 2018\end{array}$ & $\begin{array}{l}\text { Murine bone } \\
\text { marrow from } \\
\text { tibia and femur }\end{array}$ & - & $\begin{array}{l}\text { Flow cytometry } \\
\text { (CD73+, CD90+). } \\
\text { Osteogenic and } \\
\text { adipogenic } \\
\text { differentiation }\end{array}$ & $\begin{array}{l}\text { MSCs of passage } \\
2 \text { were used. CM } \\
\text { was collected }\end{array}$ & $\begin{array}{l}\text { Murine. } \\
\text { Full-thickness } \\
\text { skin wounds, } \\
20 \mathrm{~mm} \text { in } \\
\text { diameter, on the } \\
\text { back }\end{array}$ & $\begin{array}{l}100 \mu \mathrm{I} \text { MSC-CM } \\
\text { or control CM } \\
\text { was injected into } \\
\text { the wound bed } \\
\text { each other day } \\
\text { five times ( } n=\text { not } \\
\text { specified) }\end{array}$ & 14 & $\begin{array}{l}\text { Clinical } \\
\text { examination, } \\
\text { histology }\end{array}$ & $\begin{array}{l}\text { MSC-CM group } \\
\text { showed greater } \\
\text { number of blood } \\
\text { vessels } \\
\text { (53.20 } \pm 2.58 \\
\text { blood vessels per } \\
\text { field of view) } \\
\text { compared with } \\
\text { controls } \\
(37.20 \pm 4.73) \text {, } \\
p<0.05\end{array}$ & $\begin{array}{l}\text { MSC-CM group } \\
\text { showed less } \\
\text { intensive } \\
\text { inflammation and } \\
\text { more complete } \\
\text { epithelialization } \\
\text { compared with } \\
\text { controls }\end{array}$ \\
\hline $\begin{array}{l}\text { Park et al., } \\
2018\end{array}$ & $\begin{array}{l}\text { Human } \\
\text { amniotic fluid }\end{array}$ & Amniocentesis & $\begin{array}{l}\text { Flow cytometry } \\
\text { (CD13+, CD29+, } \\
\text { CD44+, CD71+, } \\
\text { CD90+, CD120a+, } \\
\text { CD31-, CD106-, } \\
\text { CD15-, CD33-, } \\
\text { CD34-, CD45-). } \\
\text { Adipogenic, } \\
\text { osteogenic, and } \\
\text { chondrogenic } \\
\text { differentiation }\end{array}$ & $\begin{array}{l}\text { MSCs of passage } \\
12 \text { at } 70-100 \% \\
\text { confluence were } \\
\text { used. They were } \\
\text { supplemented } \\
\text { with selenium } \\
\text { and bFGF. CM } \\
\text { was collected }\end{array}$ & $\begin{array}{l}\text { Murine. } \\
\text { Full-thickness } \\
\text { skin wounds, } \\
8 \mathrm{~mm} \text {, side of the } \\
\text { midline }\end{array}$ & $\begin{array}{l}\text { Vehicle, CM } \\
\text { supplemented } \\
\text { with selenium } \\
(-/ \mathrm{s}), \mathrm{CM} \\
\text { supplemented } \\
\text { with bFGF (b/-), } \\
\text { or CM } \\
\text { supplemented } \\
\text { with bot selenium } \\
\text { and bFGF (b/s), } \\
\text { was topically } \\
\text { applied to the } \\
\text { induced wounds } \\
\text { in a volume of } \\
20 \mu \mathrm{l} \\
(n=10 / \text { group) }\end{array}$ & 11 & $\begin{array}{l}\text { Macroscopic } \\
\text { appearance } \\
\text { (photography), } \\
\text { histology (HE, } \\
3,3^{\prime}- \\
\text { diaminobenzidine } \\
\text { tetrahydrochloride } \\
\text { staining), IHC }\end{array}$ & $\begin{array}{l}\text { Treatment with } \\
\mathrm{CM}(\mathrm{b} / \mathrm{s}) \text { resulted } \\
\text { in complete } \\
\text { wound closure, } \\
\text { while not } \\
\text { completed } \\
\text { closure was } \\
\text { observed in the } \\
\text { other groups }\end{array}$ & $\begin{array}{l}\text { The CM }(-/ \mathrm{s}) \\
\text { group exhibited } \\
\text { better recovery } \\
\text { than the CM (b/-) } \\
\text { group. The CM } \\
\text { (b/s) group showed } \\
\text { the thickest } \\
\text { epidermis region } \\
\text { and the highest } \\
\text { expression of } \\
\text { involucrin. Smad2, } \\
\text { AKT-MEK1/2-ERK, } \\
\text { and NFKB signaling } \\
\text { pathways were } \\
\text { more effectively } \\
\text { activated by CM } \\
\text { (-/s) than by CM } \\
\text { (b/-), and their }\end{array}$ \\
\hline
\end{tabular}


TABLE 1 | Continued

\begin{tabular}{|c|c|c|c|c|c|c|c|c|c|c|}
\hline & MSC source & $\begin{array}{l}\text { Method of } \\
\text { tissue } \\
\text { extraction }\end{array}$ & $\begin{array}{l}\text { MSC } \\
\text { characterization }\end{array}$ & $\begin{array}{l}\text { Preparation of } \\
\text { MSC-CM }\end{array}$ & Model & $\begin{array}{l}\text { Groups of } \\
\text { treatments and } \\
\text { via of } \\
\text { administration }\end{array}$ & $\begin{array}{l}\text { Follow-up } \\
\text { (days) }\end{array}$ & Assessment & Main outcome & Other outcomes \\
\hline & & & & & & & & & & $\begin{array}{l}\text { highest activation } \\
\text { was seen when } \\
\text { treated with CM } \\
\text { (b/s) }\end{array}$ \\
\hline $\begin{array}{l}\text { Tarcisia et al., } \\
2017\end{array}$ & Adipose tissue & - & $\begin{array}{l}\text { Flow cytometry } \\
\text { positive for } \\
\text { (CD73+, CD90+, } \\
\text { CD34-). } \\
\text { Osteogenic, } \\
\text { chondrogenic, and } \\
\text { adipogenic } \\
\text { differentiation }\end{array}$ & $\begin{array}{l}\text { MSCs of passage } \\
3 \text { were used. CM } \\
\text { was then } \\
\text { collected }\end{array}$ & $\begin{array}{l}\text { Murine. } \\
\text { Full-thickness } \\
\text { excisional skin } \\
\text { wounds, } 20 \mathrm{~mm} \\
\text { long and } 5 \mathrm{~mm} \\
\text { depth, on the } \\
\text { back }\end{array}$ & $\begin{array}{l}\text { The four cuts of } \\
\text { each rat were } \\
\text { treated randomly } \\
\text { with MSC-CM } \\
\text { (100\%), complete } \\
\text { culture medium, } \\
\text { basal medium, } \\
\text { and without } \\
\text { treatment } \\
\text { (control). The } \\
\text { treatment was } \\
\text { only done once } \\
\text { after the rat skin } \\
\text { injury } \\
\text { ( } n=30 / \text { group) }\end{array}$ & 28 & $\begin{array}{l}\text { Macroscopic } \\
\text { appearance } \\
\text { (photography), } \\
\text { histology (HE, } \\
\text { MT). }\end{array}$ & $\begin{array}{l}\text { Wounds treated } \\
\text { with MSC-CM } \\
\text { showed } \\
\text { improvement in } \\
\text { wound healing } \\
\text { process }\end{array}$ & $\begin{array}{l}\text { MSC-CM showed } \\
\text { greater collagen } \\
\text { density, } \\
\text { angiogenesis, ratio, } \\
\text { and length of } \\
\text { epithelialization } \\
\text { than the other } \\
\text { groups }(p<0.05)\end{array}$ \\
\hline $\begin{array}{l}\text { Tarcisia et al., } \\
2017\end{array}$ & Adipose tissue & - & $\begin{array}{l}\text { Flow cytometry } \\
\text { positive for } \\
\text { (CD73+, CD90+, } \\
\text { CD34-). } \\
\text { Osteogenic, } \\
\text { chondrogenic, and } \\
\text { adipogenic } \\
\text { differentiation }\end{array}$ & $\begin{array}{l}\text { MSCs of passage } \\
3 \text { were used. CM } \\
\text { was then } \\
\text { collected }\end{array}$ & $\begin{array}{l}\text { Murine. } \\
\text { Full-thickness } \\
\text { excisional skin } \\
\text { wounds, } 20 \mathrm{~mm} \\
\text { long and } 5 \mathrm{~mm} \\
\text { depth, on the } \\
\text { back }\end{array}$ & $\begin{array}{l}\text { The four cuts of } \\
\text { each rat were } \\
\text { treated randomly } \\
\text { with MSC-CM } \\
\text { ( } 100 \%) \text {, complete } \\
\text { culture medium, } \\
\text { basal medium, } \\
\text { and without } \\
\text { treatment } \\
\text { (control). The } \\
\text { treatment was } \\
\text { only done once } \\
\text { after the rat skin } \\
\text { injury } \\
(n=30 / \text { group) }\end{array}$ & 28 & $\begin{array}{l}\text { Macroscopic } \\
\text { appearance } \\
\text { (photography), } \\
\text { histology (HE, } \\
\text { MT). }\end{array}$ & $\begin{array}{l}\text { Wounds treated } \\
\text { with MSC-CM } \\
\text { showed } \\
\text { improvement in } \\
\text { wound healing } \\
\text { process }\end{array}$ & $\begin{array}{l}\text { MSC-CM showed } \\
\text { greater collagen } \\
\text { density, } \\
\text { angiogenesis, ratio, } \\
\text { and length of } \\
\text { epithelialization } \\
\text { than the other } \\
\text { groups }(p<0.05 \text { ) }\end{array}$ \\
\hline Lee et al., 2017 & Adipose tissue & - & - & $\begin{array}{l}\text { Ell3 expression } \\
\text { was suppressed } \\
\text { using siRNA } \\
\text { transfection in } \\
\text { MSCs. CM } \\
\text { harvested from } \\
\text { MSCs } \\
\text { transfected with } \\
\text { siNS or siEll3 was } \\
\text { collected }\end{array}$ & $\begin{array}{l}\text { Murine. } \\
\text { Full-thickness } \\
\text { excisional skin } \\
\text { wound, back }\end{array}$ & $\begin{array}{l}100 \mu \text { l of CM } \\
\text { prepared from } \\
\text { siNS- or } \\
\text { siElll-transfected } \\
\text { MSCs or } \\
\text { serum-free media } \\
\text { was applied to } \\
\text { the wound } \\
\text { ( } n=\text { not specified) }\end{array}$ & 7 & $\begin{array}{l}\text { Macroscopic } \\
\text { appearance } \\
\text { (photography), } \\
\text { histology (HE), } \\
\text { IHC. }\end{array}$ & $\begin{array}{l}\text { Skin wounds } \\
\text { treated with siEll3 } \\
\mathrm{CM} \text { recovered to } \\
\text { a lesser extent } \\
\text { than those } \\
\text { treated with } \\
\text { serum-free media }\end{array}$ & $\begin{array}{l}\text { siEll3 CM could not } \\
\text { enhance the wound } \\
\text { healing rate, } \\
\text { whereas siNS CM } \\
\text { significantly } \\
\text { promoted wound } \\
\text { repair }\end{array}$ \\
\hline
\end{tabular}


TABLE 1 | Continued

\begin{tabular}{|c|c|c|c|c|c|c|c|c|c|c|}
\hline & MSC source & $\begin{array}{l}\text { Method of } \\
\text { tissue } \\
\text { extraction }\end{array}$ & $\begin{array}{l}\text { MSC } \\
\text { characterization }\end{array}$ & $\begin{array}{l}\text { Preparation of } \\
\text { MSC-CM }\end{array}$ & Model & $\begin{array}{l}\text { Groups of } \\
\text { treatments and } \\
\text { via of } \\
\text { administration }\end{array}$ & $\begin{array}{l}\text { Follow-up } \\
\text { (days) }\end{array}$ & Assessment & Main outcome & Other outcomes \\
\hline Du et al., 2017 & $\begin{array}{l}\text { Rabbit bone } \\
\text { marrow }\end{array}$ & - & - & $\begin{array}{l}\text { MSCs of passage } \\
2 \text { were used. } \\
\text { MSCs were } \\
\text { cultured in } \\
\text { normoxic (Nc) } \\
\text { and chemical } \\
\text { hypoxic } \\
\text { conditioning by } \\
\text { adding CoCl } 2 \\
\text { (Cc). } \\
\text { Decellularization } \\
\text { was conducted } \\
\text { and extracellular } \\
\text { matrices (ECM) } \\
\text { cell-free were } \\
\text { constructed }\end{array}$ & $\begin{array}{l}\text { Murine. } \\
\text { Full-thickness } \\
\text { excisional skin } \\
\text { wound, } 7 \mathrm{~mm} \text {, on } \\
\text { the back }\end{array}$ & $\begin{array}{l}\text { No treated group } \\
\text { (control), mice } \\
\text { treated with } \\
\text { Nc-ECM sheets } \\
\text { or Cc-ECM } \\
\text { sheets } \\
\text { ( } n=16 / \text { group) }\end{array}$ & 7 & $\begin{array}{l}\text { Macroscopic } \\
\text { appearance } \\
\text { (photography), } \\
\text { histology (HE, } \\
\text { MT, picrosirius } \\
\text { red) }\end{array}$ & $\begin{array}{l}\text { All the } \\
\text { Cc-ECM-treated } \\
\text { wounds } \\
\text { completely } \\
\text { healed on day } 7 \text {, } \\
\text { while } \\
\text { Nc-ECM-treated } \\
\text { wounds healed } \\
\text { about } \\
85.0 \pm 8.6 \% \text {, } \\
\text { and non-treated } \\
\text { wounds only } \\
\text { healed } \\
69.8 \pm 9.6 \%\end{array}$ & $\begin{array}{l}\text { No inflammatory } \\
\text { signs or visible } \\
\text { indication of } \\
\text { necrosis or other } \\
\text { adverse events } \\
\text { were observed }\end{array}$ \\
\hline $\begin{array}{l}\text { Dong et al., } \\
2017\end{array}$ & $\begin{array}{l}\text { Human } \\
\text { umbilical cord }\end{array}$ & - & - & $\begin{array}{l}\text { MSCs were } \\
\text { transduced with } \\
\text { human Wnt7a } \\
\text { cDNA retroviral } \\
\text { vector. MSCs of } \\
\text { passage } 3 \text { at } \\
50-60 \% \\
\text { confluence were } \\
\text { used. Passage-3 } \\
\text { MSCs were. CM } \\
\text { from MSCs } \\
\text { (MSC-CM) and } \\
\text { from MSC with } \\
\text { Wnt7a (Wnt-CM) } \\
\text { was collected }\end{array}$ & $\begin{array}{l}\text { Murine. } \\
\text { Full-thickness } \\
\text { excisional wound, } \\
10 \mathrm{~mm} \text {, on the } \\
\text { back }\end{array}$ & $\begin{array}{l}100 \mu \text { l of } \\
\text { Wnt-CM, } \\
\text { MSC-CM, or } \\
\text { DMEM was } \\
\text { subcutaneously } \\
\text { injected at } \\
\text { multiple points } \\
\text { into the wound } \\
\text { area ( } n=3 / \text { group) }\end{array}$ & 14 & $\begin{array}{l}\text { Macroscopic } \\
\text { appearance } \\
\text { (photography), } \\
\text { histology (HE, } \\
\text { MT) }\end{array}$ & $\begin{array}{l}\text { Wnt-CM } \\
\text { significantly } \\
\text { enhanced the } \\
\text { closure rates in } \\
\text { comparison with } \\
\text { MSC-CM and } \\
\text { DMEM ( } 91.5 \text { vs. } \\
76.3 \text { vs. } 65.1 \% \text {, } \\
\text { respectively) }\end{array}$ & $\begin{array}{l}\text { Wnt-CM } \\
\text { accelerated } \\
\text { migration of HFs } \\
\text { into the wound } \\
\text { area, had a thicker } \\
\text { epidermis with } \\
\text { more organized cell } \\
\text { layers, and showed } \\
\text { regeneration of } \\
\text { more hair follicles. } \\
\text { Increased } \\
\text { expression of the } \\
\alpha \text {-SMA, collagen I, } \\
\text { and collagen III was } \\
\text { also observed in } \\
\text { Wnt-CM group }\end{array}$ \\
\hline
\end{tabular}


TABLE 1 | Continued

\begin{tabular}{|c|c|c|c|c|c|c|c|c|c|c|}
\hline & MSC source & $\begin{array}{l}\text { Method of } \\
\text { tissue } \\
\text { extraction }\end{array}$ & $\begin{array}{l}\text { MSC } \\
\text { characterization }\end{array}$ & $\begin{array}{l}\text { Preparation of } \\
\text { MSC-CM }\end{array}$ & Model & $\begin{array}{l}\text { Groups of } \\
\text { treatments and } \\
\text { via of } \\
\text { administration }\end{array}$ & $\begin{array}{l}\text { Follow-up } \\
\text { (days) }\end{array}$ & Assessment & Main outcome & Other outcomes \\
\hline $\begin{array}{l}\text { Dong et al., } \\
2017\end{array}$ & $\begin{array}{l}\text { Human adipose } \\
\text { tissues }\end{array}$ & - & - & $\begin{array}{l}\text { Coleman adipose } \\
\text { tissue was } \\
\text { mechanically } \\
\text { emulsified to } \\
\text { obtain } \\
\text { ECM/SVF-gel. } \\
\text { For SVF } \\
\text { preparation, the } \\
\text { Coleman adipose } \\
\text { tissue was } \\
\text { digested. } \\
\text { Supernatant from } \\
\text { ECM/SVF-gel } \\
\text { (gel-CM), } \\
\text { Coleman adipose } \\
\text { tissue (adi-CM), } \\
\text { and SVF } \\
\text { (SVF-CM) culture } \\
\text { were collected to } \\
\text { obtain CM }\end{array}$ & $\begin{array}{l}\text { Murine. } \\
\text { Full-thickness } \\
\text { excisional skin } \\
\text { wound, } 8 \mathrm{~mm} \text {, on } \\
\text { the back }\end{array}$ & $\begin{array}{l}100 \mathrm{ml} \mathrm{PBS} \\
\text { (control), gel-CM, } \\
\text { adi-CM, or } \\
\text { SVF-CM was } \\
\text { injected into the } \\
\text { wounds } \\
\text { ( } n=15 \text { /group) }\end{array}$ & 14 & $\begin{array}{l}\text { Macroscopic } \\
\text { appearance } \\
\text { (photography), } \\
\text { histology (HE, } \\
\text { MT), ELISA }\end{array}$ & $\begin{array}{l}\mathrm{CM} \text { treatments } \\
\text { resulted in a } \\
\text { significant } \\
\text { upregulation of } \\
\text { collagen } \\
\text { production } \\
\text { compared with } \\
\text { controls, } \\
\text { revealing that the } \\
\text { Gel-CM-group } \\
\text { had the highest } \\
\text { production of } \\
\text { collagen }\end{array}$ & $\begin{array}{l}\text { Higher expression } \\
\text { of bFGF, EGF, and } \\
\text { TGF-b in Gel-CM } \\
\text { was observed }\end{array}$ \\
\hline $\begin{array}{l}\text { Mehanna et al., } \\
2015\end{array}$ & $\begin{array}{l}\text { Murine bone } \\
\text { marrow }\end{array}$ & Needle flushing & $\begin{array}{l}\text { Flow cytometry } \\
\text { (CD44+, CD45-) }\end{array}$ & $\begin{array}{l}\text { MSCs of passage } \\
3 \text { were used, and } \\
\text { CM was collected }\end{array}$ & $\begin{array}{l}\text { Murine. } \\
\text { Full-thickness } \\
\text { square-shaped } \\
\text { skin wound } \\
(35 \mathrm{~mm} \times 35 \mathrm{~mm}) \text {, } \\
\text { on the back }\end{array}$ & $\begin{array}{l}\text { Topical } \\
\text { application } \\
\text { - Untreated group } \\
\text { (control) } \\
\text { - Fibrin glue only } \\
\text { group } \\
\text { - Fibrin+MSCs } \\
\text { group } \\
\text { - Fibrin } \\
\text { +MSC-CM group } \\
\text { ( } n=13 \text { /group) }\end{array}$ & 35 & $\begin{array}{l}\text { Macroscopic } \\
\text { appearance } \\
\text { (photography), } \\
\text { functional } \\
\text { parameters } \\
\text { (TEWL, SCH, } \\
\text { tensile strength } \\
\text { assessment), } \\
\text { histology (HE, } \\
\text { MT), IHC }\end{array}$ & $\begin{array}{l}\text { Wounds' size in } \\
\text { fibrin+MSCs and } \\
\text { fibrin+MSC-CM } \\
\text { groups showed } \\
\text { significant } \\
\text { decrease in } \\
\text { comparison with } \\
\text { only fibrin and } \\
\text { controls }\end{array}$ & $\begin{array}{l}\text { CD68+ } \\
\text { macrophages } \\
\text { infiltrating } \\
\text { granulation tissue } \\
\text { were considerably } \\
\text { higher in } \\
\text { fibrin+MSC and } \\
\text { fibrin+CM groups. } \\
\text { SCH and tensile } \\
\text { strength were } \\
\text { higher, while TEWL } \\
\text { was lower in both } \\
\text { fibrin+MSC and } \\
\text { fibrin+CM than in } \\
\text { only fibrin and } \\
\text { control group }\end{array}$ \\
\hline
\end{tabular}


TABLE 1 | Continued

\begin{tabular}{|c|c|c|c|c|c|c|c|c|c|c|}
\hline & MSC source & $\begin{array}{l}\text { Method of } \\
\text { tissue } \\
\text { extraction }\end{array}$ & $\begin{array}{l}\text { MSC } \\
\text { characterization }\end{array}$ & $\begin{array}{l}\text { Preparation of } \\
\text { MSC-CM }\end{array}$ & Model & $\begin{array}{l}\text { Groups of } \\
\text { treatments and } \\
\text { via of } \\
\text { administration }\end{array}$ & $\begin{array}{l}\text { Follow-up } \\
\text { (days) }\end{array}$ & Assessment & Main outcome & Other outcomes \\
\hline $\begin{array}{l}\text { Tam et al., } \\
2014\end{array}$ & $\begin{array}{l}\text { Wharton's jelly } \\
\text { from human } \\
\text { umbilical cord }\end{array}$ & $\begin{array}{l}\text { Cutting } \\
\text { umbilical cords }\end{array}$ & $\begin{array}{l}\text { Flow cytometry } \\
\text { (CD13+, CD29+, } \\
\text { CD44+, CD90+, } \\
\text { CD10-, CD14-, } \\
\text { CD34, CD117) }\end{array}$ & $\begin{array}{l}\text { MSCs of passage } \\
3-4 \text { were used. It } \\
\text { was a } \\
\text { constructed } \\
\text { wound dressing } \\
\text { patch made up of } \\
\text { an aloe } \\
\text { vera-PCL } \\
\text { (AV/PCL) } \\
\text { nanoscaffold } \\
\text { impregnated with } \\
\text { WJ-MSCs or its } \\
\text { CM }\end{array}$ & $\begin{array}{l}\text { Murine. } \\
\text { Full-thickness } \\
\text { skin wounds, } \\
8 \mathrm{~mm} \text {, on dorsal } \\
\text { region }\end{array}$ & $\begin{array}{l}\text { - MSCs+AV/PC } \\
\text { - MSC- } \\
\text { CM+AV/PCL } \\
\text { - Fibroblast+ } \\
\text { AV/PCL } \\
\text { - Fibroblast- } \\
\text { CM+AV/PCL } \\
\text { - PBS+ AV/PCL } \\
\text { - Untreated } \\
\text { (n = 9/group) }\end{array}$ & 28 & $\begin{array}{l}\text { Macroscopic } \\
\text { appearance } \\
\text { (photography), } \\
\text { histology (HE and } \\
\text { MT), IF, WB, } \\
\text { qRT-PCR }\end{array}$ & $\begin{array}{l}\text { MSCs+AV/PCL } \\
\text { and MSC- } \\
\mathrm{CM}+\mathrm{AV} / \mathrm{PCL} \\
\text { treatment arms } \\
\text { showed faster } \\
\text { wound closure } \\
\text { compared with } \\
\text { other groups } \\
(p<0.05)\end{array}$ & $\begin{array}{l}\text { MSCs+AV/PCL } \\
\text { and } \\
\text { MSC-CM+AV/PCL } \\
\text { groups showed } \\
\text { higher numbers of } \\
\text { sebaceous glands, } \\
\text { hair follicles, } \\
\text { cellularity, and } \\
\text { vasculature } \\
\text { compared with } \\
\text { other groups }\end{array}$ \\
\hline Sun et al., 2014 & $\begin{array}{l}\text { Murine } \\
\text { abdominal } \\
\text { subcutaneous } \\
\text { adipose tissue }\end{array}$ & Incision & $\begin{array}{l}\text { Flow cytometry } \\
\text { (CD29+, CD90+, } \\
\text { CD105+, CD34-). } \\
\text { Osteogenic and } \\
\text { adipogenic } \\
\text { differentiation }\end{array}$ & $\begin{array}{l}\text { MSCs of passage } \\
3 \text { at } 90 \% \\
\text { confluence were } \\
\text { used. Hypoxic } \\
\text { microenvironment } \\
\text { was generated } \\
\text { using a } \\
\text { disposable } \\
\text { oxygen-absorbed } \\
\text { and CO2 } \\
\text { generator. CM } \\
\text { was collected }\end{array}$ & $\begin{array}{l}\text { Murine. } \\
\text { Full-thickness } \\
\text { skin incisions, } \\
30 \mathrm{~mm} \text { in } \\
\text { diameter, on the } \\
\text { back }\end{array}$ & $\begin{array}{l}\text { Topical } \\
\text { application } \\
\text { - Concentrated } \\
\text { hypoxic MSC-CM } \\
\text { - Hypoxic } \\
\text { MSC-CM } \\
\text { - Serum medium } \\
\text { ( } n=10 / \text { group) }\end{array}$ & 21 & $\begin{array}{l}\text { Macroscopic } \\
\text { appearance } \\
\text { (photography), } \\
\text { histology (HE) }\end{array}$ & $\begin{array}{l}\text { The average } \\
\text { healing time was } \\
\text { lower in } \\
\text { concentrated } \\
\text { hypoxic MSC-CM } \\
\text { than in hypoxic } \\
\text { MSC-CM and } \\
\text { control group } \\
(16.2 \pm 0.98 \text { vs. } \\
17.7 \pm 0.78 \text { vs. } \\
21.3 \pm 1.10 \text { days) }\end{array}$ & $\begin{array}{l}\text { Wound closure } \\
\text { after treatment with } \\
\text { concentrated } \\
\text { hypoxic MSC-CM } \\
\text { showed } \\
\text { well-organized } \\
\text { epidermis, thick } \\
\text { cuticular layer, and } \\
\text { increased collagen } \\
\text { content than the } \\
\text { other groups }\end{array}$ \\
\hline Jun et al., 2014 & $\begin{array}{l}\text { Human } \\
\text { amniotic fluid }\end{array}$ & Amniocentesis & $\begin{array}{l}\text { Immunofluorescence. } \\
\text { Adipogenic and } \\
\text { osteogenic } \\
\text { differentiation }\end{array}$ & $\begin{array}{l}\text { MSCs at } 70 \% \\
\text { confluence were } \\
\text { used. Cells were } \\
\text { cultured in } \\
\text { normoxic (nor) } \\
\text { and hypoxic } \\
\text { (hypo) conditions. } \\
\text { CM was collected }\end{array}$ & $\begin{array}{l}\text { Murine. } \\
\text { Full-thickness } \\
\text { excisional skin } \\
\text { wound, } 2 \mathrm{~mm} \text { full } \\
\text { thickness, on } \\
\text { each side of the } \\
\text { midline }\end{array}$ & $\begin{array}{l}100 \mu \text { l topically } \\
\text { applied } \\
\text { - MSC-hypoCM } \\
\text { - MSC-norCM } \\
\text { - DMEM } \\
\text { (n=10/group) }\end{array}$ & 5 & $\begin{array}{l}\text { Macroscopic } \\
\text { appearance } \\
\text { (photography), } \\
\text { histology (HE), } \\
\text { IHC }\end{array}$ & $\begin{array}{l}\text { MSC-hypoCM } \\
\text { significantly } \\
\text { accelerated } \\
\text { wound closure } \\
\text { compared with } \\
\text { DMEM and } \\
\text { MSC-norCM } \\
\text { groups }(p<0.05)\end{array}$ & $\begin{array}{l}\text { The skin structure } \\
\text { of wounds treated } \\
\text { by MSC-hypoCM } \\
\text { was more similar to } \\
\text { normal skin } \\
\text { structure. } \\
\text { TGF-B/SMAD2 and } \\
\text { PI3K/AKT signal } \\
\text { pathways were } \\
\text { upregulated in } \\
\text { AF-MSC-hypoCM }\end{array}$ \\
\hline
\end{tabular}


TABLE 1 | Continued

\begin{tabular}{|c|c|c|c|c|c|c|c|c|c|c|}
\hline & MSC source & $\begin{array}{l}\text { Method of } \\
\text { tissue } \\
\text { extraction }\end{array}$ & $\begin{array}{l}\text { MSC } \\
\text { characterization }\end{array}$ & $\begin{array}{l}\text { Preparation of } \\
\text { MSC-CM }\end{array}$ & Model & $\begin{array}{l}\text { Groups of } \\
\text { treatments and } \\
\text { via of } \\
\text { administration }\end{array}$ & $\begin{array}{l}\text { Follow-up } \\
\text { (days) }\end{array}$ & Assessment & Main outcome & Other outcomes \\
\hline $\begin{array}{l}\text { Fong et al., } \\
2014\end{array}$ & $\begin{array}{l}\text { Wharton's jelly } \\
\text { from human } \\
\text { umbilical cord }\end{array}$ & $\begin{array}{l}\text { Full-term } \\
\text { delivery }\end{array}$ & $\begin{array}{l}\text { Immunofluorescence } \\
\text { (CD10+, CD13+, } \\
\text { CD29+, CD44+, } \\
\text { CD90+) }\end{array}$ & $\begin{array}{l}\text { MSCs of } \\
\text { passages 3-4 at } \\
80 \% \text { confluence } \\
\text { were used. CM } \\
\text { was then } \\
\text { collected }\end{array}$ & $\begin{array}{l}\text { Murine. } \\
\text { Full-thickness } \\
\text { excisional skin } \\
\text { wound, } 8 \mathrm{~mm} \text {, on } \\
\text { dorsum surface }\end{array}$ & $\begin{array}{l}100 \mu \mathrm{l} \text { injected } \\
\text { intraperitoneally } \\
\text { - MSCs } \\
\text { - MSC-CM } \\
\text { - Fibroblast } \\
\text { - Fibroblast-CM } \\
\text { - UCM } \\
\text { ( } n=9 \text { /group) }\end{array}$ & 28 & $\begin{array}{l}\text { Macroscopic } \\
\text { appearance } \\
\text { (photography), } \\
\text { histology (HE), } \\
\text { IHC }\end{array}$ & $\begin{array}{l}\text { MSC and } \\
\text { MSC-CM healing } \\
\text { rates were } \\
\text { greater compared } \\
\text { with controls } \\
(p<0.05)\end{array}$ & $\begin{array}{l}\text { Wounds treated } \\
\text { with MSCs and } \\
\text { MSC-CMs showed } \\
\text { greater } \\
\text { re-epithelialization, } \\
\text { vascularity, cellular } \\
\text { density, sebaceous } \\
\text { gland, and hair } \\
\text { follicle numbers } \\
\text { compared with } \\
\text { controls }\end{array}$ \\
\hline $\begin{array}{l}\text { Chen et al., } \\
2014\end{array}$ & $\begin{array}{l}\text { Human bone } \\
\text { marrow }\end{array}$ & - & - & $\begin{array}{l}\text { MSCs of } \\
\text { passages 3-4 at } \\
80 \% \text { confluence } \\
\text { were used. MSCs } \\
\text { were cultured } \\
\text { and expanded } \\
\text { under normoxic } \\
\text { or hypoxic } \\
\text { conditions. CM } \\
\text { was collected } \\
\text { from the } \\
\text { normoxic and } \\
\text { hypoxic MSCs to } \\
\text { yield norCM and } \\
\text { hypoCM }\end{array}$ & $\begin{array}{l}\text { Murine. } \\
\text { Full-thickness } \\
\text { excisional skin } \\
\text { wounds, } 18 \mathrm{~mm} \text {, } \\
\text { on dorsal surface }\end{array}$ & $\begin{array}{l}100 \mu l \text { of } \\
\text { treatment } \\
\text { topically applied } \\
\text { to skin wounds } \\
\text { and covered with } \\
\text { dressings daily } \\
\text { for the first } 4 \text { days } \\
\text { - MSC-norCM } \\
\text { - MSC-hypoCM } \\
\text { - Vehicle (control) } \\
\text { ( } n=16 \text { /group) }\end{array}$ & 14 & $\begin{array}{l}\text { Macroscopic } \\
\text { appearance } \\
\text { (photography), } \\
\text { IHC, IF }\end{array}$ & $\begin{array}{l}\text { HypoCM-treated } \\
\text { mice showed } \\
\text { smaller wound } \\
\text { area compared } \\
\text { with norCM } \\
\text { groups and } \\
\text { vehicle control } \\
(26.42 \pm 62.48 \\
\text { vs. } \\
37.92 \pm 62.44 \\
\text { vs. } \\
45.00 \pm 61.97 \% \text {, } \\
\text { respectively) }\end{array}$ & $\begin{array}{l}\text { MSC-hypoCM } \\
\text { accelerated wound } \\
\text { closure compared } \\
\text { with norCM and } \\
\text { vehicle control }\end{array}$ \\
\hline $\begin{array}{l}\text { Tamari et al., } \\
2013\end{array}$ & $\begin{array}{l}\text { Human bone } \\
\text { marrow }\end{array}$ & - & - & $\begin{array}{l}\text { MSCs purchased } \\
\text { from LONZA }\end{array}$ & $\begin{array}{l}\text { Murine. } \\
\text { Full-thickness } \\
\text { excisional skin } \\
\text { wound, } 8 \mathrm{~mm} \text {, on } \\
\text { the midline on the } \\
\text { back }\end{array}$ & $\begin{array}{l}\text { Injection } \\
\text { administered at } 4 \\
\text { spots around the } \\
\text { wound } \\
\text { - PBS } \\
\text { - MSCs } \\
\text { - MSC-CM } \\
\text { ( } n=\text { not specified) }\end{array}$ & 14 & $\begin{array}{l}\text { Macroscopic } \\
\text { appearance } \\
\text { (photography), } \\
\text { histology, ELISA }\end{array}$ & $\begin{array}{l}\text { Epithelialization } \\
\text { rate was higher in } \\
\text { MSC and } \\
\text { MSC-CM group } \\
\text { compared with } \\
\text { controls: } \\
\text { non-epithelialized } \\
\text { wound area after } \\
\text { treatment was } \\
42.64 \pm 5.36 \% \text { in } \\
\text { the control group, } \\
4.90 \pm 2.36 \% \text { in } \\
\text { MSC group, and } \\
5.74 \pm 2.85 \% \text { in } \\
\text { MSC-CM group }\end{array}$ & $\begin{array}{l}\text { MSC and MSC-CM } \\
\text { accelerated wound } \\
\text { healing. HA } \\
\text { production in MSC } \\
\text { and MSC-CM } \\
\text { group was } \\
\text { increased } \\
\text { compared with } \\
\text { controls }\end{array}$ \\
\hline
\end{tabular}


TABLE 1 | Continued

\begin{tabular}{|c|c|c|c|c|c|c|c|c|c|c|}
\hline & MSC source & $\begin{array}{l}\text { Method of } \\
\text { tissue } \\
\text { extraction }\end{array}$ & $\begin{array}{l}\text { MSC } \\
\text { characterization }\end{array}$ & $\begin{array}{l}\text { Preparation of } \\
\text { MSC-CM }\end{array}$ & Model & $\begin{array}{l}\text { Groups of } \\
\text { treatments and } \\
\text { via of } \\
\text { administration }\end{array}$ & $\begin{array}{l}\text { Follow-up } \\
\text { (days) }\end{array}$ & Assessment & Main outcome & Other outcomes \\
\hline Lee et al., 2011 & $\begin{array}{l}\text { hCB: human } \\
\text { cord blood } \\
\text { hESC: human } \\
\text { embryo }\end{array}$ & - & $\begin{array}{l}\text { Fluorescence- } \\
\text { activated cell sorter } \\
\text { (CD133+, KDR+) }\end{array}$ & $\begin{array}{l}\text { MSCs of } \\
\text { passages 5-8 at } \\
80 \text { confluence } \\
\text { were used. CM } \\
\text { was collected }\end{array}$ & $\begin{array}{l}\text { Murine. } \\
\text { Full-thickness } \\
\text { skin wound, } \\
12 \mathrm{~mm} \text {, on dorsal } \\
\text { surface }\end{array}$ & $\begin{array}{l}200 \mu \mathrm{l} \text { of CM was } \\
\text { subcutaneously } \\
\text { injected around } \\
\text { the wound site or } \\
\text { applied topically } \\
\text { - hESC-CM } \\
\text { - hCB-CM } \\
\text { - Control medium } \\
\text { ( } n=10 / \text { group) }\end{array}$ & 21 & $\begin{array}{l}\text { Macroscopic } \\
\text { appearance } \\
\text { (photography), } \\
\text { histology }\end{array}$ & $\begin{array}{l}\text { Wound healing } \\
\text { rate was higher in } \\
\text { groups treated } \\
\text { with CM }(90,70 \text {, } \\
\text { and } 40 \% \text { in the } \\
\text { hESC-CM, } \\
\text { hCB-CM, and } \\
\text { vehicle medium, } \\
\text { respectively) }\end{array}$ & $\begin{array}{l}\text { Wound closure rate } \\
\text { in hESC-CM group } \\
\text { was higher when it } \\
\text { was used topically } \\
\text { instead of } \\
\text { subcutaneously }\end{array}$ \\
\hline $\begin{array}{l}\text { Heo et al., } \\
2011\end{array}$ & $\begin{array}{l}\text { Human adipose } \\
\text { tissue }\end{array}$ & Elective surgery & - & $\begin{array}{l}\text { MSCs of } \\
\text { passages 2-5 } \\
\text { were used. CM } \\
\text { was collected. } \\
\text { Immunoprecipitation } \\
\text { of TNF- } \alpha \text { was } \\
\text { also used, and } \\
\text { CM implemented } \\
\text { TNF- } \alpha \text { was } \\
\text { collected }\end{array}$ & $\begin{array}{l}\text { Murine. } \\
\text { Full-thickness } \\
\text { excisional skin } \\
\text { wounds, } 8 \mathrm{~mm} \text {, } \\
\text { non the dorsal } \\
\text { surface }\end{array}$ & $\begin{array}{l}20 \mu l \text { topically } \\
\text { applied on the } \\
\text { wound bed daily } \\
\text { - PBS } \\
\text { - MSC-CM } \\
\text { - MSC-CM with } \\
\text { TNF- } \alpha \\
\text { (n=8/group) }\end{array}$ & 12 & $\begin{array}{l}\text { Macroscopic } \\
\text { appearance } \\
\text { (photography), } \\
\text { histology }\end{array}$ & $\begin{array}{l}\text { MSC-CM with } \\
\text { TNF- } \alpha \\
\text { accelerated } \\
\text { wound closure } \\
\text { compared with } \\
\text { PBS MSC-CM }\end{array}$ & $\begin{array}{l}\text { Number of blood } \\
\text { vessel was the } \\
\text { highest in MSC-CM } \\
\text { with TNF- } \alpha \text { group }\end{array}$ \\
\hline $\begin{array}{l}\text { Yoon et al., } \\
2010\end{array}$ & $\begin{array}{l}\text { Human } \\
\text { amniotic fluid }\end{array}$ & Amniocentesis & $\begin{array}{l}\text { Immunofluorescence } \\
\text { (CD13+, CD29+, } \\
\text { CD44+). } \\
\text { Osteogenic, } \\
\text { adipogenic, and } \\
\text { chondrogenic } \\
\text { differentiation }\end{array}$ & $\begin{array}{l}\text { MSCs of passage } \\
3 \text { at } 70 \% \\
\text { confluence were } \\
\text { used. CM was } \\
\text { collected }\end{array}$ & $\begin{array}{l}\text { Murine. } \\
\text { Full-thickness } \\
\text { excisional skin } \\
\text { wound, } 2 \mathrm{~mm} \text {, on } \\
\text { each side of the } \\
\text { midline. }\end{array}$ & $\begin{array}{l}100 \mu l \\
\text { subcutaneous } \\
\text { injection around } \\
\text { the wound and } \\
\text { topically applied } \\
\text { on the wound } \\
\text { bed } \\
\text { - Control medium } \\
\text { - MSC-CM } \\
\text { ( } n=10 / \text { group) }\end{array}$ & 8 & $\begin{array}{l}\text { Macroscopic } \\
\text { appearance } \\
\text { (photography), } \\
\text { histology (HE), } \\
\text { IHC }\end{array}$ & $\begin{array}{l}\text { MSC-CM } \\
\text { accelerated } \\
\text { wound closure } \\
\text { compared with } \\
\text { control }\end{array}$ & $\begin{array}{l}\text { No difference in } \\
\text { skin structure was } \\
\text { observed between } \\
\text { groups }\end{array}$ \\
\hline $\begin{array}{l}\text { Cho et al., } \\
2010\end{array}$ & $\begin{array}{l}\text { Human } \\
\text { subcutaneous } \\
\text { adipose tissue }\end{array}$ & Liposuction & $\begin{array}{l}\text { Flow cytometry } \\
\text { (CD90+, CD49d-) }\end{array}$ & $\begin{array}{l}\text { MSCs of } \\
\text { passage. } \\
\text { TGF- } \beta 1 \text {-treated } \\
\text { MSC-CM or } \\
\text { non-treated } \\
\text { MSC-CM was } \\
\text { collected }\end{array}$ & $\begin{array}{l}\text { Murine. Circular } \\
\text { full-thickness skin } \\
\text { wounds, 4-mm } \\
\text { diameter, on the } \\
\text { back }\end{array}$ & $\begin{array}{l}\text { Intradermal } \\
\text { injections } \\
(0.05 \mathrm{ml} / \text { point } \times 4 \\
\text { points) into the } \\
\text { wound base } \\
\text { twice per week }\end{array}$ & 10 & $\begin{array}{l}\text { Macroscopic } \\
\text { appearance } \\
\text { (photography), } \\
\text { histology (HE) }\end{array}$ & $\begin{array}{l}\text { Wound size was } \\
\text { reduced in both } \\
\text { groups }\end{array}$ & $\begin{array}{l}\text { TGF- } \beta 1 \text {-treated } \\
\text { MSC-CM } \\
\text { accelerated wound } \\
\text { healing compared } \\
\text { with MSC-CM }\end{array}$ \\
\hline
\end{tabular}


TABLE 1 | Continued

\begin{tabular}{|c|c|c|c|c|c|c|c|c|c|c|}
\hline & MSC source & $\begin{array}{l}\text { Method of } \\
\text { tissue } \\
\text { extraction }\end{array}$ & $\begin{array}{l}\text { MSC } \\
\text { characterization }\end{array}$ & $\begin{array}{l}\text { Preparation of } \\
\text { MSC-CM }\end{array}$ & Model & $\begin{array}{l}\text { Groups of } \\
\text { treatments and } \\
\text { via of } \\
\text { administration }\end{array}$ & $\begin{array}{l}\text { Follow-up } \\
\text { (days) }\end{array}$ & Assessment & Main outcome & Other outcomes \\
\hline & & & & & & $\begin{array}{l}\text { - Bactroban oint } \\
\text { with MSC-CM } \\
\text { - Bactroban oint } \\
\text { with } \\
\text { TGF- } \beta 1 \text {-treated } \\
\text { MSC-CM } \\
\text { ( } n=3 \text { /group) }\end{array}$ & & & & \\
\hline $\begin{array}{l}\text { Templin et al., } \\
2009\end{array}$ & $\begin{array}{l}\text { Murine bone } \\
\text { marrow }\end{array}$ & - & - & $\begin{array}{l}\text { Retroviral gene } \\
\text { transfer into lin- } \\
\text { cells was } \\
\text { performed, and } \\
\text { DK mix cells were } \\
\text { created. Cells } \\
\text { and CM were } \\
\text { then collected }\end{array}$ & $\begin{array}{l}\text { Murine. } \\
\text { Full-thickness } \\
\text { skin wounds, } \\
\text { 5-mm diameter, } \\
\text { on dorsal surface }\end{array}$ & $\begin{array}{l}200 \mu l \\
\text { subcutaneously } \\
\text { injected around } \\
\text { the wound at } 8 \\
\text { different sites } \\
\text { - MSC-CM } \\
\text { - MSCs } \\
\text { - PBS } \\
\text { ( } n=8 \text { /group) }\end{array}$ & 13 & $\begin{array}{l}\text { Macroscopic } \\
\text { appearance } \\
\text { (photography), }\end{array}$ & $\begin{array}{l}\text { MSC and } \\
\text { MCS-CM } \\
\text { accelerated } \\
\text { wound healing } \\
\text { compared with } \\
\text { PBS (area } \\
\text { non-epithelialized } \\
\text { after follow-up: } \\
\text { MSC }=25.9 \pm 2.6 \% \text {, } \\
\text { MSC- } \\
\text { CM }=25.1 \pm 1.5 \% \text {, } \\
\text { PBS }=48.3 \pm 4.7 \% \text { ) }\end{array}$ & $\begin{array}{l}\text { Capillary density } \\
\text { was higher in } \\
\text { MSC-CM and MSC } \\
\text { groups } \\
\text {, }\end{array}$ \\
\hline $\begin{array}{l}\text { Chen et al., } \\
2008\end{array}$ & $\begin{array}{l}\text { Murine bone } \\
\text { marrow from } \\
\text { femurs and } \\
\text { tibia }\end{array}$ & - & q & $\begin{array}{l}\text { MSCs in passage } \\
3 \text { at } 80 \% \\
\text { confluence under } \\
\text { hypoxic } \\
\text { conditions were } \\
\text { used }\end{array}$ & $\begin{array}{l}\text { Murine. } \\
\text { Full-thickness } \\
\text { skin wounds, } \\
6-\mathrm{mm} \text { diameter, } \\
\text { on each side of } \\
\text { midline }\end{array}$ & $\begin{array}{l}100 \mathrm{ml} \text { ( } 80 \mathrm{ml} \text { for } \\
\text { subcutaneous } \\
\text { injection around } \\
\text { the wound and } \\
20 \mathrm{ml} \text { for topical } \\
\text { application on the } \\
\text { wound bed) } \\
\text { - MSC-CM } \\
\text { - Fibroblast-CM } \\
\text { - Vehicle } \\
\text { ( } n=5 \text { /group) }\end{array}$ & 14 & $\begin{array}{l}\text { Macroscopic } \\
\text { appearance } \\
\text { (photography), } \\
\text { histology (HE), } \\
\text { IHC }\end{array}$ & $\begin{array}{l}\text { MSC-CM } \\
\text { significantly } \\
\text { accelerated } \\
\text { wound closure } \\
\text { compared with } \\
\text { fibroblast-CM or } \\
\text { vehicle (wound } \\
\text { closure } \\
\text { percentage: } 61 \\
\text { vs. } 53 \text { vs. } 51 \% \text {, } \\
\text { respectively) }\end{array}$ & $\begin{array}{l}\text { MSC-CM increased } \\
\text { cell recruitment. }\end{array}$ \\
\hline
\end{tabular}

ASCs, antler stem cells; AT, Adipose tissue-derived; bFGF, basic fibroblast growth factor; AF, amniotic fluid; BM, bone marrow; CM, conditioned medium; DMEM, Dulbecco's modified Eagle medium; DP, dental pulp; ECM, extracellular matrix; EGF, epidermal growth factor; ELISA, enzyme-linked immunosorbent assay; EVs, extracellular vesicles; Exos, exosomes; HE, hematoxylin and eosin; hCB, human cord blood; hESC, human embryonic stem cell; IHC, immunohistochemistry; IF, immunofluorescence; MPF, micro-nano polylactic acid electrospun fiber; MSCs, mesenchymal stromal cells; MT, Masson's trichrome; PBM, photobiomodulation; PBS, phosphate-buffered saline; GRT-PCR, real-time quantitative polymerase chain reaction; SVF, stromal vascular fraction; UCM, unconditioned medium; WB, Western blotting; WJ, Wharton's jelly.

${ }^{*} 0,10,50$, and $100 \%$ MSC-CM refers to the dilutions of the conditioned medium in DMEM/F12 with $2 \%$ FBS. 
graft reperfusion, hair restoration, aesthetic applications, and cutaneous inflammatory diseases.

\section{Wounds \\ Preclinical Studies}

Fifty-three studies evaluated the effects of MSC-CM on wound healing, $58.49 \%(31 / 53)$ evaluated outcomes in non-diabetic wounds, and $35.85 \%(19 / 53)$ in diabetic wounds, including three studies that evaluated wound healing in both diabetic and nondiabetic animals (Fong et al., 2014; Tam et al., 2014; Raj et al., 2019). Moreover MSC-CM has also been tested on burn wounds $(5.66 \%, 3 / 53)$, infected wounds $(3.77 \%, 2 / 53)$, and radiationinduced wounds $(1.89 \%, 1 / 53)$.

\section{Non-diabetic wounds}

Thirty-one studies evaluated the potential of MSC-CM for treating non-diabetic wounds (Table 1). To obtain CM, cells were mainly isolated from human tissues $(74.19 \%, 23 / 31)$ : from adipose tissue (Cho et al., 2010; Heo et al., 2011; Deng et al., 2017; Yuan et al., 2018; Chen et al., 2021) (21.74\%, 5/23), amnion (Yoon et al., 2010; Jun et al., 2014; Park et al., 2018; He et al., 2020) (17.34\%, 4/23), umbilical cord blood (Lee et al., 2011; Dong et al., 2017; Raj et al., 2019; Rong et al., 2019) (17.34\%, 4/23), bone marrow (Tamari et al., 2013; Chen et al., 2014; Ahangar et al., 2020) (13.04\%, 3/23), and Wharton's jelly (Fong et al., 2014; Tam et al., 2014; Sabzevari et al., 2020) (13.04\%, 3/23). Human dental pulp (Zhou et al., 2020) and skin (Robert et al., 2019) were also used. Moreover, murine, swine, caprine, canine, deer, and rabbit tissues were also employed (Chen et al., 2008; Templin et al., 2009; Sun et al., 2014; Mehanna et al., 2015; Du et al., 2017; Payushina et al., 2018; Rong et al., 2019; Joseph et al., 2020). CM was collected from MSCs between passages 1 and 12 at $50-100 \%$ confluence. The most common model was murine $(96.77 \%, 30 / 31)$, although a swine model was also used (Joseph et al., 2020). Regarding the route of administration, MSC-CM was mainly used topically $(51.61 \%, 16 / 31)$, applied to the wounds or around them in cream, hydrogel, or membranes (Heo et al., 2011; Lee et al., 2011; Chen et al., 2014; Jun et al., 2014; Sun et al., 2014; Mehanna et al., 2015; Park et al., 2018; Joseph et al., 2020). MSC-CM was also injected (41.94\%, 13/31), mainly subcutaneously $(25.81 \%, 8 / 31)$ (Templin et al., 2009; Lee et al., 2011; Deng et al., 2017; He et al., 2020; Zhou et al., 2020) but also intradermally (Cho et al., 2010) and intraperitoneally (Fong et al., 2014). Subcutaneously injected and topically applied concomitant MSC-CM was also tested (Chen et al., 2008; Yoon et al., 2010). Topical application might be more effective than subcutaneous injections (Lee et al., 2011).

MSC-CM was tested for treating wounds in 421 animals. The mean wound size was $11.65 \mathrm{~mm}$ (from 2 to $35 \mathrm{~mm}$ ), and the mean follow-up was 16.48 days (from 5 to 35 days). Wounds were assessed mainly by macroscopic appearance, histology, immunohistochemistry, and qRT-PCR. Outcomes showed that MSC-CM had better results in terms of wound closure, re-epithelialization, and vascularization than nontreated groups or other treatment groups (phosphate-buffered saline (PBS), hydrogel without cells, Dulbecco's modified Eagle medium (DMEM), and unconditioned medium). Moreover, some research compared the effects between MSCs and MSC$\mathrm{CM}$ with similar results. Topically applied MSCs and their CM via fibrin vehicle showed similar wound healing rates (Mehanna et al., 2015). Healing rates, vascularity, and cellular density were similar between MSCs and MSC-CM injected intraperitoneally (Fong et al., 2014). Injections of MSCs or MSC-CM around the wound showed similar results in wound healing (Templin et al., 2009; Tamari et al., 2013) (non-epithelialized area after 14 days' follow-up: $25.9 \pm 2.6 \%$ in MSCs and $25.1 \pm 1.5 \%$ in the MSC-CM group).

Different MSC sources and CM delivery were also compared. Allogeneic MSC-CM showed better healing rate than xenogeneic MSC-CM treatment (Joseph et al., 2020). The wound closure rate was higher in animals treated with carrageenan-embedded CM than mice treated with polyvinyl alcohol-embedded CM (Robert et al., 2019). Moreover, CM supplemented with selenium and basic fibroblast growth factor (bFGF) showed better results in wound healing than $\mathrm{CM}$ alone or CM only supplemented with bFGF or selenium, as complete wound closure after 11 days' follow-up was only observed in CM supplemented with both growth factors (Park et al., 2018). Hypoxic conditions also improved wound healing, accelerating wound closure (Chen et al., 2014; Jun et al., 2014; Sun et al., 2014; Du et al., 2017). TNF$\alpha$ - and TFG- $\beta 1$-implemented CM also accelerated wound healing as compared with non-supplemented MSC-CM (Cho et al., 2010; Heo et al., 2011). CM derived from Wnt7a-transduced MSCs also showed higher closures rates than did the MSC-CM group (Dong et al., 2017). No adverse events were reported in these studies.

\section{Diabetic wounds}

Nineteen studies evaluated the effects of MSC-CM for treating diabetic wounds (Table 2). To obtain CM, cells were mainly isolated from human tissues $(89.47 \%, 17 / 19)$ : from umbilical cord blood (Kim et al., 2010; Kusindarta et al., 2016; Chen Z. et al., 2018; Raj et al., 2019; Zhang S. et al., 2020) (29.41\%, 5/17), bone marrow (Pouriran et al., 2016; Amini et al., 2018; Bagheri et al., 2018; Saheli et al., 2020) (23.53\%, 4/17), adipose tissue (Deng et al., 2019; De Gregorio et al., 2020) (11.76\%, 2/17), and Wharton's jelly (Fong et al., 2014; Tam et al., 2014) $(11.76 \%, 2 / 17)$. Human hair follicles (Ma et al., 2015), menstrual blood (Dalirfardouei et al., 2019), and urine (Chen C. Y. et al., 2018) were also used. Moreover, murine (Li T. et al., 2019) and swine (Irons et al., 2018) adipose tissues were employed. CM was collected from MSCs between passages 1 and 12 at 50-100\% confluence. The most common model was murine $(94.12 \%, 16 / 17)$, although a swine model was also used (Irons et al., 2018). Regarding the route of administration, MSC-CM was injected $(78.95 \%, 15 / 19)$ mainly intraperitoneally $(26.31 \%$, 5/19) (Fong et al., 2014; Pouriran et al., 2016; Amini et al., 2018; Bagheri et al., 2018; Saheli et al., 2020), subcutaneously (15.79\%, 3/19) (Chen C. Y. et al., 2018; Li T. et al., 2019; Zhang S. et al., 2020), intradermally (15.79\%, 3/19) (Kim et al., 2010; Dalirfardouei et al., 2019; Deng et al., 2019), or intravenously $(5.26 \%, 1 / 19)$ (De Gregorio et al., 2020). MSC-CM was also applied topically $(21.05 \%, 4 / 19)$ to the wounds or around them in creams, hydrogels, or membranes (Kusindarta et al., 2016; Chen Z. et al., 2018; Irons et al., 2018). 
TABLE 2 | Studies regarding mesenchymal stromal cell-conditioned medium for treating diabetic wounds in animal models.

\begin{tabular}{|c|c|c|c|c|c|c|c|c|c|c|}
\hline & MSC source & $\begin{array}{l}\text { Method of } \\
\text { tissue } \\
\text { extraction }\end{array}$ & $\begin{array}{l}\text { MSC } \\
\text { characterization }\end{array}$ & $\begin{array}{l}\text { Preparation of } \\
\text { MSC-CM }\end{array}$ & Model & $\begin{array}{l}\text { Groups of } \\
\text { treatments and } \\
\text { via of } \\
\text { administration }\end{array}$ & $\begin{array}{l}\text { Follow-up } \\
\text { (days) }\end{array}$ & Assessment & Main outcome & Other outcomes \\
\hline $\begin{array}{l}\text { Zhang S. et al., } \\
2020\end{array}$ & $\begin{array}{l}\text { Human } \\
\text { umbilical cords }\end{array}$ & $\begin{array}{l}\text { Full-term } \\
\text { delivered } \\
\text { infants }\end{array}$ & $\begin{array}{l}\text { Flow cytometry } \\
\text { (CD105+, CD73+, } \\
\text { CD90+, CD166+, } \\
\text { CD54+, CD13+, } \\
\text { CD45-, CD34-, } \\
\text { CD14-, CD19-, } \\
\text { CD117-, } \\
\text { HLA-DR-) }\end{array}$ & $\begin{array}{l}\text { MSCs of } \\
\text { passages 3-4 at } \\
80 \% \text { confluence } \\
\text { were used. CM } \\
\text { was collected }\end{array}$ & $\begin{array}{l}\text { Murine. Diabetic } \\
\text { model. } \\
\text { Full-thickness } \\
\text { excisional skin } \\
\text { wounds, } 800 \\
\mathrm{~mm}^{2} \text {, on the } \\
\text { back }\end{array}$ & $\begin{array}{l}150 \mu \mathrm{l} \\
\text { subcutaneously } \\
\text { injected around } \\
\text { the wounds at six } \\
\text { injection sites } \\
(25 \mu l \text { per site) } \\
\text { every day for } \\
\text { three consecutive } \\
\text { days } \\
\text { - Control } \\
\text { (non-CM) } \\
\text { - FB } \\
\text { - UC-MSC } \\
\text { - UC-MSC-CM } \\
\text { (n = 12/group) }\end{array}$ & 14 & $\begin{array}{l}\text { Macroscopic } \\
\text { appearance } \\
\text { (photography), } \\
\text { histology (HE), } \\
\text { IHC, qRT-PCR }\end{array}$ & $\begin{array}{l}\text { UC-MSC and } \\
\text { UC-MSC-CM } \\
\text { treatment } \\
\text { accelerated } \\
\text { wound healing } \\
\text { rate. The wound } \\
\text { area of UC-MSC } \\
\text { and } \\
\text { UC-MSC-CM } \\
\text { was } \approx 15 \% \\
\text { reduced } \\
\text { compared with } \\
\text { controls }\end{array}$ & $\begin{array}{l}\text { UC-MSC and } \\
\text { UC-MSC-CM } \\
\text { increased the } \\
\text { percentage of M2 } \\
\text { macrophages in the } \\
\text { local wounds and } \\
\text { the levels of } \\
\text { anti-inflammatory } \\
\text { cytokines, IL-10, } \\
\text { and VEGF and } \\
\text { significantly } \\
\text { decreased the } \\
\text { levels of } \\
\text { proinflammatory } \\
\text { cytokines, IL-1 } 1 \beta \text {, } \\
\text { TNF- } \alpha \text {, and IL-6 }\end{array}$ \\
\hline $\begin{array}{l}\text { Saheli et al., } \\
2020\end{array}$ & $\begin{array}{l}\text { Human bone } \\
\text { marrow }\end{array}$ & - & $\begin{array}{l}\text { Flow cytometry } \\
\text { (CD73+, CD90+, } \\
\text { CD105+, CD34-, } \\
\text { CD45-). } \\
\text { Osteogenic and } \\
\text { adipogenic } \\
\text { differentiation }\end{array}$ & $\begin{array}{l}\text { MSCs of passage } \\
4 \text { at } 80 \% \text { were } \\
\text { used. CM was } \\
\text { then collected }\end{array}$ & $\begin{array}{l}\text { Murine. Diabetic } \\
\text { model. } \\
\text { Full-thickness } \\
\text { excisional skin } \\
\text { wounds, } 20 \mathrm{~mm} \\
\text { long, on the chest } \\
\text { proximal part } \\
\text { intraperitoneal }\end{array}$ & $\begin{array}{l}\text { 50-fold } \\
\text { concentrated } \\
\text { DMEM or CM } \\
\text { twice at } 12 \text { and } \\
24 \text { h after } \\
\text { wounding } \\
\text { intraperitoneally } \\
\text { - Control (no } \\
\text { treatment) } \\
\text { - Placebo } \\
\text { - hBM-MSC-CM } \\
\text { (n=6/group) }\end{array}$ & 15 & $\begin{array}{l}\text { Macroscopic } \\
\text { appearance, } \\
\text { histology (HE, } \\
\text { MT), qRT-PCR }\end{array}$ & $\begin{array}{l}\text { MSC-CM } \\
\text { accelerated } \\
\text { diabetic wound } \\
\text { closure }(67 \% \\
\text { wound closure in } \\
\text { CM group vs. } \\
33 \% \text { in placebo } \\
\text { group, } p<0.05 \text { ) }\end{array}$ & $\begin{array}{l}\text { MSC-CM treatment } \\
\text { leads to } \\
\text { upregulation of EGF } \\
\text { and bFGF genes } \\
\text { and higher cell } \\
\text { viability/proliferation } \\
\text { and migration }\end{array}$ \\
\hline $\begin{array}{l}\text { De Gregorio } \\
\text { et al., } 2020\end{array}$ & $\begin{array}{l}\text { Human } \\
\text { subcutaneous } \\
\text { adipose tissue } \\
\text { samples from } \\
\text { abdominal } \\
\text { region }\end{array}$ & Liposuction & $\begin{array}{l}\text { Flow cytometry } \\
\text { (CD29+, CD13+, } \\
\text { CD105+, CD73+, } \\
\text { CD90+, CD235a-, } \\
\text { CD31-, CD45-). } \\
\text { Adipogenic and } \\
\text { osteogenic } \\
\text { differentiation }\end{array}$ & $\begin{array}{l}\text { MSCs of passage } \\
3 \text { at } 70 \% \\
\text { confluence were } \\
\text { used. Cells were } \\
\text { supplemented } \\
\text { with } 400 \mu \mathrm{M} \text { DFX } \\
\text { (preconditioned } \\
\text { MSCs) or with } \\
\text { saline (vehicle) as } \\
\text { non- } \\
\text { preconditioned } \\
\text { MSCs. CM was } \\
\text { then collected }\end{array}$ & $\begin{array}{l}\text { Murine. Diabetic } \\
\text { mice. } \\
\text { Full-thickness } \\
\text { skin } \\
(2.5 \mathrm{~mm} \times 3.5 \mathrm{~mm}) \\
\text { surgically } \\
\text { removed from the } \\
\text { dorsal surface of } \\
\text { both feet, } \\
\text { mimicking a foot } \\
\text { ulcer }\end{array}$ & $\begin{array}{l}\text { Intravenous } \\
\text { administration of } \\
50 \mu \text { l of CM every } \\
2 \text { weeks } \\
\text { - CM derived } \\
\text { from DFX- } \\
\text { preconditioned } \\
\text { MSCs } \\
\text { - CM derived } \\
\text { from non- } \\
\text { preconditioned } \\
\text { MSCs } \\
\text { - Vehicle } \\
\text { (n=6/group) }\end{array}$ & 14 & $\begin{array}{l}\text { Macroscopic } \\
\text { appearance } \\
\text { (photography), } \\
\text { histology (HE, } \\
\text { MT), qRT-PCR, } \\
\text { proteomic } \\
\text { analysis }\end{array}$ & $\begin{array}{l}\text { MSC-CM } \\
\text { accelerated } \\
\text { wound healing. } \\
\text { The wound area } \\
\text { of MSC-CM was } \\
\approx 20 \% \text { reduced } \\
\text { compared with } \\
\text { controls at day } 7\end{array}$ & $\begin{array}{l}\text { MSC-CM derived } \\
\text { from DFX- } \\
\text { preconditioned } \\
\text { MSCs had a more } \\
\text { potent effect in } \\
\text { recovering the skin } \\
\text { vasculature }\end{array}$ \\
\hline
\end{tabular}


TABLE 2 | Continued

\begin{tabular}{|c|c|c|c|c|c|c|c|c|c|c|}
\hline & MSC source & $\begin{array}{l}\text { Method of } \\
\text { tissue } \\
\text { extraction }\end{array}$ & $\begin{array}{l}\text { MSC } \\
\text { characterization }\end{array}$ & $\begin{array}{l}\text { Preparation of } \\
\text { MSC-CM }\end{array}$ & Model & $\begin{array}{l}\text { Groups of } \\
\text { treatments and } \\
\text { via of } \\
\text { administration }\end{array}$ & $\begin{array}{l}\text { Follow-up } \\
\text { (days) }\end{array}$ & Assessment & Main outcome & Other outcomes \\
\hline $\begin{array}{l}\text { Bian et al., } \\
2020\end{array}$ & $\begin{array}{l}\text { Human } \\
\text { placenta }\end{array}$ & $\begin{array}{l}\text { Cesarean } \\
\text { section births }\end{array}$ & $\begin{array}{l}\text { Flow cytometry } \\
\text { (CD73+, CD90+, } \\
\text { CD105+, CD19-, } \\
\text { CD34-, CD45-, } \\
\text { HLA-DR-). } \\
\text { Osteogenic, } \\
\text { adipogenic, and } \\
\text { chondrogenic } \\
\text { differentiation }\end{array}$ & $\begin{array}{l}\text { MSCs of } \\
\text { passages 3-7 } \\
\text { were used. CM } \\
\text { was collected, } \\
\text { and EVs were } \\
\text { obtained }\end{array}$ & $\begin{array}{l}\text { Murine. Diabetic } \\
\text { model. } \\
\text { Full-thickness } \\
\text { excisional } \\
\text { wounds, } 16 \mathrm{~mm} \text {, } \\
\text { on the back }\end{array}$ & $\begin{array}{l}100 \mu \text { l was } \\
\text { injected around } \\
\text { the wounds at } 4 \\
\text { sites ( } 25 \mu \text { l per } \\
\text { site) } \\
\text { - MSC-EVs } \\
\text { - PBS } \\
\text { ( } n=5 \text { /group) }\end{array}$ & 28 & $\begin{array}{l}\text { Photography, } \\
\text { histology (HE, } \\
\text { MT), IHC }\end{array}$ & $\begin{array}{l}\text { MSC-EVs } \\
\text { significantly } \\
\text { accelerated } \\
\text { wound healing. } \\
\text { The narrowest } \\
\text { scar widths were } \\
\text { observed at day } \\
14 \\
\text { post-wounding } \\
\text { (2.41 } 0.24 \mathrm{~mm} \\
\text { in MSC-EVs } \\
\text { group vs. } \\
3.87 \pm 0.60 \mathrm{~mm} \\
\text { in PBS group) }\end{array}$ & $\begin{array}{l}\text { CXCR4, p21 } \\
\text { PCNA, and } \alpha \text {-SMA } \\
\text { were upregulated in } \\
\text { the MSC-EV group }\end{array}$ \\
\hline Raj et al., 2019 & $\begin{array}{l}\text { Human } \\
\text { umbilical cord }\end{array}$ & $\begin{array}{l}\text { Umbilical cord } \\
\text { dissection }\end{array}$ & $\begin{array}{l}\text { Flow cytometry } \\
\text { (CD13+, CD29+, } \\
\text { CD44+, CD90+, } \\
\text { CD10-, CD14-, } \\
\text { CD34-, CD117-) }\end{array}$ & $\begin{array}{l}\text { MSCs were } \\
\text { transduced with a } \\
\text { lentiviral vector } \\
\text { (green } \\
\text { fluorescence } \\
\text { protein tagged). } \\
\text { MSCs of } \\
\text { passages 3-4 } \\
\text { were used. CM } \\
\text { was collected. } \\
\text { Wound dressing } \\
\text { patches: } \\
\text { impregnated with } \\
\text { aloe } \\
\text { verapolycaprolactone } \\
\text { (AV/PCL) } \\
\text { nanoscaffolds } \\
\text { with hWJSCs or } \\
\text { hWJSC-CM } \\
\text { were also created }\end{array}$ & $\begin{array}{l}\text { Murine. Diabetic } \\
\text { model. } \\
\text { Full-thickness } \\
\text { excisional } \\
\text { wounds, } 6 \mathrm{~mm} \text {, } \\
\text { on the back } \\
\text { e }\end{array}$ & $\begin{array}{l}100 \mu \text { l of: } \\
- \text { PBS with } \\
1 \times 10^{6} \mathrm{MSCs} \\
-\mathrm{MSC}-\mathrm{CM} \\
- \text { UCM } \\
-\mathrm{PBS} \text { with } \\
1 \times 10^{6} \\
\mathrm{MSCS}+\mathrm{AV} / \mathrm{PCL} \\
-\mathrm{MSC}- \\
\mathrm{CM}+\mathrm{AV} / \mathrm{PCL} \\
- \text { UCM+ AV/PCL } \\
\text { - Untreated group } \\
\text { (n=12/group) }\end{array}$ & 28 & $\begin{array}{l}\text { Macroscopic } \\
\text { appearance } \\
\text { (photography), } \\
\text { histology (HE), } \\
\text { IHC, qRT-PCR }\end{array}$ & $\begin{array}{l}\text { Thickness of the } \\
\text { epidermis and } \\
\text { dermis was } \\
\text { significantly } \\
\text { greater in both } \\
\text { MSCs and } \\
\text { MSC-CMs } \\
\text { without AV/PCL } \\
\text { compared with } \\
\text { their controls } \\
\text { without AV/PCL }\end{array}$ & $\begin{array}{l}\text { AV/PCL groups } \\
\text { showed an earlier } \\
\text { re-epithelialization } \\
\text { and increases in } \\
\text { thickness of dermis } \\
\text { and epidermis, } \\
\text { cellularity, } \\
\text { vasculature, and } \\
\text { hair follicle numbers }\end{array}$ \\
\hline Li T. et al., 2019 & $\begin{array}{l}\text { Murine adipose } \\
\text { tissue }\end{array}$ & - & $\begin{array}{l}\text { Flow cytometry and } \\
\text { oil red O staining } \\
\text { (CD29+, CD90, } \\
\text { CD45-) }\end{array}$ & $\begin{array}{l}\text { MSCs of } \\
\text { passages } 3-5 \\
\text { were used. They } \\
\text { were cultured on } \\
\text { various matrices } \\
\text { (tissue culture } \\
\text { plates (TCP), pure } \\
\text { three- } \\
\text { dimensional- } \\
\text { printed }\end{array}$ & $\begin{array}{l}\text { Murine. Diabetic } \\
\text { murine model. } \\
\text { Full-thickness } \\
\text { skin defects, } \\
7 \text { mm diameter }\end{array}$ & $\begin{array}{l}200 \mu \mathrm{l} \text { of each } \\
\text { solution was } \\
\text { used }(150 \mu \mathrm{l} \\
\text { injected } \\
\text { subcutaneously } \\
\text { around the defect } \\
\text { and } 50 \mu \mathrm{l} \\
\text { smeared onto the } \\
\text { wound bed) } \\
\text { - DMEM (control) }\end{array}$ & 14 & $\begin{array}{l}\text { Macroscopic } \\
\text { appearance } \\
\text { (photography), } \\
\text { histology (HE, } \\
\text { MT), IF }\end{array}$ & $\begin{array}{l}\text { All groups } \\
\text { improved wound } \\
\text { healing. The } \\
\text { highest } \\
\text { wound-healing } \\
\text { rate was } \\
\text { observed in } \\
\text { DOPA-BC-CM } \\
\text { group. Remaining } \\
\text { wound area at }\end{array}$ & $\begin{array}{l}\text { The newly formed } \\
\text { capillary network } \\
\text { around the } \\
\text { excisional regions } \\
\text { was the most } \\
\text { intense in the } \\
\text { DOPA-BC-CM } \\
\text { group. Higher levels } \\
\text { of CD31 and a } \\
\text { higher amount of }\end{array}$ \\
\hline
\end{tabular}


TABLE 2 | Continued

\begin{tabular}{|c|c|c|c|c|c|c|c|c|c|c|}
\hline & MSC source & $\begin{array}{l}\text { Method of } \\
\text { tissue } \\
\text { extraction }\end{array}$ & $\begin{array}{l}\text { MSC } \\
\text { characterization }\end{array}$ & $\begin{array}{l}\text { Preparation of } \\
\text { MSC-CM }\end{array}$ & Model & $\begin{array}{l}\text { Groups of } \\
\text { treatments and } \\
\text { via of } \\
\text { administration }\end{array}$ & $\begin{array}{l}\text { Follow-up } \\
\text { (days) }\end{array}$ & Assessment & Main outcome & Other outcomes \\
\hline & & & & $\begin{array}{l}\text { bioceramic (BC), } \\
\text { and } \\
\text { polydopamine- } \\
\text { modified BC } \\
\text { scaffolds } \\
\text { (DOPA-BC), and } \\
\text { each CM was } \\
\text { collected }\end{array}$ & & $\begin{array}{l}\text { - MSC-CMs } \\
\text { derived from TCP } \\
\text { - MSC-CMs } \\
\text { derived from BC } \\
\text { - MSC-CMs } \\
\text { derived from } \\
\text { DOPA-BC } \\
\text { ( } n=4 / \text { group) }\end{array}$ & & & $\begin{array}{l}\text { day } 14 \text { was } \\
7.1 \pm 3.4 \% \text { in } \\
\text { DOPA-BC-CM } \\
\text { group, } \\
\sim 15.2 \pm 6.6 \% \text { in } \\
\text { BC-CM, } \\
\sim 21.2 \pm 11.3 \% \\
\text { in TCP-CM, and } \\
\sim 31.8 \pm 7.2 \% \text { in } \\
\text { DMEM group }\end{array}$ & $\begin{array}{l}\text { collagen deposition } \\
\text { were also observed } \\
\text { in this group }\end{array}$ \\
\hline $\begin{array}{l}\text { Deng et al., } \\
2019\end{array}$ & $\begin{array}{l}\text { Human adipose } \\
\text { tissue }\end{array}$ & Liposuction & - & $\begin{array}{l}\text { SVF gel was } \\
\text { prepared, and its } \\
\text { CM was collected } \\
\text { (Gel-CM). CM } \\
\text { from MSCs was } \\
\text { also collected } \\
\text { (MSC-CM) }\end{array}$ & $\begin{array}{l}\text { Murine. Diabetic } \\
\text { model. Full- } \\
\text { thickness } \\
\text { excisional wound, } \\
\text { 20-mm diameter, } \\
\text { on the back }\end{array}$ & $\begin{array}{l}100 \mu \mathrm{l} \text { was } \\
\text { administered } \\
\text { intradermally } \\
\text { every } 2 \text { days: } \\
\text { - Gel-CM } \\
\text { - MSC-CM } \\
\text { - PBS } \\
\text { ( } n=18 / \text { group) }\end{array}$ & 14 & $\begin{array}{l}\text { Macroscopic } \\
\text { appearance } \\
\text { (photography), } \\
\text { histology (HE), } \\
\text { ELISA }\end{array}$ & $\begin{array}{l}\text { The wound size } \\
\text { in all groups was } \\
\text { reduced. } \\
\text { Wound-healing } \\
\text { rate in the } \\
\text { Gel-CM-treated } \\
\text { group was } \\
\text { significantly } \\
\text { higher than that } \\
\text { in the MSC-CM } \\
\text { group }(p<0.05 \text { ) }\end{array}$ & $\begin{array}{l}\text { Gel-CM-treated } \\
\text { rats exhibited } \\
\text { complete } \\
\text { re-epithelialization } \\
\text { of the wound, while } \\
\text { MSC-CM did not. } \\
\text { Number of } \\
\text { capillaries in the } \\
\text { Gel-CM-treated } \\
\text { group was higher in } \\
\text { MSC-CM }\end{array}$ \\
\hline $\begin{array}{l}\text { Dalirfardouei } \\
\text { et al., } 2019\end{array}$ & $\begin{array}{l}\text { Human } \\
\text { menstrual } \\
\text { blood }\end{array}$ & $\begin{array}{l}\text { Collecting } \\
\text { menstrual } \\
\text { blood from } \\
\text { healthy women }\end{array}$ & $\begin{array}{l}\text { Flow cytometry } \\
\text { (CD29+, CD44+, } \\
\text { CD90+, CD34-, } \\
\text { CD45-, CD117-, } \\
\text { HLA-DR-). } \\
\text { Adipogenic and } \\
\text { osteogenic } \\
\text { differentiation }\end{array}$ & $\begin{array}{l}\text { MSCs of } \\
\text { passages 4-6 at } \\
70-80 \% \\
\text { confluence were } \\
\text { used. CM was } \\
\text { collected, and } \\
\text { exosomes were } \\
\text { isolated }\end{array}$ & $\begin{array}{l}\text { Murine. Diabetic } \\
\text { mice models. } \\
\text { Full-thickness } \\
\text { excisional wound } \\
\text { including the } \\
\text { panniculus } \\
\text { carnosus, } 8 \mathrm{~mm} \text {, } \\
\text { on the back }\end{array}$ & $\begin{array}{l}100 \mu \mathrm{l} \text { was } \\
\text { intradermally } \\
\text { injected around } \\
\text { the wound } \\
\text { - PBS } \\
\text { - MSCs } \\
\text { - Exos-MSCs } \\
\text { ( } n=6 / \text { group) }\end{array}$ & 14 & $\begin{array}{l}\text { Macroscopic } \\
\text { appearance } \\
\text { (photography), } \\
\text { histology (HE, } \\
\text { MT), IHC, } \\
\text { qRT-PCR }\end{array}$ & $\begin{array}{l}\text { Increased wound } \\
\text { closure was } \\
\text { observed in } \\
\text { Exo-group } \\
\text { compared with } \\
\text { the control or } \\
\text { MSC group. At } \\
\text { day } 12 \text {, wound } \\
\text { closure was } \\
84.34 \pm 7.00 \% \text { in } \\
\text { Exo-MSCs, } \\
46.4 \pm 8.5 \% \text { in } \\
\text { MSCs, and } \\
43.78 \pm 6.95 \% \text { in } \\
\text { controls }\end{array}$ & $\begin{array}{l}\text { Microvessel density } \\
\text { was significantly } \\
\text { higher in the } \\
\text { Exo-group } \\
\text { compared with the } \\
\text { other two groups. } \\
\text { Size of scar tissues } \\
\text { significantly } \\
\text { decreased in } \\
\text { themice treated } \\
\text { with MSCs and } \\
\text { their exosomes } \\
\text { compared with } \\
\text { control group. } \\
\text { A major reduction } \\
\text { in the granulation } \\
\text { tissue cellularity } \\
\text { was observed in } \\
\text { mice treated with } \\
\text { exosomes } \\
\text { compared with the } \\
\text { cell group }\end{array}$ \\
\hline
\end{tabular}


TABLE 2 | Continued

\begin{tabular}{|c|c|c|c|c|c|c|c|c|c|c|}
\hline & MSC source & $\begin{array}{l}\text { Method of } \\
\text { tissue } \\
\text { extraction }\end{array}$ & $\begin{array}{l}\text { MSC } \\
\text { characterization }\end{array}$ & $\begin{array}{l}\text { Preparation of } \\
\text { MSC-CM }\end{array}$ & Model & $\begin{array}{l}\text { Groups of } \\
\text { treatments and } \\
\text { via of } \\
\text { administration }\end{array}$ & $\begin{array}{l}\text { Follow-up } \\
\text { (days) }\end{array}$ & Assessment & Main outcome & Other outcomes \\
\hline $\begin{array}{l}\text { Irons et al., } \\
2018\end{array}$ & $\begin{array}{l}\text { Adipose tissue } \\
\text { from pigs' } \\
\text { gluteal regions }\end{array}$ & Wound incision & - & $\begin{array}{l}\text { MSCs at } 90 \% \\
\text { were used. CM } \\
\text { was collected }\end{array}$ & $\begin{array}{l}\text { Pigs. Diabetic } \\
\text { pigs. } \\
\text { Full-thickness } \\
\text { skin wounds, } \\
50 \mathrm{~mm} \text { circular, } \\
\text { on the back }\end{array}$ & $\begin{array}{l}\text {-Injection of } \\
\text { low-dose MSCs } \\
\text { - Injection of } \\
\text { high-dose MSCs } \\
\text { - Injection of } \\
\text { low-dose } \\
\text { EC/MSCs } \\
\text { - Injection of } \\
\text { high-dose } \\
\text { EC/MSCs } \\
-2 \text { ml of } \\
\text { MSC-CM } \\
\text { topically applied } \\
\text { every } 3 \text { days } \\
-2 \text { ml of EC-CM } \\
\text { topically applied } \\
\text { every } 3 \text { days } \\
-2 \text { ml of } \\
\text { serum-free } \\
\text { medium topically } \\
\text { applied every } \\
3 \text { days (control) } \\
\text { ( } n=7 / \text { group) }\end{array}$ & 28 & $\begin{array}{l}\text { Macroscopic } \\
\text { appearance } \\
\text { (photography), } \\
\text { histology (HE) }\end{array}$ & $\begin{array}{l}\text { Wounds treated } \\
\text { with MSCs and } \\
\text { MSC-CMs } \\
\text { displayed a } \\
\text { significant } \\
\text { increase in the } \\
\text { percentage of } \\
\text { wound closure } \\
\text { compared with } \\
\text { controls } \\
(p<0.05)\end{array}$ & $\begin{array}{l}\text { Decreases in the } \\
\text { acute inflammation } \\
\text { scores were } \\
\text { observed in } \\
\text { wounds treated } \\
\text { with MSCs and } \\
\text { MSC-CMs } \\
\text { compared with } \\
\text { controls }\end{array}$ \\
\hline $\begin{array}{l}\text { Chen Z. et al., } \\
2018\end{array}$ & $\begin{array}{l}\text { Human } \\
\text { umbilical cord }\end{array}$ & $\begin{array}{l}\text { Umbilical cords } \\
\text { sections }\end{array}$ & $\begin{array}{l}\text { Electron } \\
\text { microscopy } \\
\text { (CD63+, CD81+) }\end{array}$ & $\begin{array}{l}\text { MSCs of } \\
\text { passages } 3-5 \text { at } \\
100 \% \text { confluence } \\
\text { were used. CM } \\
\text { was collected, } \\
\text { and Exos were } \\
\text { obtained. PF-127 } \\
\text { hydrogel was } \\
\text { mixed with Exos, } \\
\text { and PF-127 } \\
\text { composite (MSC- } \\
\text { Exos/PF-127) } \\
\text { was obtained }\end{array}$ & $\begin{array}{l}\text { Murine. Diabetic } \\
\text { rat model. } \\
\text { Full-thickness } \\
\text { skin wounds, } \\
10 \text { mm circular, } \\
\text { on the back }\end{array}$ & $\begin{array}{l}\text { Treatment was } \\
\text { used topically } \\
-100 \mu g \\
\text { MSC-Exos } \\
\text { dissolved in } \\
100 \mu \text { I Pluronic } \\
\text { F127 hydrogel } \\
(24 \%) \\
-100 \mu g \\
\text { MSC-Exos } \\
\text { dissolved in } \\
100 \mu \text { I PBS } \\
-100 \mu \text { I PF-127 } \\
\text { hydrogel (24\%) } \\
-100 \mu l \text { PBS } \\
\text { (control) } \\
\text { ( } n=6 / \text { group) }\end{array}$ & 14 & $\begin{array}{l}\text { Macroscopic } \\
\text { appearance } \\
\text { (photography), } \\
\text { histology (HE), } \\
\text { IHC, qRT-PCR, IF }\end{array}$ & $\begin{array}{l}\text { Wound area was } \\
\text { significantly } \\
\text { smaller in the } \\
\text { MSC-Exos/PF- } \\
127 \text { group than in } \\
\text { the other groups. } \\
\text { Wounds in the } \\
\text { MSC-Exos/PF- } \\
127 \text { group were } \\
\text { almost } \\
\text { completely } \\
\text { healed at day 14, } \\
\text { while the wound } \\
\text { healing rates in } \\
\text { the MSC-Exos, } \\
\text { PF-127 hydrogel, } \\
\text { and control } \\
\text { groups were } \\
8.95,14.52, \text { and } \\
23.09 \% \text {, } \\
\text { respectively }\end{array}$ & $\begin{array}{l}\text { New hair was only } \\
\text { evident in the } \\
\text { MSC-Exos/PF-127 } \\
\text { group. Number of } \\
\text { blood vessels was } \\
\text { higher in the } \\
\text { MSC-ExoS/PF-127 } \\
\text { and MSC-Exos } \\
\text { groups than in the } \\
\text { PF- } 127 \text { hydrogel or } \\
\text { control group }\end{array}$ \\
\hline
\end{tabular}


TABLE 2 | Continued

\begin{tabular}{|c|c|c|c|c|c|c|c|c|c|c|}
\hline & MSC source & $\begin{array}{l}\text { Method of } \\
\text { tissue } \\
\text { extraction }\end{array}$ & $\begin{array}{l}\text { MSC } \\
\text { characterization }\end{array}$ & $\begin{array}{l}\text { Preparation of } \\
\text { MSC-CM }\end{array}$ & Model & $\begin{array}{l}\text { Groups of } \\
\text { treatments and } \\
\text { via of } \\
\text { administration }\end{array}$ & $\begin{array}{l}\text { Follow-up } \\
\text { (days) }\end{array}$ & Assessment & Main outcome & Other outcomes \\
\hline $\begin{array}{l}\text { Chen C. Y. } \\
\text { et al., } 2018\end{array}$ & $\begin{array}{l}\text { Human urine } \\
\text { samples }\end{array}$ & $\begin{array}{l}\text { Urine sample } \\
\text { collection }\end{array}$ & $\begin{array}{l}\text { Flow cytometry, } \\
\text { and electron } \\
\text { microscopy } \\
\text { (CD29+, CD44+, } \\
\text { CD73+, CD90+, } \\
\text { CD34-, CD45-). } \\
\text { Osteogenic, } \\
\text { adipogenic, and } \\
\text { chondrogenic } \\
\text { differentiation }\end{array}$ & $\begin{array}{l}\text { MSCs of } \\
\text { passages 2-6 at } \\
80-90 \% \\
\text { confluence were } \\
\text { used. CM was } \\
\text { collected, and } \\
\text { Exos were } \\
\text { created. } \\
\text { Lentivirus } \\
\text { shRNAs were } \\
\text { transfected }\end{array}$ & $\begin{array}{l}\text { Murine. Diabetic } \\
\text { rat model. } \\
\text { Full-thickness } \\
\text { skin wounds, } \\
6 \mathrm{~mm} \text {, on upper } \\
\text { back }\end{array}$ & $\begin{array}{l}\text { Treatment was } \\
\text { subcutaneously } \\
\text { injected around } \\
\text { the wounds at } 4 \\
\text { injection sites } \\
(25 \mu \mathrm{l} \text { per site) } \\
-100 \mu \mathrm{l} \text { PBS } \\
-200 \mu \mathrm{g} \\
\text { MSC-Exos in } \\
100 \mu \mathrm{l} \mathrm{PBS} \\
-200 \mu \mathrm{g} \\
\text { MSC-Exos } \\
\text { without DMBT1 } \\
\text { in } 100 \mu \mathrm{I} \text { PBS } \\
\text { ( } n=8 / \text { group) }\end{array}$ & 12 & $\begin{array}{l}\text { Macroscopic } \\
\text { appearance } \\
\text { (photography), } \\
\text { histology (HE, } \\
\text { MT), IHC, } \\
\text { qRT-PCR, IF }\end{array}$ & $\begin{array}{l}\text { Faster wound } \\
\text { closure was } \\
\text { observed in } \\
\text { MSC-Exos group } \\
\text { compared with } \\
\text { controls and } \\
\text { MSC-Exos } \\
\text { without DMBT1 }\end{array}$ & $\begin{array}{l}\text { Higher rate of } \\
\text { re-epithelialization, } \\
\text { lower level of scar } \\
\text { formation, and } \\
\text { higher number of } \\
\text { newly formed blood } \\
\text { vessels were } \\
\text { observed in } \\
\text { MSC-Exos group } \\
\text { compared with } \\
\text { controls and } \\
\text { MSC-Exos without } \\
\text { DMBT1 }\end{array}$ \\
\hline $\begin{array}{l}\text { Bagheri et al., } \\
2018\end{array}$ & $\begin{array}{l}\text { Human bone } \\
\text { marrow }\end{array}$ & Aspiration & $\begin{array}{l}\text { Flow cytometry } \\
\text { (CD73+, CD90+, } \\
\text { CD105+, CD34-, } \\
\text { CD45-) }\end{array}$ & $\begin{array}{l}\text { MSCs of passage } \\
4 \text { at } 80 \% \\
\text { confluence were } \\
\text { used. CM was } \\
\text { collected }\end{array}$ & $\begin{array}{l}\text { Murine. Diabetic } \\
\text { rat model. } \\
\text { Full-thickness } \\
\text { skin wounds, } \\
12 \mathrm{~mm} \text {, on upper } \\
\text { back }\end{array}$ & $\begin{array}{l}\text { PBM was } \\
\text { administered } \\
\text { once daily, } 6 \text { days } \\
\text { per week. CM } \\
\text { was administered } \\
\text { at days } 0 \text { and } 1 \\
\text { intraperitoneally } \\
\text { - DMEM vehicle } \\
\text { (control) } \\
\text { - MSC-CM } \\
\text { - PBM } \\
\text { - PMB+MSC-CM } \\
\text { (n=18/group) }\end{array}$ & 15 & $\begin{array}{l}\text { Stereological } \\
\text { methods, } \\
\text { tensiometric } \\
\text { examination }\end{array}$ & $\begin{array}{l}\text { MSC-CM and } \\
\text { PBM+MSC-CM } \\
\text { increased the } \\
\text { tensiometric } \\
\text { properties } \\
\text { compared with } \\
\text { DMEM and PBM }\end{array}$ & $\begin{array}{l}\text { MSC-CM, PBM, } \\
\text { and } \\
\text { PBM+MSC-CM } \\
\text { groups showed a } \\
\text { significant decrease } \\
\text { in the three types of } \\
\text { mast cells and in } \\
\text { the total number of } \\
\text { mast cells } \\
\text { compared with } \\
\text { controls }\end{array}$ \\
\hline $\begin{array}{l}\text { Amini et al., } \\
2018\end{array}$ & $\begin{array}{l}\text { Human bone } \\
\text { marrow }\end{array}$ & Aspiration & $\begin{array}{l}\text { Flow cytometry } \\
\text { (CD73+, CD90+, } \\
\text { CD105+, CD34-, } \\
\text { CD45-) }\end{array}$ & $\begin{array}{l}\text { MSCs of passage } \\
4 \text { at } 80 \% \\
\text { confluence were } \\
\text { used. CM was } \\
\text { collected }\end{array}$ & $\begin{array}{l}\text { Murine. Diabetic } \\
\text { rat model. } \\
\text { Full-thickness } \\
\text { skin wounds, } \\
12 \mathrm{~mm} \text {, on upper } \\
\text { thoracic and } \\
\text { lumbar regions }\end{array}$ & $\begin{array}{l}\text { PBM was } \\
\text { administered } \\
\text { once daily, } 6 \text { days } \\
\text { per week. CM } \\
\text { was administered } \\
\text { at days } 0 \text { and } 1 \\
\text { intraperitoneally } \\
\text { - DMEM vehicle } \\
\text { (control) } \\
\text { - MSC-CM } \\
\text { - PBM } \\
\text { - PMB+MSC-CM } \\
\text { (n=18/group) }\end{array}$ & 15 & $\begin{array}{l}\text { Stereological } \\
\text { methods, } \\
\text { tensiometric } \\
\text { examination, } \\
\text { qRT-PCR }\end{array}$ & $\begin{array}{l}\text { All treated groups } \\
\text { significantly } \\
\text { enhanced wound } \\
\text { healing compared } \\
\text { with controls. The } \\
\text { extent of healing } \\
\text { was significantly } \\
\text { greater in the } \\
\text { CM+PBM group }\end{array}$ & $\begin{array}{l}\text { Number of } \\
\text { fibroblast and } \\
\text { epidermal cells, the } \\
\text { lengths of blood } \\
\text { vessels, and bFGF } \\
\text { and SDF-1 } \alpha \\
\text { expression were } \\
\text { significantly higher } \\
\text { in the CM+PBM } \\
\text { group }\end{array}$ \\
\hline
\end{tabular}


TABLE 2 | Continued

\begin{tabular}{|c|c|c|c|c|c|c|c|c|c|c|}
\hline & MSC source & $\begin{array}{l}\text { Method of } \\
\text { tissue } \\
\text { extraction }\end{array}$ & $\begin{array}{l}\text { MSC } \\
\text { characterization }\end{array}$ & $\begin{array}{l}\text { Preparation of } \\
\text { MSC-CM }\end{array}$ & Model & $\begin{array}{l}\text { Groups of } \\
\text { treatments and } \\
\text { via of } \\
\text { administration }\end{array}$ & $\begin{array}{l}\text { Follow-up } \\
\text { (days) }\end{array}$ & Assessment & Main outcome & Other outcomes \\
\hline $\begin{array}{l}\text { Pouriran et al., } \\
2016\end{array}$ & $\begin{array}{l}\text { Human bone } \\
\text { marrow }\end{array}$ & Aspiration & $\begin{array}{l}\text { Flow cytometry } \\
\text { (CD105+, CD90+, } \\
\text { CD73+, CD34-, } \\
\text { CD45-) }\end{array}$ & $\begin{array}{l}\text { MSCs of passage } \\
4 \text { at } 80 \% \\
\text { confluence were } \\
\text { used. CM was } \\
\text { then collected }\end{array}$ & $\begin{array}{l}\text { Murine. Diabetic } \\
\text { rat model. } \\
\text { Full-thickness } \\
\text { skin wounds, } \\
12 \mathrm{~mm} \text {, on the } \\
\text { thoracic and } \\
\text { lumbar regions }\end{array}$ & $\begin{array}{l}\text { PWLLLT was } \\
\text { administered } \\
\text { once daily, } 6 \text { days } \\
\text { per week. } \\
\text { MSC-CM was } \\
\text { administered } \\
\text { twice } \\
\text { intraperitoneally } \\
\text { - Non-treated } \\
\text { - MSC-CM } \\
\text { - PWLLLT } \\
\text { - MSC- } \\
\text { CM+PWLLLT } \\
\text { (n= } 7 / \text { group) } \\
\text { - Cream } \\
\text { containing } 1 \text { ml } \\
\text { MSC-CM in ratio } \\
10 \text { g cream base } \\
\text { - Povidone iodine } \\
\text { (control) } \\
\text { ( } n=6 / g r o u p)\end{array}$ & 15 & $\begin{array}{l}\text { Macroscopic } \\
\text { appearance } \\
\text { (photography), } \\
\text { biomechanical } \\
\text { examination }\end{array}$ & $\begin{array}{l}\text { PWLLLT and } \\
\text { MSC-CM, alone } \\
\text { or in combination, } \\
\text { improved } \\
\text { biomechanical } \\
\text { parameters in the } \\
\text { wound }\end{array}$ & $\begin{array}{l}\text { PWLLLT was more } \\
\text { effective compared } \\
\text { with MSC-CM }\end{array}$ \\
\hline $\begin{array}{l}\text { Kusindarta } \\
\text { et al., } 2016\end{array}$ & $\begin{array}{l}\text { Human } \\
\text { umbilical cord }\end{array}$ & - & - & $\begin{array}{l}\text { MSCs of passage } \\
4 \text { at } 60 \% \\
\text { confluence were } \\
\text { used. CM was } \\
\text { then collected }\end{array}$ & $\begin{array}{l}\text { Murine. Diabetic } \\
\text { rat model. } \\
\text { Full-thickness } \\
\text { skin wounds, } \\
7 \mathrm{~mm} \text {, on the left } \\
\text { side of the body }\end{array}$ & $\begin{array}{l}\text { Topical } \\
\text { application twice } \\
\text { daily }\end{array}$ & 9 & $\begin{array}{l}\text { Macroscopic } \\
\text { appearance } \\
\text { (photography), } \\
\text { histology (HE) }\end{array}$ & $\begin{array}{l}\text { MSC-CM } \\
\text { induced faster } \\
\text { re-epithelialization } \\
\text { than other groups }\end{array}$ & $\begin{array}{l}\text { MSC-CM promoted } \\
\text { increasing density } \\
\text { of collagen fiber } \\
\text { and stimulated hair } \\
\text { follicle and muscle } \\
\text { regeneration } \\
\text { greater than the } \\
\text { other groups }\end{array}$ \\
\hline Ma et al., 2015 & $\begin{array}{l}\text { Human hair } \\
\text { follicle }\end{array}$ & $\begin{array}{l}\text { Dissection from } \\
\text { excess scalp } \\
\text { tissue } \\
\text { discarded after } \\
\text { surgery }\end{array}$ & $\begin{array}{l}\text { Flow cytometry } \\
\text { (CD105+, CD29+, } \\
\text { CD49b+, CD49d+, } \\
\text { CD73+, CD271+, } \\
\text { GD2+, CD90-, } \\
\text { CD44-, CD34-, } \\
\text { CD45-). } \\
\text { Adipogenic, } \\
\text { osteogenic and } \\
\text { chondrogenic } \\
\text { differentiation }\end{array}$ & $\begin{array}{l}\text { MSCs of passage } \\
1 \text { at } 80-90 \% \\
\text { confluence were } \\
\text { used. CM was } \\
\text { then collected }\end{array}$ & $\begin{array}{l}\text { Murine. Diabetic } \\
\text { rat model. } \\
\text { Full-thickness } \\
\text { skin wound, } \\
6 \mathrm{~mm} \text {, on dorsal } \\
\text { surface }\end{array}$ & $\begin{array}{l}100 \text { ml injected } \\
\text { into each wound } \\
\text { - DMEM } \\
\text { - Normal } \\
\text { fibroblast-CM } \\
\text { - HF-MSC-CM } \\
\text { ( } n=3 \text { /group) }\end{array}$ & 24 & $\begin{array}{l}\text { Macroscopic } \\
\text { appearance } \\
\text { (photography), } \\
\text { histology (HE) }\end{array}$ & $\begin{array}{l}\text { HF-MSC-CM } \\
\text { accelerated } \\
\text { wound healing } \\
\text { compared with } \\
\text { the other groups. } \\
\text { The average } \\
\text { number of days } \\
\text { to complete } \\
\text { wound closure in } \\
\text { the group } \\
\text { administered with } \\
\text { HF-MSC-CM } \\
\text { was } 18.7 \text { days } \\
\text { compared with }\end{array}$ & $\begin{array}{l}\text { The epidermal } \\
\text { thickness of the } \\
\text { HF-MSC-CM- } \\
\text { treated wound sites } \\
\text { was significantly } \\
\text { higher than the } \\
\text { other groups }\end{array}$ \\
\hline
\end{tabular}


TABLE 2 | Continued

\begin{tabular}{|c|c|c|c|c|c|c|c|c|c|c|}
\hline & MSC source & $\begin{array}{l}\text { Method of } \\
\text { tissue } \\
\text { extraction }\end{array}$ & $\begin{array}{l}\text { MSC } \\
\text { characterization }\end{array}$ & $\begin{array}{l}\text { Preparation of } \\
\text { MSC-CM }\end{array}$ & Model & $\begin{array}{l}\text { Groups of } \\
\text { treatments and } \\
\text { via of } \\
\text { administration }\end{array}$ & $\begin{array}{l}\text { Follow-up } \\
\text { (days) }\end{array}$ & Assessment & Main outcome & Other outcomes \\
\hline & & & & & & & & & $\begin{array}{l}22.3 \text { days in the } \\
\text { group treated } \\
\text { with } \\
\text { fibroblast-CM } \\
\text { and } 24 \text { days in } \\
\text { DMEM group }\end{array}$ & \\
\hline $\begin{array}{l}\text { Tam et al., } \\
2014\end{array}$ & $\begin{array}{l}\text { Wharton's jelly } \\
\text { from human } \\
\text { umbilical cord }\end{array}$ & $\begin{array}{l}\text { Cutting } \\
\text { umbilical cords }\end{array}$ & $\begin{array}{l}\text { Flow cytometry } \\
\text { (CD13+, CD29+, } \\
\text { CD44+, CD90+, } \\
\text { CD10-, CD14-, } \\
\text { CD34, CD117) }\end{array}$ & $\begin{array}{l}\text { MSCs of passage } \\
3-4 \text { were used. It } \\
\text { was constructed } \\
\text { wound dressing } \\
\text { patch made up of } \\
\text { an aloe } \\
\text { vera-PCL } \\
\text { (AV/PCL) } \\
\text { nanoscaffold } \\
\text { impregnated with } \\
\text { WJ-MSCs or its } \\
\text { CM }\end{array}$ & $\begin{array}{l}\text { Murine. } \\
\text { Full-thickness } \\
\text { skin wounds, } \\
6 \mathrm{~mm} \text {, on dorsal } \\
\text { region }\end{array}$ & $\begin{array}{l}-\mathrm{MSCs}+\mathrm{AV} / \mathrm{PCL} \\
-\mathrm{MSC}- \\
\mathrm{CM}+\mathrm{AV} / \mathrm{PCL} \\
-\mathrm{UCM}+\mathrm{AV} / \mathrm{PCL} \\
\text { ( } n=12 \text { /group) }\end{array}$ & 28 & $\begin{array}{l}\text { Macroscopic } \\
\text { appearance } \\
\text { (photography), } \\
\text { histology (HE and } \\
\text { MT), IF, WB, } \\
\text { qRT-PCR }\end{array}$ & $\begin{array}{l}\text { MSCs+AV/PCL } \\
\text { and MSC- } \\
\mathrm{CM}+\mathrm{AV} / \mathrm{PCL} \\
\text { groups showed } \\
\text { faster wound } \\
\text { closure } \\
\text { compared with } \\
\text { other groups }\end{array}$ & $\begin{array}{l}\text { MSCs+AV/PCL } \\
\text { and } \\
\text { MSC-CM+AV/PCL } \\
\text { groups showed } \\
\text { increased numbers } \\
\text { of sebaceous } \\
\text { glands and hair } \\
\text { follicles and greater } \\
\text { cellularity and } \\
\text { vasculature } \\
\text { compared with } \\
\text { other groups }\end{array}$ \\
\hline $\begin{array}{l}\text { Fong et al., } \\
2014\end{array}$ & $\begin{array}{l}\text { Wharton's jelly } \\
\text { from human } \\
\text { umbilical cord }\end{array}$ & $\begin{array}{l}\text { Full-term } \\
\text { delivery }\end{array}$ & $\begin{array}{l}\text { Immunofluorescence } \\
\text { (CD10+, CD13+, } \\
\text { CD29+, CD44+, } \\
\text { CD90+) }\end{array}$ & $\begin{array}{l}\text { MSCs of } \\
\text { passages 3-4 at } \\
80 \% \text { confluence } \\
\text { were used. CM } \\
\text { was then } \\
\text { collected }\end{array}$ & $\begin{array}{l}\text { Murine. } \\
\text { Full-thickness } \\
\text { excisional skin } \\
\text { wound, } 6 \mathrm{~mm} \text {, on } \\
\text { dorsum }\end{array}$ & $\begin{array}{l}100 \mu \text { linjected } \\
\text { intraperitoneally } \\
\text { - MSCs } \\
\text { - MSC-CM } \\
\text { - UCM } \\
\text { ( } n=12 / \text { group) }\end{array}$ & 28 & $\begin{array}{l}\text { Macroscopic } \\
\text { appearance } \\
\text { (photography), } \\
\text { histology (HE), } \\
\text { IHC }\end{array}$ & $\begin{array}{l}\text { MSC and } \\
\text { MSC-CM healing } \\
\text { rates were } \\
\text { greater compared } \\
\text { with controls }\end{array}$ & $\begin{array}{l}\text { MSCs and } \\
\text { MSC-CMs showed } \\
\text { greater } \\
\text { re-epithelialization, } \\
\text { increased } \\
\text { vascularity, cellular } \\
\text { density, sebaceous } \\
\text { gland, and hair } \\
\text { follicle numbers } \\
\text { compared with } \\
\text { controls }\end{array}$ \\
\hline Kim et al., 2010 & $\begin{array}{l}\text { Human } \\
\text { umbilical cord }\end{array}$ & & $\begin{array}{l}\text { Not specified } \\
\text { (CD34+, CD31+, } \\
\text { KDR+, Tie2+) }\end{array}$ & $\begin{array}{l}\text { Cells were } \\
\text { cultured, and CM } \\
\text { was then } \\
\text { collected }\end{array}$ & $\begin{array}{l}\text { Murine. Diabetic } \\
\text { rats. } \\
\text { Full-thickness } \\
\text { excisional } \\
\text { wounds, } 5 \mathrm{~mm} \text {, } \\
\text { on dorso-lateral } \\
\text { area }\end{array}$ & $\begin{array}{l}\text { Intradermal } \\
\text { injections injected } \\
\text { at three different } \\
\text { intact dermis site } \\
\text { near the wound } \\
\text { - MSC } \\
\text { - MSC-CM } \\
\text { - PBS } \\
\text { (n=6/group) }\end{array}$ & 12 & $\begin{array}{l}\text { Macroscopic } \\
\text { appearance } \\
\text { (photography), } \\
\text { histology (HE) }\end{array}$ & $\begin{array}{l}\text { MSC-CM and } \\
\text { MSC promoted } \\
\text { wound healing } \\
\text { greater than } \\
\text { controls }\end{array}$ & $\begin{array}{l}\text { MSC-CM and MSC } \\
\text { groups showed } \\
\text { greater increases in } \\
\text { neovascularization } \\
\text { compared with } \\
\text { controls. The effect } \\
\text { of MSC and } \\
\text { MSC-CM improving } \\
\text { wound healing was } \\
\text { similar }\end{array}$ \\
\hline
\end{tabular}

AT, adipose tissue-derived; bFGF, basic fibroblast growth factor; AF, amniotic fluid; BM, bone marrow; CM, conditioned medium; DFX, deferoxamine; DMEM, Dulbecco's modified Eagle medium; DP, dental pulp; EC, endothelial-differentiated; ECM, extracellular matrix; EGF, epidermal growth factor; ELISA, enzyme-linked immunosorbent assay; EVs, extracellular vesicles; Exos; exosomes; HE, hematoxylin and eosin; hCB, human cord blood; hESC, human embryonic stem cell; IHC, immunohistochemistry; IF, immunofluorescence; MPF, micro-nano polylactic acid electrospun fiber; MSCs, mesenchymal stromal cells; MT, Masson's trichrome; PBM, photobiomodulation; PBS, phosphate-buffered saline; qRT-PCR, real-time quantitative polymerase chain reaction; SVF, stromal vascular fraction; UCM, unconditioned medium; WB, Western blotting; WJ, Wharton's jelly. 
MSC-CM has been tested on 256 animals with diabetic wounds. The mean wound size was $13.47 \mathrm{~mm}$ (from 3.5 to $50 \mathrm{~mm}$ ), and the mean follow-up was 18.83 days (from 9 to 28 days). Wounds were assessed mainly by macroscopic appearance, histology, immunohistochemistry, and qRT-PCR. MSC-CM had better results in terms of wound closure, reepithelialization, and vessel formation than non-treated groups or other treatment groups (PBS, hydrogel without cells, DMEM, unconditioned medium, or povidone iodine). Moreover, some studies compared the effect between cells and its CM with similar results (Kim et al., 2010; Fong et al., 2014; Tam et al., 2014; Irons et al., 2018; Dalirfardouei et al., 2019; Zhang S. et al., 2020). MSC-CM was also used to heal wounds in combination with laser therapy, showing that the combined treatment enhanced wound healing compared with laser or MSC-CM alone (Pouriran et al., 2016; Amini et al., 2018; Bagheri et al., 2018).

Different ways of CM implementation have been also evaluated. CM supplemented with deferoxamine, a hypoxic mimetic agent, had a more potent effect on recovering skin vasculatures than non-supplemented CM (De Gregorio et al., 2020). DMBT1 expression also improves wound healing (Chen C. Y. et al., 2018). Moreover, CM cultured on polydopamine-modified three-dimensional-printed bioceramic (DOPA-BC) scaffolds showed a higher healing rate than CM cultured on tissue culture plates (TCPs) or pure threedimensional-printed bioceramic (pure BC) (Li T. et al., 2019). After 14 days' follow-up, the remaining wound area was $7.1 \pm 3.4 \%$ in the DOPA-BC-CM group, $15.2 \pm 6.6 \%$ in the BC-CM group, and $21.2 \pm 11.3 \%$ in TCP-CM group (Li T. et al., 2019).

\section{Other wounds}

MSC-CM was also evaluated in second- and third-degree burn wounds (Aryan et al., 2019; Li J. Y. et al., 2019; Zhou et al., 2019), radiation-induced wounds (Sun et al., 2019), and infected wounds (Fridoni et al., 2019; Kouhkheil et al., 2019; Table 3). Cells were isolated from human tissues: bone marrow (Aryan et al., 2019; Fridoni et al., 2019; Kouhkheil et al., 2019), umbilical cord (Zhou et al., 2019), Wharton's jelly (Sun et al., 2019), and placenta (Li J. Y. et al., 2019). MSCs from passages 3 to 8 at $60-80 \%$ confluence were used. All tested models were murine.

Twenty-eight mice with burn wounds were treated with MSC-CM with a mean follow-up of 25.67 days (from 21 to 28 days). MSC-CM was tested using subcutaneous (Li J. Y. et al., 2019) or intraperitoneal (Aryan et al., 2019) injections or topically applied (Zhou et al., 2019). In burn wounds, MSC$\mathrm{CM}$ showed faster wound healing, increased re-epithelialization, and vascularization compared with controls (unconditioned medium, PBS, or DMEM).

Moreover, 72 mice infected with methicillin-resistant Staphylococcus aureus were treated with MSC-CM or MSC-CM plus photobiomodulation (PBM). MSC-CM plus PBM decreased colony-forming units and the number of inflammatory cells (Fridoni et al., 2019; Kouhkheil et al., 2019).

Twelve mice with radiation-induced skin injuries were also treated with MSC-CM. Topical application of MSC-CM in hydrogel accelerated wound closure and enhanced the wound healing quality (Sun et al., 2019).

\section{Combined therapies using mesenchymal stromal cell-conditioned medium}

Five studies evaluated the effects of MSC-CM combined with PBM or pulsed wave low-level laser therapy (PWLLLT) for treating diabetic wounds and infected wounds (Pouriran et al., 2016; Amini et al., 2018; Bagheri et al., 2018; Fridoni et al., 2019; Kouhkheil et al., 2019) (Supplementary Table 1). Regarding diabetic wounds, the results are controversial (Pouriran et al., 2016; Amini et al., 2018; Bagheri et al., 2018). Two studies showed that MSC-CM, PBM, and the combined therapy improved wound healing as compared with control group (Pouriran et al., 2016; Bagheri et al., 2018). Moreover, it was found that the extent of healing was significantly greater in the MSC-CM+PBM group (Amini et al., 2018). On the other hand, it was showed that PWLLLT and MSC-CM, alone or in combination, improved biomechanical parameters in the wound but that PWLLLT was more effective compared with MSC-CM (Pouriran et al., 2016). Concerning infected wounds, it was observed that both $\mathrm{PBM}+\mathrm{MSC}-\mathrm{CM}$ and PBM groups decreased colony-forming units and hastened wound healing process as compared with controls, while it did not happen when using MSC-CM alone (Fridoni et al., 2019; Kouhkheil et al., 2019).

\section{Clinical Studies}

Only one clinical study evaluated the effects of MSC-CM on wound healing (Table 4). This research assessed the use of MSC-CM derived from human amniotic membrane for treating chronic plantar ulcers in leprosy. The mean age of the patients was $52.12 \pm 1.33$ years, the mean ulcer duration was $1.41 \pm 0.36$ years, and the mean ulcer size at baseline was $2.64 \pm 0.5 \mathrm{~cm}^{2}$ with a depth lower than $0.5 \mathrm{~cm}$. Sixty-six patients were divided into groups to receive MSC-CM, MSC$\mathrm{CM}+$ vitamin $\mathrm{C}$, or MSC-CM+vitamin E topically applied every 3 days for 8 weeks. All groups improved wound healing, with MSC-CM+vitamin E being the most effective treatment. Wound size was reduced by $1.7 \pm 1.05$ vs. $2.01 \pm 1.19$ vs. $2.84 \pm 1.67 \mathrm{~cm}^{2}$; and depth was decreased by $0.35 \pm 0.14$ vs. $0.25 \pm 0.11$ vs. $0.27 \pm 0.15 \mathrm{~cm}$ in MSC-CM, MSC-CM+vitamin C, and MSC$\mathrm{CM}+$ vitamin $\mathrm{E}$ groups, respectively. No adverse events were reported (Prakoeswa et al., 2018).

\section{Hypertrophic and Keloid Scars \\ Preclinical Studies}

Nine studies evaluated the potential of MSC-CM in the treatment of hypertrophic scars or avoiding scar formation ( $\mathrm{Wu}$ et al., 2015; Zhang et al., 2015; Du et al., 2016a,b; Li et al., 2016; Choi et al., 2017; Liu et al., 2018; Arjunan et al., 2020; Hu et al., 2020; Table 5). To obtain CM, MSCs were mainly isolated from human tissues: adipose tissue (Li et al., 2016; Choi et al., 2017; Liu et al., 2018) (33.33\%, 3/9), umbilical cord blood (Arjunan et al., 2020), placenta (Du et al., 2016a), and bone marrow (Wu et al., 2015). Murine bone marrow (Hu et al., 2020), murine placenta (Du et al., 2016b), and rabbit adipose tissue (Zhang et al., 2015) were also used. CM was collected from MSCs between passages 
TABLE 3 | Studies regarding mesenchymal stromal cell-conditioned medium for treating other types of wounds in animal models.

\begin{tabular}{|c|c|c|c|c|c|c|c|c|c|c|}
\hline & MSC source & $\begin{array}{l}\text { Method of } \\
\text { tissue } \\
\text { extraction }\end{array}$ & $\begin{array}{l}\text { MSC } \\
\text { characterization }\end{array}$ & $\begin{array}{l}\text { Preparation of } \\
\text { MSC-CM }\end{array}$ & Model & $\begin{array}{l}\text { Groups of } \\
\text { treatments and } \\
\text { via of } \\
\text { administration }\end{array}$ & $\begin{array}{l}\text { Follow-up } \\
\text { (days) }\end{array}$ & Assessment & Main outcomes & Other outcomes \\
\hline $\begin{array}{l}\text { Zhou et al., } \\
2019\end{array}$ & $\begin{array}{l}\text { Human } \\
\text { umbilical cords }\end{array}$ & $\begin{array}{l}\text { Umbilical cord } \\
\text { section from } \\
\text { full-term healthy } \\
\text { fetuses that } \\
\text { were born via } \\
\text { cesarean } \\
\text { section }\end{array}$ & $\begin{array}{l}\text { Flow cytometry } \\
\text { (CD29+, CD44+, } \\
\text { CD73+, CD90+, } \\
\text { CD105+, CD34-, } \\
\text { CD45, CD31-, } \\
\text { CD271-) }\end{array}$ & $\begin{array}{l}\text { MSCs of } \\
\text { passages 3-8 at } \\
70-80 \% \\
\text { confluence were } \\
\text { used. CM was } \\
\text { collected. The } \\
\text { thermosensitive } \\
\text { MSC- } \\
\text { CM/hydrogel was } \\
\text { prepared by } \\
\text { mixing the } \\
\text { precooled } \\
\text { MSC-CM, } \\
\text { chitosan/ } \beta-G P, \\
\text { and collagen } \\
\text { solutions at a } \\
\text { ratio of } 1: 2: 1 \text { on } \\
\text { ice }\end{array}$ & $\begin{array}{l}\text { Murine. } \\
\text { Third-degree } \\
\text { burned mice, } 15 \\
\text { mm }\end{array}$ & $\begin{array}{l}\text { Wound was } \\
\text { covered and } \\
\text { changed twice } \\
\text { daily } \\
\text { - Unconditioned } \\
\text { medium (UM) } \\
\text { - MSC-CM group } \\
\text { - UM/hydrogel } \\
\text { - MSC- } \\
\text { CM/hydrogel } \\
\text { (n=18/group) }\end{array}$ & 28 & $\begin{array}{l}\text { Macroscopic } \\
\text { appearance } \\
\text { (photography), } \\
\text { histology (HE), } \\
\text { IHC }\end{array}$ & $\begin{array}{l}\text { Application of the } \\
\text { MSC- } \\
\text { CM/hydrogel } \\
\text { shortened healing } \\
\text { time. The average } \\
\text { healing time in } \\
\text { MSC- } \\
\text { CM/hydrogel } \\
\text { group was } \\
\text { approximately } \\
5 \text { days shorter } \\
\text { than in UM group } \\
\text { and shorter than } \\
\text { MSC-CM and } \\
\text { UM/hydrogel } \\
\text { groups }\end{array}$ & $\begin{array}{l}\text { MSC-CM/hydrogel } \\
\text { limited the area of } \\
\text { inflammation; } \\
\text { enhanced } \\
\text { re-epithelialization; } \\
\text { promoted the } \\
\text { formation of } \\
\text { high-quality, } \\
\text { well-vascularized } \\
\text { granulation tissue; } \\
\text { and attenuated the } \\
\text { formation of fibrotic } \\
\text { and hypertrophic } \\
\text { scar tissue }\end{array}$ \\
\hline Sun et al., 2019 & $\begin{array}{l}\text { Wharton's jelly } \\
\text { from human } \\
\text { umbilical cords }\end{array}$ & $\begin{array}{l}\text { Section from } \\
\text { umbilical cords }\end{array}$ & - & $\begin{array}{l}\text { MSCs of passage } \\
3 \text { at } 60 \% \\
\text { confluence were } \\
\text { used. CM was } \\
\text { collected }\end{array}$ & $\begin{array}{l}\text { Murine. } \\
\text { Radiation- } \\
\text { induced skin } \\
\text { injury rat model, } \\
20 \mathrm{~mm} \times 20 \mathrm{~mm}\end{array}$ & $\begin{array}{l}200 \mathrm{ml} \text { of } \\
\text { hydrogel was } \\
\text { pipetted onto the } \\
\text { radiation wound } \\
\text { every } 2 \text { days } \\
\text { - Non-treated } \\
\text { - EGF } \\
\text { - MSC-CM } \\
\text { ( } n=12 / \text { group) }\end{array}$ & 56 & $\begin{array}{l}\text { Macroscopic } \\
\text { appearance } \\
\text { (photography), } \\
\text { histology (HE), } \\
\text { IHC }\end{array}$ & 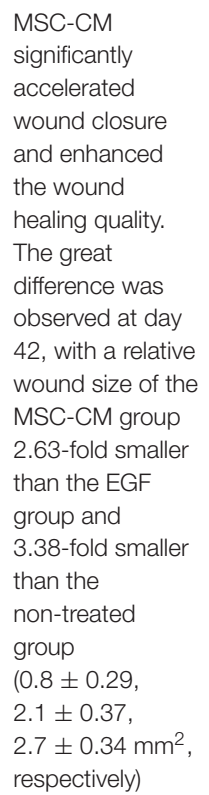 & $\begin{array}{l}\alpha \text {-SMA, Ki-67 } \\
\text { expression, and the } \\
\text { number of } \\
\text { vessels/HPF were } \\
\text { increased in } \\
\text { MSC-CM group }\end{array}$ \\
\hline
\end{tabular}


TABLE 3 | Continued

\begin{tabular}{|c|c|c|c|c|c|c|c|c|c|c|}
\hline & MSC source & $\begin{array}{l}\text { Method of } \\
\text { tissue } \\
\text { extraction }\end{array}$ & $\begin{array}{l}\text { MSC } \\
\text { characterization }\end{array}$ & $\begin{array}{l}\text { Preparation of } \\
\text { MSC-CM }\end{array}$ & Model & $\begin{array}{l}\text { Groups of } \\
\text { treatments and } \\
\text { via of } \\
\text { administration }\end{array}$ & $\begin{array}{l}\text { Follow-up } \\
\text { (days) }\end{array}$ & Assessment & Main outcomes & Other outcomes \\
\hline $\begin{array}{l}\text { Li J. Y. et al., } \\
2019\end{array}$ & $\begin{array}{l}\text { Human fetal } \\
\text { placenta }\end{array}$ & $\begin{array}{l}\text { Placenta } \\
\text { section }\end{array}$ & $\begin{array}{l}\text { Flow cytometry } \\
\text { adipogenic and } \\
\text { qRT-PCR (CD29+, } \\
\text { CD73+, CD105+, } \\
\text { CD90+, CD34-, } \\
\text { CD45-, CD133-). } \\
\text { Adipogenic and } \\
\text { osteogenic } \\
\text { differentiation }\end{array}$ & $\begin{array}{l}\text { MSCs of } \\
\text { passages 3-7 at } \\
80 \% \text { confluence } \\
\text { were used. CM } \\
\text { was collected }\end{array}$ & $\begin{array}{l}\text { Murine. } \\
\text { Second-degree } \\
\text { burn injury model. } \\
\text { Back skin of mice } \\
\text { was injured with } \\
80^{\circ} \mathrm{C} \text { water for } \\
100 \text { s to create a } \\
10 \text {-mm diameter } \\
\text { wound }\end{array}$ & $\begin{array}{l}200 \mu \text { l of the } \\
\text { treatments was } \\
\text { subcutaneously } \\
\text { injected near the } \\
\text { wound at four } \\
\text { sites } \\
\text { - PBS containing } \\
2 \times 10^{6} \text { MSCs } \\
\text { - MSC-CM } \\
\text { - PBS } \\
\text { - DMEM } \\
\text { ( } n=5 / \text { group) }\end{array}$ & 21 & $\begin{array}{l}\text { Macroscopic } \\
\text { appearance } \\
\text { (photography), } \\
\text { histology (HE), IF }\end{array}$ & $\begin{array}{l}\text { MSCs and } \\
\text { MSC-CMs } \\
\text { promoted wound } \\
\text { healing } \\
\text { compared with } \\
\text { PBS and DMEM }\end{array}$ & $\begin{array}{l}\text { High levels of new } \\
\text { blood vessels and } \\
\text { tubular structures } \\
\text { were observed in } \\
\text { the MSC and } \\
\text { MSC-CM groups }\end{array}$ \\
\hline $\begin{array}{l}\text { Kouhkheil et al., } \\
2019\end{array}$ & $\begin{array}{l}\text { Human bone } \\
\text { marrow }\end{array}$ & Aspiration & Flow cytometry & $\begin{array}{l}\text { MSCs of passage } \\
4 \text { at } 80 \% \\
\text { confluence were } \\
\text { used. CM was } \\
\text { collected }\end{array}$ & $\begin{array}{l}\text { Murine. MRSA } \\
\text { rats infected. } \\
\text { Full-thickness } \\
\text { excisional wound, } \\
15 \mathrm{~mm} \text {, on the } \\
\text { back }\end{array}$ & $\begin{array}{l}\text { PBM was } \\
\text { administered } \\
\text { once daily, } 6 \text { days } \\
\text { per week. } 50 \mu \mathrm{l} \\
\text { of the } 10 \text {-fold CM } \\
\text { was administered } \\
\text { from day } 0 \text { until } \\
\text { day } 3 \\
\text { - Control } \\
\text { - PBM } \\
\text { - MSC-CM } \\
\text { - PBM+MSC-CM } \\
\text { ( } n=18 \text { /group) }\end{array}$ & 15 & $\begin{array}{l}\text { Clinical } \\
\text { observation, } \\
\text { microbiological, } \\
\text { tensiometric, and } \\
\text { stereological } \\
\text { analyses }\end{array}$ & $\begin{array}{l}\text { There was a } \\
\text { significant } \\
\text { decrease in } \\
\text { colony-forming } \\
\text { units in } \\
\text { PBM+MSC-CM } \\
\text { and PBM groups } \\
\text { compared with } \\
\text { controls }\end{array}$ & $\begin{array}{l}\text { PBM+MSC-CM, } \\
\text { PBM, and } \\
\text { MSC-CM groups } \\
\text { significantly } \\
\text { increased wound } \\
\text { strength compared } \\
\text { with the control } \\
\text { group. The } \\
\text { PBM+MSC-CM } \\
\text { and PBM groups } \\
\text { had more stable } \\
\text { MCs, less } \\
\text { significant } \\
\text { degranulated and } \\
\text { disintegrated MCs, } \\
\text { and less significant } \\
\text { total number of } \\
\text { MCs compared } \\
\text { with the control } \\
\text { group }\end{array}$ \\
\hline
\end{tabular}


TABLE 3 | Continued

\begin{tabular}{|c|c|c|c|c|c|c|c|c|c|c|}
\hline & MSC source & $\begin{array}{l}\text { Method of } \\
\text { tissue } \\
\text { extraction }\end{array}$ & $\begin{array}{l}\text { MSC } \\
\text { characterization }\end{array}$ & $\begin{array}{l}\text { Preparation of } \\
\text { MSC-CM }\end{array}$ & Model & $\begin{array}{l}\text { Groups of } \\
\text { treatments and } \\
\text { via of } \\
\text { administration }\end{array}$ & $\begin{array}{l}\text { Follow-up } \\
\text { (days) }\end{array}$ & Assessment & Main outcomes & Other outcomes \\
\hline $\begin{array}{l}\text { Fridoni et al., } \\
2019\end{array}$ & $\begin{array}{l}\text { Human bone } \\
\text { marrow }\end{array}$ & Aspiration & $\begin{array}{l}\text { Flow cytometry } \\
\text { (CD105+, CD90+, } \\
\text { CD73+, CD34-, } \\
\text { CD45-) }\end{array}$ & $\begin{array}{l}\text { MSCs of passage } \\
4 \text { were used. CM } \\
\text { was collected }\end{array}$ & $\begin{array}{l}\text { Murine. MRSA } \\
\text { diabetic rats } \\
\text { infected. } \\
\text { Full-thickness } \\
\text { wound, } 15-\mathrm{mm} \\
\text { diameter round, } \\
\text { on the back }\end{array}$ & $\begin{array}{l}\text { PBM was } \\
\text { administered } \\
\text { once daily, } 6 \text { days } \\
\text { per week. } 500 \mu l \\
\text { of the } 10 \text {-fold CM } \\
\text { was injected } \\
\text { intraperitoneally } \\
\text { daily from day } 0 \\
\text { until day } 3 \\
\text { - Control group } \\
\text { - PBM } \\
\text { - MSC-CM } \\
\text { - PBM+MSC-CM } \\
\text { ( } n=18 / \text { group) }\end{array}$ & 15 & $\begin{array}{l}\text { Histology (HE), } \\
\text { IHC }\end{array}$ & $\begin{array}{l}\text { PBM+MSC-CM } \\
\text { hastened wound } \\
\text { healing process }\end{array}$ & $\begin{array}{l}\text { PBM+MSC-CM, } \\
\text { MSC-CM, and } \\
\text { PBM groups } \\
\text { showed a decrease } \\
\text { in the number of } \\
\text { neutrophils and } \\
\text { macrophages and } \\
\text { an increase in the } \\
\text { number of } \\
\text { fibroblasts and } \\
\text { angiogenesis } \\
\text { compared with } \\
\text { those of the control } \\
\text { group }\end{array}$ \\
\hline $\begin{array}{l}\text { Aryan et al., } \\
2019\end{array}$ & $\begin{array}{l}\text { Human bone } \\
\text { marrow }\end{array}$ & - & $\begin{array}{l}\text { Flow cytometry } \\
\text { (CD73+, CD90+, } \\
\text { CD105+, CD45-) }\end{array}$ & $\begin{array}{l}\text { MSCs of } \\
\text { passages 3-4 at } \\
80-90 \% \\
\text { confluence were } \\
\text { used. CM was } \\
\text { collected }\end{array}$ & $\begin{array}{l}\text { Murine. } \\
\text { Second-degree } \\
\text { burns (induced } \\
\text { from boiling } \\
\text { water), } \\
30 \mathrm{~mm} \times 30 \mathrm{~mm}\end{array}$ & $\begin{array}{l}\text { - Not treated rats } \\
\text { (control) } \\
-0.5 \mathrm{ml} \text { of DMEM } \\
\text { injected } \\
\text { intraperitoneally } \\
\text { every other day } \\
-1 \% \text { topical silver } \\
\text { sulfadiazine } \\
\text { cream daily } \\
-0.5 \mathrm{ml} \text { of } \\
\text { MSC-CM injected } \\
\text { intraperitoneally } \\
\text { every other day } \\
\text { ( } n=5 / \text { group) }\end{array}$ & 28 & $\begin{array}{l}\text { Macroscopic } \\
\text { appearance } \\
\text { (photography), } \\
\text { histology (HE, } \\
\text { MT), IHC }\end{array}$ & $\begin{array}{l}\text { Wound closure } \\
\text { area was } \\
\text { significantly } \\
\text { increased in the } \\
\text { MSC-CM and } \\
\text { sulfadiazine } \\
\text { groups }\end{array}$ & $\begin{array}{l}\text { There was a } \\
\text { reduction in the } \\
\text { volume of the } \\
\text { epidermis and } \\
\text { dermis in the burn } \\
\text { wound of the } \\
\text { control, DMEM, } \\
\text { and sulfadiazine } \\
\text { groups compared } \\
\text { with the MSC-CM } \\
\text { group }\end{array}$ \\
\hline
\end{tabular}

CM, conditioned medium; DMEM, Dulbecco's modified Eagle medium; ECM, extracellular matrix; EGF, epidermal growth factor; HE, hematoxylin and eosin; IHC, immunohistochemistry; IF, immunofluorescence; MRSA, methicillin-resistant Staphylococcus aureus; MSCs, mesenchymal stromal cells; MT, Masson's trichrome; PBM, photobiomodulation; PBS, phosphate-buffered saline; qRT-PCR, real-time quantitative polymerase chain reaction. 


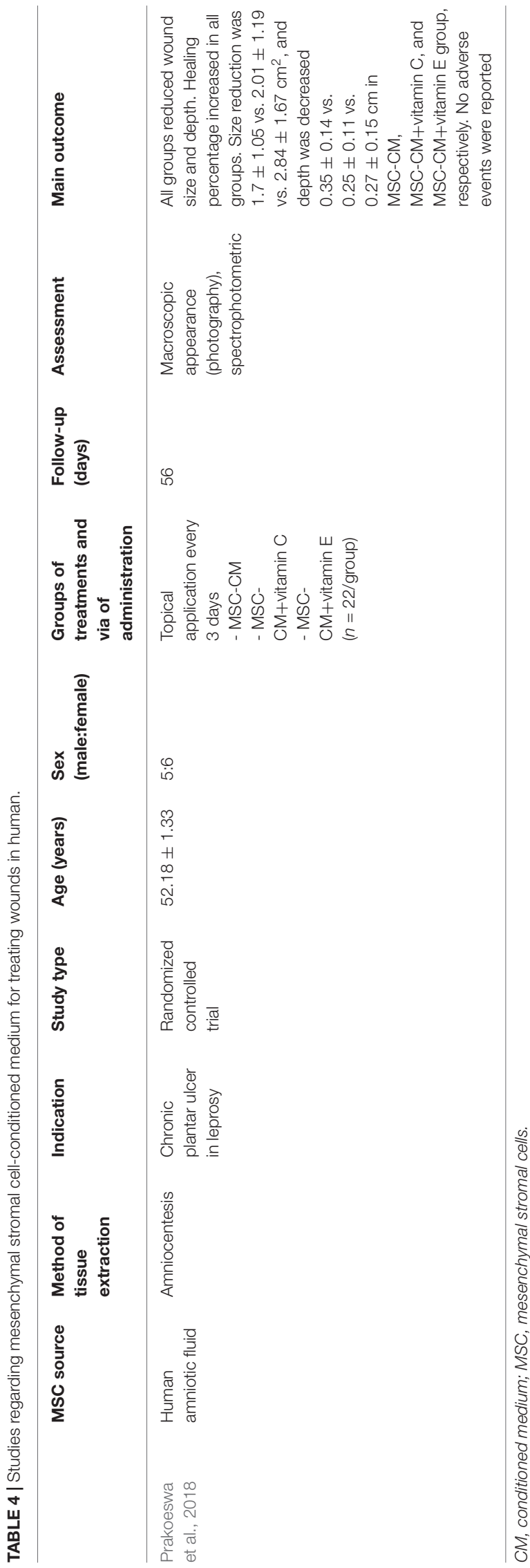

3 and 13 at $70-90 \%$ confluence. The most common model was murine $(88.89 \%, 8 / 9)$, although a rabbit model was also used (Zhang et al., 2015). CM was used mainly by subcutaneous injection $(66.66 \%, 6 / 9)$ (Wu et al., 2015; Du et al., 2016a,b; Li et al., 2016; Liu et al., 2018; Hu et al., 2020). Intralesional (Zhang et al., 2015; Arjunan et al., 2020) and intravenous (Choi et al., 2017) injections were also used. MSC-CM was tested in 97 animals for treating hypertrophic scar and keloids or preventing scar formation. The mean follow-up time was 23 days. Scars were assessed mainly by macroscopic appearance, histology, immunohistochemistry, and qRT-PCR.

Mesenchymal stromal cell-CM had better results than nontreated groups or other treatments groups (PBS, DMEM, and unconditioned medium) in terms of tumor volumes, tumor weight, collagen fiber deposition, and skin fibrosis. CM derived from MSCs cultured in hypoxic conditions showed greater effects on scar formation than cultured in normoxic conditions ( $\mathrm{Du}$ et al., 2016a,b). Moreover, the MSC-CM-treated group exhibited significantly fewer proliferating cells than did MSC-CM with TGF- $\beta 3$ blocked, showing that TGF- $\beta 3$ may be responsible for parts of the antifibrotic effect of the MSC-CM (Wu et al., 2015). The combination of MSC-CM and botulinum toxin type A (botox) had a greater effect when treating human hypertrophic scars than did botox alone, MSC-CM alone, or DMEM. Scar weight was reduced by 21,11 , or $10 \%$ more compared with DMEM, MSC-CM, or botox, respectively (Hu et al., 2020). Although both MSCs and MSC-CMs reduced hypertrophic scars, MSC-CM might be more effective than MSCs (Zhang et al., 2015). The Scar Elevation Index was reduced in both MSC- and MSCCM-treated groups compared with internal controls (44.04 and $32.48 \%, p<0.01$, respectively), and it was significantly lower in the MSC-treated group than in the MSC-CM-treated group $(p<0.01)$ (Zhang et al., 2015).

\section{Clinical Studies}

No clinical study specifically evaluated the effects of MSC-CM on hypertrophic scar formation. Nevertheless, the effect of MSC-CM has been tested on acne scars in combination with laser therapy, showing that combined therapy had a greater effect on reducing acne scars than laser alone (Zhou et al., 2016; Abdel-Maguid et al., 2019; El-Domyati et al., 2019; Park C. S. et al., 2019). These studies are further developed in the Skin Rejuvenation section.

\section{Flap and Graft Reperfusion Preclinical Studies}

Four studies evaluated the effects of MSC-CM for treating ischemic wounds or flaps (Mirabella et al., 2012; Lee S. M. et al., 2014; Cooper et al., 2018; Pu et al., 2019; Table 6). MSCs were isolated from human adipose tissue (Lee S. M. et al., 2014; Cooper et al., 2018; Pu et al., 2019) or human amniotic fluid (Mirabella et al., 2012). CM was collected from MSCs between passages 3 and 8 at $70-90 \%$ confluence. All the models employed were murine.

Two studies tested MSC-CM in ischemia/reperfusion flap models by clamping the flap and then releasing it. $\mathrm{Pu}$ et al. evaluated the effects of MSC-CM applied to the subcutaneous layer between the flap and its bed and at the proximal, middle, and distal parts as compared with saline ( $n=6$ /group) ( $\mathrm{Pu}$ 
TABLE 5 | Studies regarding mesenchymal stromal cell-conditioned medium for treating hypertrophic scars in animal models.

\begin{tabular}{|c|c|c|c|c|c|c|c|c|c|c|}
\hline & MSC source & $\begin{array}{l}\text { Method of } \\
\text { tissue } \\
\text { extraction }\end{array}$ & $\begin{array}{l}\text { MSC } \\
\text { characterization }\end{array}$ & MSC treatment & Model & $\begin{array}{l}\text { Groups of } \\
\text { treatments and } \\
\text { via of } \\
\text { administration }\end{array}$ & $\begin{array}{l}\text { Follow-up } \\
\text { (days) }\end{array}$ & Assessment & Main outcome & Other outcomes \\
\hline $\begin{array}{l}\text { Arjunan et al., } \\
2020\end{array}$ & $\begin{array}{l}\text { Human } \\
\text { umbilical cords }\end{array}$ & Dissection & $\begin{array}{l}\text { Flow cytometry and } \\
\text { IF (Tra-1-60, } \\
\text { Tra-1-81, SSEA-1, } \\
\text { SSEA-4, Oct-4 and } \\
\text { alkaline } \\
\text { phosphatase, } \\
\text { CD105, CD90, } \\
\text { CD44) }\end{array}$ & $\begin{array}{l}\text { MSCs at } 70-89 \% \\
\text { confluence were } \\
\text { used. CM was } \\
\text { then collected }\end{array}$ & $\begin{array}{l}\text { Murine. Keloid } \\
\text { xenograft SCID } \\
\text { mouse model, } \\
3-6 \mathrm{~mm} \text {, limbs }\end{array}$ & $\begin{array}{l}50 \mu \mathrm{l} \text { intralesional } \\
\text { injected } \\
\text { - Placebo } \\
\text { - HSF-CM } \\
\text { - MSC- CM } \\
\text { ( } n=9 \text { /group) }\end{array}$ & 30 & $\begin{array}{l}\text { Macroscopic } \\
\text { appearance }\end{array}$ & $\begin{array}{l}\text { MSC-CM group } \\
\text { showed greater } \\
\text { keloid reduction }\end{array}$ & $\begin{array}{l}\text { A reduction in keloid } \\
\text { tumor volumes } \\
(12.04 \pm 3.69 \mathrm{vs.} \\
54.65 \pm 8.97 \mathrm{vs} \text {. } \\
71.78 \pm 20.67 \mathrm{~mm}) \\
\text { and weights } \\
(26.50 \pm 6.38 \mathrm{vs} . \\
76.70 \pm 9.58 \mathrm{vs} . \\
73.70 \pm 12.12 \mathrm{mg}) \text { in } \\
\text { the WJ-MSC-CM } \\
\text { group compared with } \\
\text { HSF-CM and untreated } \\
\text { group were observed }\end{array}$ \\
\hline $\begin{array}{l}\text { Hu et al., } \\
2020\end{array}$ & $\begin{array}{l}\text { Murine bone } \\
\text { marrow }\end{array}$ & $\begin{array}{l}\text { Needle } \\
\text { aspiration } \\
\text { from tibia and } \\
\text { femur }\end{array}$ & $\begin{array}{l}\text { Flow cytometry } \\
\text { (CD150+/CD74+). } \\
\text { Osteogenic, } \\
\text { adipogenic, } \\
\text { chondrogenic } \\
\text { differentiation }\end{array}$ & $\begin{array}{l}\text { MSCs of } \\
\text { passages 8-13 at } \\
70 \% \text { confluence. } \\
\text { CM was then } \\
\text { collected }\end{array}$ & $\begin{array}{l}\text { Murine. Human } \\
\text { HS-buried null } \\
\text { mouse model, } \\
6 \mathrm{~mm} \text {, back }\end{array}$ & $\begin{array}{l}200 \mu \mathrm{l} \\
\text { subcutaneously } \\
\text { injected every } \\
7 \text { days } \\
\text { - DMEM } \\
\text { - Botox } \\
\text { - MSC-CM } \\
- \\
\text { MSC-CM+Botox } \\
\text { ( } n=4 / \text { group) }\end{array}$ & 28 & $\begin{array}{l}\text { Macroscopic } \\
\text { appearance, } \\
\text { histology, IF, collagen } \\
\text { deposition assay, } \\
\text { fibroblast apoptosis } \\
\text { assay (caspase-7 } \\
\text { staining), qRT-PCR, } \\
\text { WB }\end{array}$ & $\begin{array}{l}\text { HS was the most } \\
\text { reduced in } \\
\text { MSC-CM+Botox } \\
\text { group compared } \\
\text { with the other } \\
\text { groups. Scar } \\
\text { weight was } \\
\text { reduced up to } \\
70 \% \text { in MSC- } \\
\text { CM+Botox, up to } \\
80 \% \text { in MSC-CM, } \\
\text { up to } 81 \% \text { in } \\
\text { botox, and up to } \\
91 \% \text { in control } \\
\text { group }\end{array}$ & $\begin{array}{l}\text { Collagen fiber } \\
\text { deposition was eased } \\
\text { and well-arranged after } \\
\text { all treatments, except } \\
\text { control group. } \alpha \text {-SMA } \\
\text { expression was lower in } \\
\text { the combined regimen, } \\
\text { MSC-CM, and botox } \\
\text { than in DMEM group }\end{array}$ \\
\hline $\begin{array}{l}\text { Liu et al., } \\
2018\end{array}$ & $\begin{array}{l}\text { Human } \\
\text { subcutaneous } \\
\text { adipose tissue }\end{array}$ & $\begin{array}{l}\text { Surgical } \\
\text { excision of } \\
\text { redundant } \\
\text { tissue from } \\
\text { surgical } \\
\text { operations }\end{array}$ & $\begin{array}{l}\text { Flow cytometry } \\
\text { (CD105+/CD90+/ } \\
\text { CD34-/CD45-/ } \\
\text { CD19-). } \\
\text { Adipogenic and } \\
\text { osteogenic } \\
\text { differentiation }\end{array}$ & $\begin{array}{l}\text { MSCs of } \\
\text { passages 3-4 at } \\
80 \% \text { confluence } \\
\text { were used. CM } \\
\text { was then } \\
\text { collected }\end{array}$ & $\begin{array}{l}\text { Murine. Keloid } \\
\text { xenograft, } \\
10 \mathrm{~mm} \text {, back }\end{array}$ & $\begin{array}{l}200 \mu \text { linjected } \\
\text { subcutaneously } \\
\text { into each keloid } \\
\text { xenograft every } \\
\text { week } \\
\text { - Untreated } \\
\text { - DMEM } \\
\text { - MSC-CM } \\
\text { ( } n=4 \text { /group) }\end{array}$ & 28 & $\begin{array}{l}\text { Macroscopic } \\
\text { appearance, } \\
\text { histology, IHC, BrdU } \\
\text { proliferation assay } \\
\text { (bromodeoxyuridine/5- } \\
\text { bromo-2'- } \\
\text { deoxyuridine) (ELISA), } \\
\text { qRT-PCR, } \\
\text { contraction assay, } \\
\text { phosphatidylserine } \\
\text { apoptosis assay, } \\
\text { antibody-based array }\end{array}$ & $\begin{array}{l}\text { MSC-CM had a } \\
\text { greater effect in } \\
\text { scar reduction } \\
\text { than control } \\
\text { group. MSC-CM } \\
\text { group decreased } \\
\text { HS weight, by } \\
34 \% \text { compared } \\
\text { with untreated } \\
\text { group and by } \\
23 \% \text { compared } \\
\text { with DMEM } \\
\text { group }\end{array}$ & $\begin{array}{l}\text { MSC-CM reduced the } \\
\text { proportion of both } \\
\text { cellularity/inflammatory } \\
\text { cells and blood vessel } \\
\text { density }\end{array}$ \\
\hline
\end{tabular}


TABLE 5 | Continued

\begin{tabular}{|c|c|c|c|c|c|c|c|c|c|c|}
\hline & MSC source & $\begin{array}{l}\text { Method of } \\
\text { tissue } \\
\text { extraction }\end{array}$ & $\begin{array}{l}\text { MSC } \\
\text { characterization }\end{array}$ & MSC treatment & Model & $\begin{array}{l}\text { Groups of } \\
\text { treatments and } \\
\text { via of } \\
\text { administration }\end{array}$ & $\begin{array}{l}\text { Follow-up } \\
\text { (days) }\end{array}$ & Assessment & Main outcome & Other outcomes \\
\hline $\begin{array}{l}\text { Choi et al., } \\
2017\end{array}$ & $\begin{array}{l}\text { Human } \\
\text { subcutaneous } \\
\text { adipose tissue }\end{array}$ & $\begin{array}{l}\text { Cesarean } \\
\text { section }\end{array}$ & - & $\begin{array}{l}\text { MSCs of passage } \\
3 \text { at } 70-80 \% \\
\text { confluence were } \\
\text { used. CM was } \\
\text { then collected, } \\
\text { and exosomes } \\
\text { were created }\end{array}$ & $\begin{array}{l}\text { Murine. } \\
\text { Full-thickness } \\
\text { wound scar, } \\
20 \mathrm{~mm} \times 15 \mathrm{~mm} \text {, } \\
\text { on dorsal surface }\end{array}$ & $\begin{array}{l}200 \mu \mathrm{l} \\
\text { intravenously } \\
\text { injected } \\
\text { - PBS } \\
\text { - Exos-free CM } \\
\text { - Exos-MSCs } \\
\text { ( } n=6 \text { /group) }\end{array}$ & 21 & $\begin{array}{l}\text { Macroscopic } \\
\text { appearance } \\
\text { (photography), } \\
\text { histology (HE, MT, } \\
\text { picrosirius red), IHC, } \\
\text { qRT-PCR }\end{array}$ & $\begin{array}{l}\text { MSC-Exos } \\
\text { treatment } \\
\text { attenuated the } \\
\text { thickness of the } \\
\text { dermal layer and } \\
\text { the length of the } \\
\text { scar }\end{array}$ & $\begin{array}{l}\text { The surface of the } \\
\text { epidermis was more } \\
\text { flattened, and collagen } \\
\text { in the dermis was well } \\
\text { distributed with less } \\
\text { crosslinking in } \\
\text { MSC-Exos group. } \\
\text { MSC-Exos reduced } \\
\text { collagen deposition, } \\
\text { mitigated scar } \\
\text { formation, and } \\
\text { increased the ratio of } \\
\text { collagen III }\end{array}$ \\
\hline Li et al., 2016 & $\begin{array}{l}\text { Human } \\
\text { adipose tissue }\end{array}$ & Liposuction & $\begin{array}{l}\text { Flow cytometry } \\
\text { (CD73+/CD90+/ } \\
\text { CD34-/CD14-), } \\
\text { adipogenic and } \\
\text { osteogenic } \\
\text { differentiation }\end{array}$ & $\begin{array}{l}\text { MSCs of } \\
\text { passages 3-5 at } \\
80-90 \% \\
\text { confluence were } \\
\text { used. CM was } \\
\text { then collected }\end{array}$ & $\begin{array}{l}\text { Murine. } \\
\text { Full-thickness } \\
\text { excisional wound, } \\
10 \mathrm{~mm} \text {, back }\end{array}$ & $\begin{array}{l}1,000 \mu \mid \\
\text { subcutaneously } \\
\text { injected into each } \\
\text { scar at four } \\
\text { points } \\
\text { - DMEM } \\
\text { - MSC-CM } \\
\text { (n=6/group) }\end{array}$ & 14 & $\begin{array}{l}\text { Macroscopic } \\
\text { appearance } \\
\text { (photography), } \\
\text { histology (HE and } \\
\text { Masson trichrome } \\
\text { staining), } \\
\text { immunohistochemistry, } \\
\text { qRT-PCR, WB }\end{array}$ & $\begin{array}{l}\text { Reduced scar } \\
\text { formation and } \\
\text { fibrosis were } \\
\text { observed in } \\
\text { MSC-CM group }\end{array}$ & $\begin{array}{l}\text { MSC-CM decreased } \\
\text { the expression of Col1, } \\
\text { Col3, and } \alpha \text {-SMA }\end{array}$ \\
\hline $\begin{array}{l}\text { Du et al., } \\
2016 a\end{array}$ & $\begin{array}{l}\text { Murine } \\
\text { placenta }\end{array}$ & $\begin{array}{l}\text { Placenta } \\
\text { collected }\end{array}$ & $\begin{array}{l}\text { Flow cytometry } \\
\text { (CD29+, CD31-, } \\
\text { CD34-, CD44+, } \\
\text { CD45- and } \\
\text { HLA-DR-) }\end{array}$ & $\begin{array}{l}\text { MSCs of passage } \\
3 \text { were used. } \\
\text { Normoxic CM, } \\
\text { hypoxic CM, and } \\
\text { hypoxic plus } \\
\text { inhibitor CM } \\
\text { (HIF-1 } 1 \alpha \text { ) were } \\
\text { collected }\end{array}$ & $\begin{array}{l}\text { Murine. } \\
\text { Hypertrophic } \\
\text { scald mouse } \\
\text { model, } 20 \text { mm, } \\
\text { back }\end{array}$ & $\begin{array}{l}100 \mu \text { I injected } \\
\text { subcutaneously } \\
\text { - Control } \\
\text { - Normoxic } \\
\text { MSC-CM } \\
\text { - Hypoxic } \\
\text { MSC-CM } \\
\text { - HIF-1a } \\
\text { inhibitor+hypoxic } \\
\text { MSC-CM } \\
\text { ( } n=10 / \text { group) }\end{array}$ & 15 & $\begin{array}{l}\text { Macroscopic } \\
\text { appearance, } \\
\text { histology (HE), WB }\end{array}$ & $\begin{array}{l}\text { MSC-CM } \\
\text { reduced scar } \\
\text { formation }\end{array}$ & $\begin{array}{l}\text { MSC-CM attenuated } \\
\text { inflammatory responses } \\
\text { and decreased the } \\
\text { deposition of collagens }\end{array}$ \\
\hline
\end{tabular}


TABLE 5 | Continued

\begin{tabular}{|c|c|c|c|c|c|c|c|c|c|c|}
\hline & MSC source & $\begin{array}{l}\text { Method of } \\
\text { tissue } \\
\text { extraction }\end{array}$ & $\begin{array}{l}\text { MSC } \\
\text { characterization }\end{array}$ & MSC treatment & Model & $\begin{array}{l}\text { Groups of } \\
\text { treatments and } \\
\text { via of } \\
\text { administration }\end{array}$ & $\begin{array}{l}\text { Follow-up } \\
\text { (days) }\end{array}$ & Assessment & Main outcome & Other outcomes \\
\hline $\begin{array}{l}\text { Du et al., } \\
2016 b\end{array}$ & $\begin{array}{l}\text { Human } \\
\text { placenta }\end{array}$ & $\begin{array}{l}\text { Placenta } \\
\text { collected }\end{array}$ & $\begin{array}{l}\text { Flow cytometry and } \\
\text { immunofluorescence } \\
\text { positive for CD73+, } \\
\text { CD90+, CD105+, } \\
\text { CD34-, CD45-, } \\
\text { HLA-DR- }\end{array}$ & $\begin{array}{l}\text { MSCs of } \\
\text { passages 3-6 at } \\
80-90 \% \\
\text { confluence were } \\
\text { used. Normoxic } \\
\text { CM and hypoxic } \\
\text { CM were } \\
\text { collected }\end{array}$ & $\begin{array}{l}\text { Murine. } \\
\text { Hypertrophic } \\
\text { scald mouse } \\
\text { model, } 20 \mathrm{~mm} \text {, } \\
\text { back }\end{array}$ & $\begin{array}{l}100 \mu l \text { injected } \\
\text { subcutaneously } \\
\text { - Normal medium } \\
\text { - Normoxic } \\
\text { MSC-CM } \\
\text { - Hypoxic } \\
\text { MSC-CM } \\
\text { ( } n=10 / \text { group) }\end{array}$ & 15 & $\begin{array}{l}\text { Macroscopic } \\
\text { appearance } \\
\text { (photography), } \\
\text { contracture rate } \\
\text { histology (HE), Trypan } \\
\text { blue staining, } \\
\text { qRT-PCR, WB, } \\
\text { ELISA, wound } \\
\text { healing assay }\end{array}$ & $\begin{array}{l}\text { Hypoxic } \\
\text { MSC-CM } \\
\text { reduced scar } \\
\text { formation and } \\
\text { decreased } \\
\text { wound size } \\
\text { compared with } \\
\text { normal medium } \\
\text { and normoxic } \\
\text { MSC-CM }\end{array}$ & $\begin{array}{l}\text { Decreased levels of } \\
\text { TGF- } \beta 1 \text { and collagen I } \\
\text { were observed using } \\
\text { hypoxic MSC-CM. } \\
\text { Hypoxic MSC-CM also } \\
\text { inhibited the } \\
\text { proliferation and } \\
\text { migration of skin } \\
\text { fibroblasts }\end{array}$ \\
\hline $\begin{array}{l}\text { Wu et al., } \\
2015\end{array}$ & $\begin{array}{l}\text { Human bone } \\
\text { marrow }\end{array}$ & - & $\begin{array}{l}\text { Flow cytometry } \\
\text { (CD14, CD34, } \\
\text { CD45, CD44, and } \\
\text { CD73) }\end{array}$ & $\begin{array}{l}\text { MSCs of } \\
\text { passages } 5-10 \text { at } \\
80 \% \text { confluence } \\
\text { were used. CM } \\
\text { was then } \\
\text { collected }\end{array}$ & $\begin{array}{l}\text { Murine. Skin } \\
\text { fibrosis model. } \\
\text { Hypertrophic } \\
\text { skin, almost } \\
\text { 2-fold greater } \\
\text { thickness than } \\
\text { normal skin, } \\
\text { back. }\end{array}$ & $\begin{array}{l}100 \mu l \text { injected } \\
\text { subcutaneously } \\
\text { into the lesion } \\
\text { every } \\
\text { - Placebo } \\
\text { - MSC-CM } \\
\text { - BM-MSC-CM } \\
\text { with TGF- } \beta 3 \\
\text { blocked } \\
\text { ( } n=5 \text { /group) }\end{array}$ & 21 & $\begin{array}{l}\text { Macroscopic } \\
\text { appearance, } \\
\text { histology (HE), IHC, } \\
\text { cellular proliferation } \\
\text { (Ki-67) }\end{array}$ & $\begin{array}{l}\text { MSC-CM } \\
\text { decreased skin } \\
\text { fibrosis }\end{array}$ & $\begin{array}{l}\text { MSC-CM decreased } \\
\text { the fibroblast viability, } \\
\text { reduced skin dermal } \\
\text { thickness, and inhibited } \\
\text { cells proliferation. } \\
\text { Moreover, } \\
\text { MSC-CM-treated group } \\
\text { exhibited significantly } \\
\text { fewer proliferating cells } \\
\text { compared with } \\
\text { MSC-CM with } \\
\text { TGF- } \beta 3 \text {-blocked }\end{array}$ \\
\hline $\begin{array}{l}\text { Zhang et al., } \\
2015\end{array}$ & $\begin{array}{l}\text { Rabbit adipose } \\
\text { tissue }\end{array}$ & $\begin{array}{l}\text { Surgical } \\
\text { excision of } \\
\text { inguinal fat } \\
\text { pad }\end{array}$ & $\begin{array}{l}\text { Flow cytometry } \\
\text { (CD73+/CD90+/ } \\
\text { CD34-/CD14-). } \\
\text { Adipogenic and } \\
\text { osteogenic } \\
\text { differentiation }\end{array}$ & $\begin{array}{l}\text { MSCs of passage } \\
3 \text { at } 80-90 \% \\
\text { confluence were } \\
\text { used. CM was } \\
\text { then collected }\end{array}$ & $\begin{array}{l}\text { Rabbit. } \\
\text { Full-thickness } \\
\text { wound scar, } \\
10 \mathrm{~mm} \text {, ear }\end{array}$ & $\begin{array}{l}200 \mu \mathrm{l} \\
\text { intralesionally } \\
\text { injected into } \\
\text { center of each } \\
\text { scar } \\
\text { - Untreated } \\
(n=4) \\
\text { - MSCs }(n=4) \\
\text { - MSC-CM }(n=4) \\
\text { - DMEM }(n=12)\end{array}$ & 35 & $\begin{array}{l}\text { Macroscopic } \\
\text { appearance, } \\
\text { histology (HE, MT), } \\
\text { IHC, qRT-PCR, gene } \\
\text { expression, } \\
\text { ultrasonography }\end{array}$ & $\begin{array}{l}\text { MSCs and } \\
\text { MSC-CMs } \\
\text { decreased scar } \\
\text { hypertrophy and } \\
\text { led to scar with a } \\
\text { more normal } \\
\text { appearance }\end{array}$ & $\begin{array}{l}\text { MSCs and MSC-CM } \\
\text { decreased } \alpha \text {-smooth } \\
\text { muscle actin and } \\
\text { collagen type I. } \\
\text { MSC-CM was less } \\
\text { effective than MSCs }\end{array}$ \\
\hline
\end{tabular}

BM, bone marrow; CM, conditioned medium; DMEM, Dulbecco's modified Eagle medium; ELISA, enzyme-linked immunosorbent assay; Exos, exosomes; HE, hematoxylin and eosin; HS, hypertrophic scar; HSF, human skin fibroblast; IF, immunofluorescence; IHC, immunohistochemistry; MSCs, mesenchymal stromal cells; MT, Masson's trichrome; qRT-PCR, real-time quantitative polymerase chain reaction; WB, Western blotting; WJ, Wharton's jelly. 
TABLE 6 | Studies regarding mesenchymal stromal cell-conditioned medium for improving flaps reperfusion in animal models.

\begin{tabular}{|c|c|c|c|c|c|c|c|c|c|}
\hline & MSC source & $\begin{array}{l}\text { Method of } \\
\text { tissue } \\
\text { extraction }\end{array}$ & $\begin{array}{l}\text { MSC } \\
\text { characterization }\end{array}$ & MSC treatment & Model & $\begin{array}{l}\text { Groups of } \\
\text { treatments and via } \\
\text { of administration }\end{array}$ & $\begin{array}{l}\text { Follow-up } \\
\text { (days) }\end{array}$ & Assessment & Main outcome \\
\hline $\begin{array}{l}\text { Pu et al., } \\
2019\end{array}$ & $\begin{array}{l}\text { Human } \\
\text { abdominal } \\
\text { adipose tissue }\end{array}$ & Liposuction & $\begin{array}{l}\text { Flow cytometry } \\
\text { and IHC (CD34, } \\
\text { CD45, CD73, } \\
\text { CD90, CD105). } \\
\text { Adipogenic, } \\
\text { osteogenic, } \\
\text { chondrogenic } \\
\text { differentiation }\end{array}$ & $\begin{array}{l}\text { MSCs of passages } \\
3-8 \text { at } 70-80 \% \\
\text { confluence were } \\
\text { used. CM was then } \\
\text { collected }\end{array}$ & $\begin{array}{l}\text { Murine. } \\
\text { Ischemia/reperfusion } \\
\text { flap model by } \\
\text { clamping the flap } \\
\text { (ischemia) and then } \\
\text { releasing it } \\
\text { (reperfusion) }\end{array}$ & $\begin{array}{l}\text { Treatment was } \\
\text { applied to the } \\
\text { subcutaneous layer } \\
\text { between the flap and } \\
\text { its bed and at the } \\
\text { proximal, middle, and } \\
\text { distal parts of the skin } \\
\text { flap } \\
\text { - Saline injections } \\
\text { - MSC-CM } \\
\text { (n=6/group) }\end{array}$ & 5 & $\begin{array}{l}\text { Macroscopic } \\
\text { appearance } \\
\text { (photography), } \\
\text { histology (HE, } \\
\text { MT), IHC, } \\
\text { qRT-PCR }\end{array}$ & $\begin{array}{l}\text { MSC-CM treatment } \\
\text { attenuated the necrotic } \\
\text { area and reversed the } \\
\text { detrimental proliferation } \\
\text { effect induced by I/R } \\
\text { compared with saline }\end{array}$ \\
\hline $\begin{array}{l}\text { Cooper et al., } \\
2018\end{array}$ & $\begin{array}{l}\text { Human } \\
\text { adipose tissue }\end{array}$ & $\begin{array}{l}\text { Elective } \\
\text { surgery }\end{array}$ & - & $\begin{array}{l}\text { MSCs of at } \\
70-90 \% \\
\text { confluence were } \\
\text { used. CM was then } \\
\text { collected. EVs were } \\
\text { isolated by } \\
\text { centrifugation }\end{array}$ & $\begin{array}{l}\text { Murine. } \\
\text { Full-thickness } \\
\text { excisional wounds } \\
\text { were created in the } \\
\text { center of a } \\
105 \mathrm{~mm} \times 35 \mathrm{~mm} \\
\text { flap (ischemic } \\
\text { wounds) }\end{array}$ & $\begin{array}{l}20 \mu l \text { topically applied } \\
\text { daily } \\
\text { - MSC-CM } \\
\text { - Control media } \\
\text { ( } n=6 / \text { group) }\end{array}$ & 21 & $\begin{array}{l}\text { Macroscopic } \\
\text { appearance } \\
\text { (photography) }\end{array}$ & $\begin{array}{l}\text { MSC-CM accelerated } \\
\text { closure of ischemic } \\
\text { wounds. In } \\
\text { MSC-CM-treated group, } \\
\text { the wound area reduction } \\
\text { was } 65 \% \text { compared with } \\
\text { only } 15 \% \text { wound closure } \\
\text { for the control }\end{array}$ \\
\hline $\begin{array}{l}\text { Lee S. M. } \\
\text { et al., } 2014\end{array}$ & $\begin{array}{l}\text { Human } \\
\text { subcutaneous } \\
\text { adipose tissue }\end{array}$ & - & $\begin{array}{l}\text { Flow cytometry } \\
\text { (CD29+, CD44+, } \\
\text { CD73+, CD90+, } \\
\text { CD105+, } \\
\text { CD34-, CD45-, } \\
\text { CD14-) }\end{array}$ & $\begin{array}{l}\text { MSCs of passage } 3 \\
\text { at } 80 \% \text { confluence } \\
\text { were used }\end{array}$ & $\begin{array}{l}\text { Murine. } \\
\text { Full-thickness skin } \\
\text { graft, } \\
30 \mathrm{~mm} \times 30 \mathrm{~mm} \text {, } \\
\text { back }\end{array}$ & $\begin{array}{l}\text { Intravenously injected } \\
\text { - PBS } \\
\text { - MSCs } \\
\text { - MSC-CM } \\
\text { ( } n=12 / \text { group) }\end{array}$ & 30 & $\begin{array}{l}\text { Macroscopic } \\
\text { appearance } \\
\text { (photography), } \\
\text { histology (HE), } \\
\text { IHC }\end{array}$ & $\begin{array}{l}\text { MSCs and MSC-CM } \\
\text { increased skin allograft } \\
\text { survival compared with } \\
\text { control ( } 23.9 \pm 2.0 \text {, } \\
19.6 \pm 2.4 \text {, and } 9.3 \pm 1.4 \\
\text { days, respectively), without } \\
\text { differences between these } \\
\text { both groups }\end{array}$ \\
\hline $\begin{array}{l}\text { Mirabella } \\
\text { et al., } 2012\end{array}$ & $\begin{array}{l}\text { Human } \\
\text { amniotic fluid }\end{array}$ & Amniocentesis & - & $\begin{array}{l}\text { MSCs of passage } 6 \\
\text { at } 80 \% \text { confluence. } \\
\text { Lyophilized gelatine } \\
\text { film membranes } \\
\text { were prepared by } \\
\text { using MSC-CM or } \\
\text { saline as control }\end{array}$ & $\begin{array}{l}\text { Murine. } \\
\text { Ischemia/reperfusion } \\
\text { epigastric flap } \\
\text { model. Flap } \\
70 \mathrm{~mm} \times 70 \mathrm{~mm} \\
\text { with vasculature } \\
\text { ligated and then } \\
\text { opened }\end{array}$ & $\begin{array}{l}\text { A membrane with } \\
\text { MSC-CM or saline } \\
\text { was positioned under } \\
\text { the elevated skin flap } \\
\text { ( } n=5 / \text { group) }\end{array}$ & 7 & $\begin{array}{l}\text { Macroscopic } \\
\text { appearance } \\
\text { (photography), } \\
\text { histology }\end{array}$ & $\begin{array}{l}\text { Perfusion was increased in } \\
\text { flaps treated with MSC-CM } \\
\text { compared with controls. } \\
\text { Necrosis was decreased in } \\
\text { the MSC-CM group }\end{array}$ \\
\hline
\end{tabular}

CM, conditioned medium; EVs, extracellular vesicles; HE, hematoxylin and eosin; IHC, immunohistochemistry; I/R, ischemia/reperfusion; IF, immunofluorescence; MSCs, mesenchymal stromal cells; MT, Masson's trichrome; PBS, phosphate-buffered saline; qRT-PCR, real-time quantitative polymerase chain reaction. 
et al., 2019). A porcine skin-derived gelatine membrane soaked in either MSC-CM or saline was also tested ( $n=5$ /group) (Mirabella et al., 2012). Both studies observed that the MSC-CM treatment group enhanced skin flap recovery, attenuated the necrotic area, increased hair growth, and stimulated angiogenesis as compared with controls (Mirabella et al., 2012; Pu et al., 2019).

MSC-CM were also applied topically on flap ischemic wounds in six mice. It was observed that MSC-CM accelerated the closure of flap ischemic wounds by $50 \%$ as compared with controls (Cooper et al., 2018). MSC-CM was also tested on skin allografts, intravenously injected, and compared with placebo and MSCs. MSCs and MSC-CMs increased skin allograft survival as compared with the control (23.9 $\pm 2.0,19.6 \pm 2.4$, and $9.3 \pm 1.4$ days, respectively), without any differences between MSCs and MSC-CMs (Lee S. M. et al., 2014).

There are no studies at the clinical level.

\section{Hair Restoration \\ Preclinical Studies}

Ten studies evaluated the effect of MSC-CM on hair growth at the preclinical level (Park et al., 2010; Won et al., 2010, 2015; Dong et al., 2014; Shim, 2015; Choi et al., 2019; Gunawardena et al., 2019a; Park J. et al., 2019; Ou et al., 2020; Xiao et al., 2020; Table 7). MSCs were isolated mainly from human hair follicles (Won et al., 2010; Won et al., 2015; Gunawardena et al., 2019a; Ou et al., 2020) (40\%, 4/10) and human adipose tissue (Park et al., 2010; Choi et al., 2019; Xiao et al., 2020) (30\%, 3/10). Other tissues used were human amniotic fluid (Park J. et al., 2019), human deciduous teeth (Gunawardena et al., 2019a), human dermal cells (Shim, 2015), and murine bone marrow (Dong et al., 2014). CM was collected from MSCs between passages 2 and 6 at $50-100 \%$ confluence. All studies employed murine models.

Mesenchymal stromal cell-CM was used subcutaneously (Park et al., 2010; Won et al., 2015; Choi et al., 2019; Gunawardena et al., 2019a; Xiao et al., 2020) (50\%, 5/10) or intradermally (Dong et al., 2014) injected or topically applied (Won et al., 2010; Shim, 2015; Park J. et al., 2019; Ou et al., 2020) (40\%, 4/10). MSC-CM was tested on 86 animals with shaved regions. The mean follow-up time was 26.3 days (from 10 to 60 days). Hair growth improvement was assessed mainly by macroscopic appearance (skin darkening and hair weight) or histology. It was found that MSCs enhanced hair growth compared with control group (PBS, minoxidil, or DMEM). Hair weight in the MSCCM group increased by $40 \mathrm{mg}$ as compared with that in the non-treated groups and by $20 \mathrm{mg}$ as compared with that in the minoxidil group (Shim, 2015). MSC-CM stimulated hair growth by promoting dermal papilla cell proliferation, accelerating telogen-to-anagen transition, and promoting neovascularization.

The overexpression of a reprogramming factor in the CM, Nanog, improved hair induction even more than MSC-CM without Nanog (Park J. et al., 2019). Moreover, it was observed that CM collected from human deciduous teeth accelerated hair growth more than CM derived from hair follicle cells. The transition from telogen to anagen stage for teeth-MSC-CM was between 8 and 12 days, while that at hair follicle-MSC-CM ranged from 12 to 15 days (Gunawardena et al., 2019a). CM enrichment with heparin binding-epidermal growth factor-like growth factor (HB-EGF) showed a greater effect in promoting hair growth compared with non-supplemented CM (Choi et al., 2019). Furthermore, CM collected from MSCs cultured in hypoxic conditions increased hair regeneration growth factors (Park et al., 2010). No adverse events were reported when using MSC-CM in hair restoration.

\section{Clinical Studies}

Four clinical studies evaluated the effects of MSC-CM on hair growth (Shin et al., 2015; Lee et al., 2020; Narita et al., 2020; Oh et al., 2020; Table 8). To obtain CM, cells were isolated from human adipose tissue (Shin et al., 2015; Lee et al., 2020; Narita et al., 2020) (75\%) and human umbilical cord blood (Oh et al., 2020) (25\%). All studies evaluated the effect of MSC$\mathrm{CM}$ in androgenetic alopecia (AGA). MSC-CM was tested on 100 patients, both men and women, with an age range of 2374 years. Two observational studies used intradermal injections of human AT-MSC-CM and observed that hair density increased by 17.3 hairs $/ \mathrm{cm}^{2}$ and hair thickness increased by $6.5 \mu \mathrm{m}$ as compared with baseline (Shin et al., 2015; Narita et al., 2020). A clinical trial also evaluated the effects of human UC-MSC-CM enriched with TGF-1 and $\mathrm{LiCl}$ applied topically twice daily for 112 days. It was observed that MSC-CM increased hair density by $14.24 \%$, hair thickness by $28.19 \%$, and hair growth by $19.54 \%$ as compared with a placebo (Oh et al., 2020). Moreover, MSC-CM treatment was also evaluated in patients who underwent nonablative fractional laser treatment for AGA. It was found that concomitant treatment (MSC-CM+laser) had a greater effect than laser treatment only. The MSC-CM group had greater hair density $\left(102.1 \pm 4.09\right.$ vs. $\left.89.3 \pm 3.79 / \mathrm{cm}^{2}\right)$ and gross hair volume ( $2 \pm 0.13$ vs. $1.2 \pm 0.19$, evaluated by a 7 -point global improvement score) than the placebo group after 12 weeks of treatment administration (Lee et al., 2020). No serious adverse events were reported in these studies.

\section{Skin Rejuvenation \\ Preclinical Studies}

Three studies evaluated the effect of MSC-CM in 36 UV-induced photoaged mice (Ueda and Nishino, 2010; Kwon et al., 2016; Zhang K. et al., 2020; Table 9). MSCs were isolated from human umbilical cord $(33.33 \%, 1 / 3)$ (Zhang K. et al., 2020), human bone marrow $(33.33 \%, 1 / 3)$ (Kwon et al., 2016), and human dental pulp $(33.33 \%, 1 / 3)$ (Ueda and Nishino, 2010). The mean follow-up was 35 days (from 14 to 35). MSC-CM reduced the level of wrinkles, improved transepidermal water loss (TEWL) and stratum corneum hydration $(\mathrm{SCH})$ values, and increased collagen fibers than did vehicle or PBS. Nevertheless, the effect of MSC-CM on improving wrinkles was lower than that of MSCs (Ueda and Nishino, 2010).

\section{Clinical Studies}

Twelve studies evaluated the effect of MSC-CM on skin wrinkles (Seo et al., 2013; Zhou et al., 2013; Lee S. M. et al., 2014; Xu et al., 2016; Kim et al., 2018; Prakoeswa et al., 2019; El-Domyati et al., 2020; Kim J. et al., 2020) and acne scars (Zhou et al., 2016; AbdelMaguid et al., 2019; El-Domyati et al., 2019; Park C. S. et al., 
TABLE 7 | Studies regarding mesenchymal stromal cell-conditioned medium for hair restoration in animal models.

\begin{tabular}{|c|c|c|c|c|c|c|c|c|c|c|}
\hline & MSC source & $\begin{array}{l}\text { Method of } \\
\text { tissue } \\
\text { extraction }\end{array}$ & $\begin{array}{l}\text { MSC } \\
\text { characterization }\end{array}$ & MSC treatment & Model & $\begin{array}{l}\text { Groups of } \\
\text { treatments and } \\
\text { via of } \\
\text { administration }\end{array}$ & $\begin{array}{l}\text { Follow-up } \\
\text { (days) }\end{array}$ & Assessment & Main outcome & Other outcomes \\
\hline $\begin{array}{l}\text { Xiao et al., } \\
2020\end{array}$ & $\begin{array}{l}\text { Human adipose } \\
\text { tissue }\end{array}$ & Fat grafting & $\begin{array}{l}\text { IF (alkaline } \\
\text { phosphatase+ and } \\
\beta \text {-catenin+) }\end{array}$ & $\begin{array}{l}\text { MSCs of passage } \\
3 \text { were used. CM } \\
\text { from MSCs and } \\
\text { from } \\
\text { ECM/SVF-gel } \\
\text { was collected }\end{array}$ & $\begin{array}{l}\text { Murine. Back hair } \\
\text { shaved with } \\
\text { clippers and then } \\
\text { completely } \\
\text { removed using } \\
\text { hair remover } \\
\text { cream }\end{array}$ & $\begin{array}{l}\text { Injected } \\
\text { subcutaneously } \\
\text { in the dorsal skin } \\
\text { once per week } \\
\text { - PBS (control) } \\
\text { - } \\
\text { ECM/ADSVC-CM } \\
\text { - ADSVC-CM } \\
\text { (n=10/group) }\end{array}$ & 21 & $\begin{array}{l}\text { Macroscopic } \\
\text { appearance (skin } \\
\text { darkening, hair } \\
\text { growth score, } \\
\text { gross observation } \\
\text { of the inner skin } \\
\text { of the } \\
\text { hair-regrowth), } \\
\text { IHC (CD31), WB }\end{array}$ & $\begin{array}{l}\text { Both CMs } \\
\text { enhanced hair } \\
\text { growth. CM from } \\
\text { ECM/SVF had a } \\
\text { stronger ability to } \\
\text { stimulate hair } \\
\text { growth. 95-100\% } \\
\text { hair regeneration } \\
\text { to full length was } \\
\text { observed in the } \\
\text { ECM/SVF group } \\
\text { and 70-75\% in } \\
\text { the ADSVC-CM } \\
\text { group }\end{array}$ & $\begin{array}{l}\text { Both CM promoted } \\
\text { dermal papilla cells } \\
\text { and bulge cell } \\
\text { proliferation, } \\
\text { neovascularization, } \\
\text { and anagen } \\
\text { induction. Growth } \\
\text { factor levels (VEGF, } \\
\text { bFGF, PDGF, KGF) } \\
\text { increased in } \\
\text { CM-treated mice, } \\
\text { even more than in } \\
\text { ECM/ADSVC-CM } \\
\text { group }\end{array}$ \\
\hline Ou et al., 2020 & $\begin{array}{l}\text { Donor hair } \\
\text { follicles from } \\
\text { the adult } \\
\text { occipital scalp }\end{array}$ & $\begin{array}{l}\text { Biopsy sample } \\
\text { of hair follicles }\end{array}$ & - & $\begin{array}{l}\text { MSCs at } 80 \% \\
\text { confluence were } \\
\text { used. CM was } \\
\text { then collected }\end{array}$ & $\begin{array}{l}\text { Murine. Left and } \\
\text { right body of } \\
\text { each rat shaved } \\
\text { as close as } \\
\text { possible to the } \\
\text { skin }\end{array}$ & $\begin{array}{l}\text { Gel topically } \\
\text { applied } \\
\text { - Vehicle (control) } \\
\text { - MSC-CM } \\
\text { (n=4/group) }\end{array}$ & 15 & $\begin{array}{l}\text { Macroscopic } \\
\text { appearance } \\
\text { (photography), } \\
\text { histology (HE) }\end{array}$ & $\begin{array}{l}\text { No significant } \\
\text { differences in hair } \\
\text { growth were } \\
\text { observed } \\
\text { between } \\
\text { MSC-CM and } \\
\text { control group }\end{array}$ & $\begin{array}{l}\text { MSC-CM-treated } \\
\text { group showed a } \\
\text { darker area of the } \\
\text { skin and bigger } \\
\text { diffusion. } \\
\text { Histologically, the } \\
\text { hair follicle cycling } \\
\text { was enlarged in the } \\
\text { MSC-CM-treated } \\
\text { group }\end{array}$ \\
\hline $\begin{array}{l}\text { Park J. et al., } \\
2019\end{array}$ & $\begin{array}{l}\text { Human } \\
\text { amniotic fluid }\end{array}$ & $\begin{array}{l}\text { Amniocentesis } \\
\text { performed for } \\
\text { fetal } \\
\text { karyotyping } \\
\text { between 16- } \\
\text { and } 20 \text {-week } \\
\text { gestation }\end{array}$ & $\begin{array}{l}\text { IF and } \\
\text { quantification } \\
\text { (CD13+, CD29+, } \\
\text { and CD44+). } \\
\text { Osteogenic, } \\
\text { adipogenic, and } \\
\text { chondrogenic } \\
\text { differentiation }\end{array}$ & $\begin{array}{l}\text { MSCs of passage } \\
3 \text { at } 70-80 \% \\
\text { confluence were } \\
\text { used. CM was } \\
\text { then collected }\end{array}$ & $\begin{array}{l}\text { Murine. Plucking } \\
\text { the dorsal skin of } \\
\text { mice in the } \\
\text { telogen phase of } \\
\text { the hair cycle, } \\
\text { inducing the } \\
\text { second anagen } \\
\text { stage }\end{array}$ & $\begin{array}{l}50 \mu \mathrm{l} \text { topically } \\
\text { applied } \\
\text { - MSC-CM } \\
\text { - } \\
\text { MSC-Nanog-CM } \\
\text { - Minoxidil 2\% } \\
\text { (control) } \\
\text { ( } n=3 \text { /group) }\end{array}$ & 10 & $\begin{array}{l}\text { Macroscopic } \\
\text { appearance } \\
\text { (photography), } \\
\text { histology (HE), } \\
\text { IHC (ALP, CK15), } \\
\text { qRT-PCR, WB } \\
\text { (ALP, LEF1, and } \\
\text { Versican) }\end{array}$ & $\begin{array}{l}\text { The dorsal skin of } \\
\text { MSC-Nanog-CM } \\
\text { and } \\
\text { minoxidil-treated } \\
\text { mice was fully } \\
\text { darkened, while } \\
\text { bare spots were } \\
\text { observed in } \\
\text { MSC-CM group }\end{array}$ & $\begin{array}{l}\text { MSC-Nanog-CM } \\
\text { accelerated the } \\
\text { telogen-to-anagen } \\
\text { transition in HFS } \\
\text { and increased HF } \\
\text { density to a greater } \\
\text { extent than } \\
\text { MSC-CM. The } \\
\text { expression of DP } \\
\text { and HF stem cell } \\
\text { markers and genes } \\
\text { related to hair } \\
\text { induction were } \\
\text { higher in } \\
\text { MSC-Nanog-CM } \\
\text { than in } \\
\text { AF-MSC-CM. } \\
\text { Paracrine factors } \\
\text { contained in } \\
\text { MSC-Nanog-CM }\end{array}$ \\
\hline
\end{tabular}


TABLE $7 \mid$ Continued

\begin{tabular}{llllll}
\hline MSC source & $\begin{array}{l}\text { Method of } \\
\text { tissue } \\
\text { extraction }\end{array}$ & $\begin{array}{l}\text { MSC } \\
\text { characterization }\end{array}$ & MSC treatment & Model & $\begin{array}{l}\text { Groups of } \\
\text { treatments and } \\
\text { via of } \\
\text { administration }\end{array}$ \\
\hline
\end{tabular}

$\begin{array}{lllll}\text { Gunawardena } & \text { hDP-MSCs: } & \text { hDP-MSCs: } & \text { Flow cytometry } & \text { SHED of } \\ \text { et al., 2019a } & \text { human } & \text { teeth extraction } & \text { (CD73+, CD90+, } & \text { passages 2-5 } \\ & \text { deciduous } & \text { hHF-MSCs: } & \text { CD105+). } & \text { and HFSCs of } \\ & \text { teeth } & \text { scalp biopsy } & \text { Adipogenic, } & \text { passage 1 at } \\ & \text { hHF-MSCs: } & & \text { chondrogenic, } & 80 \% \text { confluence } \\ & \text { human donor } & & \text { osteogenic } & \text { were used. CM } \\ & \text { hair follicles } & & \text { differentiation } & \text { was then } \\ & & & & \text { collected }\end{array}$

\begin{tabular}{|c|c|}
\hline $\begin{array}{l}\text { Murine. Dorsal } \\
\text { region shaved } \\
\text { with clippers }\end{array}$ & $\begin{array}{l}100 \mu \mathrm{l} \\
\text { subcutaneously } \\
\text { injected at the } \\
\text { dorsal region } \\
\text { every } 3 \text { days } \\
\text { - hDP-MSCs -CM } \\
(n=9) \\
\text { - hHF-MSC-CM } \\
(n=9) \\
\text { - STK2 media, } \\
\text { control }(n=3) \\
\text { - No treatment, } \\
\text { control }(n=2)\end{array}$ \\
\hline
\end{tabular}

upregulated the

expression of hair

induction genes

and accelerated

$\begin{array}{lllll}\text { Choi et al., Human adipose Liposuction } & \text { H } & \text { MSCs were of } & \text { Murine. Dorsal } & \text { Subcutaneously } \\ 2019 & \text { subcutaneous } & \text { passages 4-6 } & \text { region shaved } & \text { injected } \\ & \text { fat } & \text { were used. Cells } & \text { with clippers } & \text { - ADSC-CM } \\ & \text { were seeded and } & \text { - ADSC-HB-EGF- } \\ & \text { treated with } & \text { CM }(n=4 / \text { group }) \\ & \text { HB-EGF. CM was } & \\ & \text { then collected. }\end{array}$

\begin{tabular}{|c|c|c|c|c|c|c|}
\hline $\begin{array}{l}\text { Won et al., } \\
2015\end{array}$ & $\begin{array}{l}\text { Donor hair } \\
\text { follicles }\end{array}$ & CELLnTEC & $\begin{array}{l}\text { Flow cytometry } \\
\text { (integrin a6 and } \\
\text { CD71) }\end{array}$ & $\begin{array}{l}\text { MSCs were } \\
\text { obtained from } \\
\text { CELLnTEC. } \\
\text { MSCs were used }\end{array}$ & $\begin{array}{l}\text { Murine. Dorsal } \\
\text { side shaved with } \\
\text { a clipper and } \\
\text { electric shaver }\end{array}$ & $\begin{array}{l}\text { Subcutaneously } \\
\text { injected every } \\
2 \text { days } \\
\text { - PBS (control) }\end{array}$ \\
\hline
\end{tabular}

60

Macroscopic
appearance
(photography)

hDP-MSC-CM- VEGF-A and HGF

treated group were

showed a faster overexpressed in

stimulation of hair hDP-MSC-CM and

growth in

hHF-MSC-CM

comparison with group. No adverse

hHF-MSC-CM. events were

The visual reported

observance for

the appearance

of dark patches

indicating the

transition from

telogen to

anagen stage by

hDP-MSC-CM

ranged from 8 to

12 days while

hHF-MSC-CM

ranged from 12

to 15 days

MSC-CM and MSC-HB-EGF-CM

MSC-HB-EGF- more rapidly

$\begin{array}{ll}\text { appearance } & \text { MSC-HB-EGF- } \\ \text { (photography), CM promoted }\end{array}$

induced

(photography),

hair growth.

telogen-to-anagen

IHC, GRT-PCR

MSC-HB-EGF-

$\mathrm{CM}$ showed

hair cycling and

higher increase in number of mature

hair weight

hair follicles.

Expression levels of

several growth

factors in the

MSC-HB-EGF-CM

were upregulated

compared with

MSC-CM group

MSC-CM-treated MSC-CM

group increased enhanced the

hair growth proliferation of HFs.

compared

The level of 
TABLE 7 | Continued

\begin{tabular}{|c|c|c|c|c|c|c|c|c|c|c|}
\hline & MSC source & $\begin{array}{l}\text { Method of } \\
\text { tissue } \\
\text { extraction }\end{array}$ & $\begin{array}{l}\text { MSC } \\
\text { characterization }\end{array}$ & MSC treatment & Model & $\begin{array}{l}\text { Groups of } \\
\text { treatments and } \\
\text { via of } \\
\text { administration }\end{array}$ & $\begin{array}{l}\text { Follow-up } \\
\text { (days) }\end{array}$ & Assessment & Main outcome & Other outcomes \\
\hline & & & & $\begin{array}{l}\text { at } 100 \% \\
\text { confluence. CM } \\
\text { was then } \\
\text { collected }\end{array}$ & & $\begin{array}{l}\text { - MSC-CM } \\
(n=5 / \text { group })\end{array}$ & & & with controls & $\begin{array}{l}\text { phosphorylated } \\
\text { AKT and } \\
\text { phosphorylated } \\
\text { ERK1/2 was } \\
\text { significantly } \\
\text { increased after } \\
\text { MSC-CM treatment }\end{array}$ \\
\hline Shim, 2015 & $\begin{array}{l}\text { Human dermal } \\
\text { cells }\end{array}$ & - & $\begin{array}{l}\text { Flow cytometry. } \\
\text { Adipogenic, } \\
\text { chondrogenic, } \\
\text { osteogenic } \\
\text { differentiation }\end{array}$ & $\begin{array}{l}\text { MSCs of passage } \\
2 \text { were used. CM } \\
\text { was then } \\
\text { collected }\end{array}$ & $\begin{array}{l}\text { Murine. Dorsal } \\
\text { region shaved } \\
\text { with a clipper }\end{array}$ & $\begin{array}{l}100 \mu \text { I topically } \\
\text { applied daily } \\
\text { - MSC-CM or } \\
\text { - Minoxidil } \\
\text { - Non-treated } \\
\text { group } \\
\text { ( } n=6 / \text { group) }\end{array}$ & 35 & $\begin{array}{l}\text { Visual scoring of } \\
\text { hair growth }\end{array}$ & $\begin{array}{l}\text { MSC-CM } \\
\text { increased hair } \\
\text { regeneration. } \\
\text { After the } \\
\text { follow-up, hair } \\
\text { weight was } \\
\text { around } 20,40 \text {, } \\
\text { and } 80 \text { mg in } \\
\text { control, minoxidil, } \\
\text { and MSC-CM } \\
\text { group, } \\
\text { respectively }\end{array}$ & $\begin{array}{l}\text { MSC-CM increased } \\
\text { promoted early } \\
\text { telogen-to-anagen } \\
\text { phase conversion } \\
\text { of hair follicles } \\
\text { compared with } \\
\text { minoxidil treated } \\
\text { group and } \\
\text { non-treated mice }\end{array}$ \\
\hline $\begin{array}{l}\text { Dong et al., } \\
2014\end{array}$ & $\begin{array}{l}\text { Murine bone } \\
\text { marrow from } \\
\text { the femur }\end{array}$ & $\begin{array}{l}\text { Needle } \\
\text { aspiration }\end{array}$ & $\begin{array}{l}\text { Flow cytometry } \\
\text { (CD29+, CD44+, } \\
\text { CD73+, CD14-, } \\
\text { CD34, CD45, } \\
\text { CD133-). } \\
\text { Adipogenic, } \\
\text { chondrogenic, } \\
\text { osteogenic } \\
\text { differentiation }\end{array}$ & $\begin{array}{l}\text { MSCs were } \\
\text { transfected with } \\
\text { murine Wnt1a } \\
\text { cDNA retroviral } \\
\text { vector. MSCs and } \\
\text { Wnt1a-MSCs at } \\
50-60 \% \\
\text { confluence were } \\
\text { used. CM was } \\
\text { collected from } \\
\text { MSCs and } \\
\text { Wnt1a-MSC- }\end{array}$ & $\begin{array}{l}\text { Murine. Dorsal } \\
\text { region shaved } \\
\text { with a clipper }\end{array}$ & $\begin{array}{l}100 \mathrm{ml} \\
\text { intradermally } \\
\text { injected } \\
\text { - Wnt-CM } \\
\text { - MSC-CM } \\
\text { - DMEM (control) } \\
\text { ( } n=3 \text { /group) }\end{array}$ & 14 & $\begin{array}{l}\text { Macroscopic } \\
\text { appearance } \\
\text { (photography), } \\
\text { histology (HE), } \\
\text { IHC, qRT-PCR }\end{array}$ & $\begin{array}{l}\text { Both Wnt-CM } \\
\text { and MSC-CM } \\
\text { promoted the hair } \\
\text { follicle cycling } \\
\text { more than control } \\
\text { group }\end{array}$ & $\begin{array}{l}\text { Wnt-CM induces } \\
\text { hair to enter earlier } \\
\text { anagen of the hair } \\
\text { cycle. ALP } \\
\text { expression was } \\
\text { enhanced in both } \\
\text { MSC-CM and } \\
\text { Wnt-CM group. } \\
\text { More Ki67-positive } \\
\text { cells were observed } \\
\text { in Wnt-CM-treated } \\
\text { mice. Both } \\
\text { MSC-CM and } \\
\text { Wnt-CM } \\
\text { upregulated the hair } \\
\text { induction-related } \\
\text { genes }\end{array}$ \\
\hline
\end{tabular}


TABLE 7 | Continued

\begin{tabular}{|c|c|c|c|c|c|c|c|c|c|c|}
\hline & MSC source & $\begin{array}{l}\text { Method of } \\
\text { tissue } \\
\text { extraction }\end{array}$ & $\begin{array}{l}\text { MSC } \\
\text { characterization }\end{array}$ & MSC treatment & Model & $\begin{array}{l}\text { Groups of } \\
\text { treatments and } \\
\text { via of } \\
\text { administration }\end{array}$ & $\begin{array}{l}\text { Follow-up } \\
\text { (days) }\end{array}$ & Assessment & Main outcome & Other outcomes \\
\hline $\begin{array}{l}\text { Won et al., } \\
2010\end{array}$ & $\begin{array}{l}\text { Human hair } \\
\text { follicles }\end{array}$ & Dissection & $\begin{array}{l}\text { IHC (alpha smooth } \\
\text { muscle actin, } \\
\text { alkaline } \\
\text { phosphatase) }\end{array}$ & $\begin{array}{l}\text { MSCs were } \\
\text { transfected with } \\
\text { plasmid carrying } \\
\text { SV40T antigen } \\
\text { and c-myc gene } \\
\text { and neomycin- } \\
\text { resistant gene. } \\
\text { MSCs of } \\
\text { passages 3-4 } \\
\text { were used. CM } \\
\text { was collected }\end{array}$ & Murine & $\begin{array}{l}\text { Topical } \\
\text { application } \\
\text { - MSC-CM } \\
\text { - DMEM } \\
\text { ( } n=3 \text { /group) }\end{array}$ & 21 & $\begin{array}{l}\text { Macroscopic } \\
\text { appearance } \\
\text { (photography) }\end{array}$ & $\begin{array}{l}\text { MSC-CM } \\
\text { enhanced hair } \\
\text { growth. Hair } \\
\text { weight was 2- to } \\
5 \text {-fold higher in } \\
\text { MSC-CM } \\
\text { compared with } \\
\text { control group }\end{array}$ & $\begin{array}{l}\text { MSC-CM } \\
\text { accelerated hair } \\
\text { growth }\end{array}$ \\
\hline $\begin{array}{l}\text { Park et al., } \\
2010\end{array}$ & $\begin{array}{l}\text { Human } \\
\text { subcutaneous } \\
\text { adipose tissue }\end{array}$ & Liposuction & - & $\begin{array}{l}\text { MSCs of } \\
\text { passages 4-5 } \\
\text { were used. MSCs } \\
\text { were cultured in } \\
\text { nomoxic and } \\
\text { hypoxic } \\
\text { conditions. CM } \\
\text { was then } \\
\text { collected }\end{array}$ & Murine & $\begin{array}{l}\text { Subcutaneously } \\
\text { injected } \\
\text { - Normoxic } \\
\text { MSC-CM }(n=5) \\
\text { - Hypoxic } \\
\text { MSC-CM }(n=5) \\
\text { - Control }(n=3)\end{array}$ & 56 & $\begin{array}{l}\text { Macroscopic } \\
\text { appearance } \\
\text { (photography) }\end{array}$ & $\begin{array}{l}\text { MSC-CM } \\
\text { increased hair } \\
\text { regeneration } \\
\text { compared with } \\
\text { control }\end{array}$ & $\begin{array}{l}\text { MSC-CM induced } \\
\text { the anagen phase. } \\
\text { Hair regeneration } \\
\text { growth factors } \\
\text { significantly } \\
\text { increased by } \\
\text { hypoxia }\end{array}$ \\
\hline
\end{tabular}

ADSCs, adipose-derived stem cells; ADSVCs, adipose-derived stromal vascular cells; BM, bone marrow; DP, dermal papilla; $h D P s$, human dermal papilla cells; ECM, extracellular matrix; HF, hair follicle; $h F D P s$, human follicle dermal papilla cells; hHF-MSCs, human hair follicle mesenchymal stromal cells; hDSPC, human dermal stem/progenitor cell; hDP-MSC, human dental pulp mesenchymal stromal cells; IF, immunofluorescence IHC, immunohistochemistry; KSCs, keratinocyte stem/progenitor cells; MSCs, mesenchymal stromal cells, PBS, phosphate-buffered saline; SHED, dental pulp stem cells obtained from human deciduous teeth; SVF, stromal vascular fraction; WB, Western blotting. 
TABLE 8 | Studies regarding mesenchymal stromal cell-conditioned medium for hair restoration in humans.

\begin{tabular}{|c|c|c|c|c|c|c|c|c|c|c|c|c|}
\hline & MSC source & $\begin{array}{l}\text { Method of } \\
\text { tissue } \\
\text { extraction }\end{array}$ & $\begin{array}{l}\text { MSC } \\
\text { characterization }\end{array}$ & $\begin{array}{l}\text { MSC } \\
\text { treatment }\end{array}$ & Indication & Study type & Age (years) & $\begin{array}{l}\text { Sex (male: } \\
\text { female) }\end{array}$ & $\begin{array}{l}\text { Groups of } \\
\text { treatments and } \\
\text { via of } \\
\text { administration }\end{array}$ & $\begin{array}{l}\text { Follow-up } \\
\text { (days) }\end{array}$ & Assessment & Main outcomes \\
\hline $\begin{array}{l}\text { Oh et al., } \\
2020\end{array}$ & $\begin{array}{l}\text { Human } \\
\text { umbilical cord }\end{array}$ & $\begin{array}{l}\text { Umbilical } \\
\text { cord section }\end{array}$ & $\begin{array}{l}\text { Flow cytometry } \\
\text { (CD14, CD45, } \\
\text { HLA-DR, } \\
\text { PE-conjugated } \\
\text { human CD73, } \\
\text { CD166, BD, } \\
\text { CD90, and } \\
\text { CD105) }\end{array}$ & $\begin{array}{l}\text { MSCs of } \\
\text { passaged } 5 \\
\text { at 60-70\% } \\
\text { confluence } \\
\text { were used. } \\
\text { CM enriched } \\
\text { with TGF-1 } \\
\text { and LiCl } \\
\text { (primed- } \\
\text { MSC-CM). } \\
\text { CM was } \\
\text { collected } \\
\text { without } \\
\text { pretreatment } \\
\text { with TGF-1 } \\
\text { and LiCl to } \\
\text { act as the } \\
\text { control }\end{array}$ & $\begin{array}{l}\text { Healthy } \\
\text { adults } \\
\text { diagnosed } \\
\text { with AGA } \\
\text { (males: Type } \\
\text { II according } \\
\text { to the } \\
\text { modified } \\
\text { Norwood- } \\
\text { Hamilton } \\
\text { classification, } \\
\text { women: } \\
\text { Ludwig } \\
\text { classification } \\
\text { Type I) }\end{array}$ & $\begin{array}{l}\text { Double blind } \\
\text { placebo- } \\
\text { controlled } \\
\text { clinical trial }\end{array}$ & $\begin{array}{l}46.9 \text { (range } \\
33-55)\end{array}$ & $1: 30$ & $\begin{array}{l}\text { 5\% CM topically } \\
\text { applied twice } \\
\text { daily } \\
\text { - } \\
\text { Primed-MSC-CM } \\
(n=16) \\
\text { - Placebo }(n=14)\end{array}$ & 112 & $\begin{array}{l}\text { Hair density and } \\
\text { diameter } \\
\text { (phototrichogram), } \\
\text { hair density (hair } \\
\text { count/cm², } \\
\text { counting the total } \\
\text { number of hairs in } \\
\text { the target area), } \\
\text { hair thickness } \\
\text { (mm) and hair } \\
\text { growth rate } \\
\text { (mm/day), rate of } \\
\text { hair growth }\end{array}$ & $\begin{array}{l}\text { Primed-MSC-CM } \\
\text { improved } \\
\text { androgenetic } \\
\text { alopecia. Hair } \\
\text { density increased } \\
\text { by } 14.24 \% \text { in } \\
\text { primed-MSC-CM } \\
\text { group, while no } \\
\text { improvement was } \\
\text { observed in } \\
\text { placebo group. Hair } \\
\text { thickness increased } \\
\text { by } 28.19 \% \text {, and } \\
\text { hair growth rate } \\
\text { increased by } \\
19.54 \% \text { in primed- } \\
\text { MSC-CM-treated } \\
\text { group. Primed-CM } \\
\text { significantly } \\
\text { increased the } \\
\text { viability of DPCs }\end{array}$ \\
\hline $\begin{array}{l}\text { Narita et al., } \\
2020\end{array}$ & $\begin{array}{l}\text { Human } \\
\text { subcutaneous } \\
\text { adipose tissues }\end{array}$ & Liposuction & $\begin{array}{l}\text { Flow cytometry } \\
\text { (CD73+/CD90+/ } \\
\text { CD34-/CD14-). } \\
\text { Adipogenic and } \\
\text { osteogenic } \\
\text { differentiation }\end{array}$ & $\begin{array}{l}\text { MSCs of } \\
\text { passage } 4 \\
\text { were used. } \\
\text { Cells were } \\
\text { cultured } \\
\text { under } \\
\text { hypoxia } \\
\text { conditions. } \\
\text { CM was then } \\
\text { collected }\end{array}$ & $\begin{array}{l}\text { Patients with } \\
\text { AGA }\end{array}$ & $\begin{array}{l}\text { Prospective } \\
\text { observational } \\
\text { study }\end{array}$ & Range 23-74 & $21: 19$ & $\begin{array}{l}\text { Intradermal } \\
\text { injection of } \\
\text { ADSC-CM every } \\
\text { month }(n=40)\end{array}$ & 180 & $\begin{array}{l}\text { Trichograms, } \\
\text { physiological } \\
\text { examinations } \\
\text { (TEWL, SCH lipid } \\
\text { level), } \\
\text { ultrasonogray } \\
\text { (dermal thickness } \\
\text { and echogenicity), } \\
\text { histology (HE, } \\
\text { Elastica } \\
\text { Masson-Goldner } \\
\text { staining, Sirius } \\
\text { red/fast green } \\
\text { staining) }\end{array}$ & $\begin{array}{l}\text { Hair density and } \\
\text { anagen hair rate } \\
\text { increased } \\
\text { significantly } \\
\text { compared with } \\
\text { baseline. TEWL } \\
\text { increased, while } \\
\text { SCH and lipid level } \\
\text { showed no obvious } \\
\text { changes. Dermal } \\
\text { thickness and } \\
\text { dermal } \\
\text { echogenicity } \\
\text { increased } \\
\text { significantly }\end{array}$ \\
\hline
\end{tabular}


TABLE 8 | Continued

\begin{tabular}{|c|c|c|c|c|c|c|c|c|c|c|c|c|}
\hline & MSC source & $\begin{array}{l}\text { Method of } \\
\text { tissue } \\
\text { extraction }\end{array}$ & $\begin{array}{l}\text { MSC } \\
\text { characterization }\end{array}$ & $\begin{array}{l}\text { MSC } \\
\text { treatment }\end{array}$ & Indication & Study type & Age (years) & $\begin{array}{l}\text { Sex (male: } \\
\text { female) }\end{array}$ & $\begin{array}{l}\text { Groups of } \\
\text { treatments and } \\
\text { via of } \\
\text { administration }\end{array}$ & $\begin{array}{l}\text { Follow-up } \\
\text { (days) }\end{array}$ & Assessment & Main outcomes \\
\hline $\begin{array}{l}\text { Lee et al., } \\
2020\end{array}$ & $\begin{array}{l}\text { Human } \\
\text { subcutaneous } \\
\text { adipose tissues }\end{array}$ & Liposuction & $\begin{array}{l}\text { Flow cytometry } \\
\text { (CD73+/CD90+/ } \\
\text { CD34-/CD14-). } \\
\text { Adipogenic and } \\
\text { osteogenic } \\
\text { differentiation }\end{array}$ & $\begin{array}{l}\text { MSCs are } \\
\text { cultured with } \\
\text { hydrogel, and } \\
\text { the CM is } \\
\text { collected, } \\
\text { after being } \\
\text { filtered using } \\
0.22-\mathrm{mm} \\
\text { filters. Then, it } \\
\text { is added to a } \\
\text { solution, and } \\
\text { SCM2- } \\
\text { Black3 is } \\
\text { obtained }\end{array}$ & $\begin{array}{l}\text { Patients with } \\
\text { AGA }\end{array}$ & $\begin{array}{l}\text { Double- } \\
\text { blinded, } \\
\text { randomized } \\
\text { placebo- } \\
\text { controlled } \\
\text { study }\end{array}$ & $\begin{array}{l}46.6 \text { (range } \\
20-61 \text { ) }\end{array}$ & $1: 1$ & $\begin{array}{l}\text { Before CM } \\
\text { application, a } \\
\text { single session of } \\
\text { treatment was } \\
\text { performed at the } \\
\text { first visit and } \\
\text { weekly } \\
\text { single-pass } \\
\text { self-applications } \\
\text { of microneedle } \\
\text { stamps. Topically } \\
\text { applied once per } \\
\text { week } \\
\text { - MSC-CM } \\
\text { - Normal saline } \\
\text { (placebo) }(n=30)\end{array}$ & 84 & $\begin{array}{l}\text { Macroscopic } \\
\text { appearance } \\
\text { (photography), } \\
\text { phototrichograms } \\
\text { (hair density), } \\
\text { gross hair volume } \\
\text { improvement, } \\
\text { investigator's } \\
\text { improvement } \\
\text { (measured by } \\
\text { questionnaire } \\
\text { response) }\end{array}$ & $\begin{array}{l}\text { MSC-CM group } \\
\text { had significantly } \\
\text { higher hair density } \\
\text { than placebo } \\
(102.1 \pm 4.09 \text { vs. } \\
\left.89.3 \pm 3.79 / \mathrm{cm}^{2}\right) \text {. } \\
\text { The gross hair } \\
\text { volume of the } \\
\text { MSC-CM group } \\
\text { was also } \\
\text { significantly higher } \\
(2 \pm 0.13 \text { vs. } 1.2 \pm \\
\left.0.19 / \mathrm{cm}^{2}\right) \text {. } \\
\text { Investigator's } \\
\text { improvement was } \\
\text { similar in both } \\
\text { groups. No adverse } \\
\text { effects associated } \\
\text { with ADSC-CM } \\
\text { were reported }\end{array}$ \\
\hline $\begin{array}{l}\text { Shin et al., } \\
2015\end{array}$ & $\begin{array}{l}\text { Human } \\
\text { subcutaneous } \\
\text { adipose tissues }\end{array}$ & Liposuction & $\begin{array}{l}\text { Flow cytometry } \\
\text { (CD73+/CD90+/ } \\
\text { CD34-/CD14-), } \\
\text { Adipogenic and } \\
\text { osteogenic } \\
\text { differentiation }\end{array}$ & $\begin{array}{l}\text { MSCs of } \\
\text { passage } 4 \\
\text { were used. } \\
\text { Cells were } \\
\text { cultured } \\
\text { under } \\
\text { hypoxia } \\
\text { conditions. } \\
\text { CM was then } \\
\text { collected }\end{array}$ & $\begin{array}{l}\text { Patients with } \\
\text { AGA, female } \\
\text { pattern hair } \\
\text { loss }\end{array}$ & $\begin{array}{l}\text { Retrospective } \\
\text { observational } \\
\text { study. }\end{array}$ & $\begin{array}{l}41.9 \pm 13.4 \\
\text { (range 22-69) }\end{array}$ & $0: 27$ & $\begin{array}{l}\text { Intradermal } \\
\text { injection of } \\
\text { MSC-CM every } \\
\text { week ( } n=27 \text { ) }\end{array}$ & 84 & $\begin{array}{l}\text { Patients' medical } \\
\text { records and } \\
\text { phototrichographic } \\
\text { images (hair } \\
\text { density and } \\
\text { thickness) } \\
\end{array}$ & $\begin{array}{l}\text { Hair density } \\
\text { increased from } \\
17.3 \text { hairs } / \mathrm{cm}^{2} \text {, } \\
\text { and hair thickness } \\
\text { increased by } \\
6.5 \mu \mathrm{m} \text { compared } \\
\text { with baseline. None } \\
\text { of the patients } \\
\text { reported severe } \\
\text { adverse events. } \\
\text { The only } \\
\text { inconvenience } \\
\text { reported was the } \\
\text { pricking of the } \\
\text { needles during } \\
\text { application }\end{array}$ \\
\hline
\end{tabular}

AGA, androgenetic alopecia: CM, conditioned medium; DPC, dermal papilla cells; HE, hematoxylin and eosin; IHC, immunohistochemistry; IF, immunofluorescence; MSCs, mesenchymal stromal cells; MT, Masson's trichrome; PBS, phosphate-buffered saline; qRT-PCR, real-time quantitative polymerase chain reaction; SCH, stratum corneum hydration; TEWL, transepidermal water loss. 
TABLE 9 | Studies regarding mesenchymal stromal cell-conditioned medium for skin rejuvenation in animal models

\begin{tabular}{|c|c|c|c|c|c|c|c|c|c|}
\hline & MSC source & $\begin{array}{l}\text { Method of } \\
\text { tissue } \\
\text { extraction }\end{array}$ & $\begin{array}{l}\text { MSC } \\
\text { characterization }\end{array}$ & MSC treatment & Model & $\begin{array}{l}\text { Groups of treatments } \\
\text { and via of } \\
\text { administration }\end{array}$ & $\begin{array}{l}\text { Follow-up } \\
\text { (days) }\end{array}$ & Assessment & Main outcomes \\
\hline $\begin{array}{l}\text { Zhang K. } \\
\text { et al., } 2020\end{array}$ & $\begin{array}{l}\text { Human } \\
\text { umbilical cord }\end{array}$ & $\begin{array}{l}\text { Umbilical cord } \\
\text { dissection }\end{array}$ & $\begin{array}{l}\text { Western blotting } \\
\text { (CD9+, CD63+, } \\
\text { CD81+, and } \\
\text { calnexin-) }\end{array}$ & $\begin{array}{l}\text { MSC-CMs of } \\
\text { passage } 6 \text { at } \\
80-90 \% \\
\text { confluence were } \\
\text { used. CM was } \\
\text { collected, and Exos } \\
\text { were obtained }\end{array}$ & $\begin{array}{l}\text { Murine. Photoaged } \\
\text { mouse model }\end{array}$ & $\begin{array}{l}\text { - Control } \\
\text { (non-photoaged } \\
\text { mouse) } \\
\text { - SHS-PBS } \\
\text { - Exos } \\
\text { - SHS-Exos } \\
\text { ( } n=6 / \text { group) }\end{array}$ & 14 & $\begin{array}{l}\text { Macroscopic } \\
\text { appearance, } \\
\text { microscopic } \\
\text { appearance } \\
\text { (microwrinkles } \\
\text { analysis), } \\
\text { histology, and } \\
\text { qRT-PCR }\end{array}$ & $\begin{array}{l}\text { SHS-Exos reduced } \\
\text { microwrinkles, alleviated } \\
\text { histopathological changes, } \\
\text { and promoted the } \\
\text { expression of extracellular } \\
\text { matrix constituents, while } \\
\text { Exos alone produced } \\
\text { weaker effects }\end{array}$ \\
\hline $\begin{array}{l}\text { Kwon et al., } \\
2016\end{array}$ & $\begin{array}{l}\text { Human bone } \\
\text { marrow from } \\
\text { the posterior } \\
\text { iliac crest }\end{array}$ & Aspiration & $\begin{array}{l}\text { Flow cytometry } \\
\text { (CD73+, } \\
\text { CD105+, } \\
\text { CD14-, CD34-, } \\
\text { CD45-) }\end{array}$ & $\begin{array}{l}\text { MSCs of passage } 6 \\
\text { at } 80 \% \text { confluence } \\
\text { were used and } \\
\text { cultured in hypoxic } \\
\text { conditions. CM was } \\
\text { then collected }\end{array}$ & $\begin{array}{l}\text { Murine. } \\
\text { UVB-irradiated } \\
\text { mice model }\end{array}$ & $\begin{array}{l}200 \mu \text { l of treatment } \\
\text { topically applied three } \\
\text { times a week } \\
\text { - Vehicle solution } \\
\text { (polyethylene } \\
\text { glycol:ethanol) } \\
\text { - Adenosine } 0.04 \% \\
\text { - MSC-CM } 1 \% \\
\text { - MSC-CM } 10 \% \\
\text { ( } n=8 \text { /group) }\end{array}$ & 56 & $\begin{array}{l}\text { Macroscopic } \\
\text { appearance } \\
\text { (photography, } \\
\text { visual skin } \\
\text { grading), tape } \\
\text { stripping, } \\
\text { biophysical } \\
\text { measurements } \\
\text { (TEWL and } \\
\text { hydration), } \\
\text { histology (HE, } \\
\text { IHC) }\end{array}$ & $\begin{array}{l}\text { The MSC-CM group } \\
\text { exhibited significantly } \\
\text { reduced levels of total } \\
\text { wrinkle area compared with } \\
\text { the vehicle-treated group. } \\
\text { TEWL levels decreased } \\
\text { while hydration increased in } \\
\text { MSC-CM }\end{array}$ \\
\hline $\begin{array}{l}\text { Ueda and } \\
\text { Nishino, } 2010\end{array}$ & $\begin{array}{l}\text { Human dental } \\
\text { pulp tissue }\end{array}$ & $\begin{array}{l}\text { Healthy } \\
\text { permanent } \\
\text { deciduous } \\
\text { teeth } \\
\text { extraction }\end{array}$ & - & $\begin{array}{l}\text { MSCs of passage } 1 \\
\text { to } 3 \text { were used, and } \\
\text { CM was collected }\end{array}$ & $\begin{array}{l}\text { Murine. Wrinkled } \\
\text { mice induced by } \\
\text { UVB }\end{array}$ & $\begin{array}{l}\text { Subcutaneous } \\
\text { injections } \\
\text { - MSC-CM } \\
\text { - MSCs } \\
\text { - PBS ( } n=8 \text { /group) }\end{array}$ & 35 & $\begin{array}{l}\text { Macroscopic } \\
\text { appearance } \\
\text { (photography, } \\
\text { histology (HE) }\end{array}$ & $\begin{array}{l}\text { MSCs and MSC-CM } \\
\text { decreased wrinkles more } \\
\text { than the PBS group. The } \\
\text { greatest effect was } \\
\text { observed in MSC group. } \\
\text { Measurement of the dermal } \\
\text { thickness showed } \\
\text { significant increases in } \\
\text { MSC and MSC-CM groups }\end{array}$ \\
\hline
\end{tabular}

CM, conditioned medium; Exos, exosomes; HE, hematoxylin and eosin; IHC, immunohistochemistry; MSCs, mesenchymal stromal cells; MT, Masson's trichrome; PBS, phosphate-buffered saline; qRT-PCR, real-time quantitative polymerase chain reaction; SHSs, sponge Haliclona sp. spicules; TEWL, transepidermal water loss. 
2019; Table 10). MSCs were isolated from human tissues: adipose tissue (Zhou et al., 2013, 2016; Xu et al., 2016; Park C. S. et al., 2019) (30.77\%, 4/13), amniotic fluid (Abdel-Maguid et al., 2019; El-Domyati et al., 2019, 2020; Prakoeswa et al., 2019) (30.77\%, 4/13), umbilical cord blood (Kim et al., 2018; Kim J. et al., 2020) (15.38\%, 2/13), human embryos (Seo et al., 2013; Lee S. M. et al., 2014) (15.38\%, 2/13), and the placenta (Xu et al., 2016).

Two hundred six healthy volunteers were treated with MSCCM for anti-aging therapies (Seo et al., 2013; Zhou et al., 2013; Lee S. M. et al., 2014; Xu et al., 2016; Kim et al., 2018; Prakoeswa et al., 2019; El-Domyati et al., 2020; Kim J. et al., 2020). This research included women between 24 and 64 years. The studies evaluated the effects of microneedling, radiofrequency, or laser therapy alone compared with combined treatment with MSC-CM. They observed that combined therapy showed better improvement in macroscopic appearance (less pores and wrinkles), biophysical parameters (increased SCH and decreased TEWL, erythema, and melanin), and histology (increased dermal density) and had higher patient satisfaction scores. Similar results were found for the application of CM derived from human adipose tissue and human placenta, showing only a greater decrease in melanin index in the AT-MSC-CM group (Xu et al., 2016). The application of human UC-MSC-CM containing serum and cream on patients who underwent fractional laser therapy showed less microcrusts than the application of UC-MSC-CM only containing cream (Kim J. et al., 2020). No serious adverse events were observed in these reports.

Moreover, MSC-CM was also tested on acne scars (Zhou et al., 2016; Abdel-Maguid et al., 2019; El-Domyati et al., 2019; Park C. S. et al., 2019), suggesting that combined therapy (laser+MSC$\mathrm{CM}$ ) may increase the regenerative effects of fractional laser. Four studies evaluated the therapeutic potential in 71 patients with a mean follow-up of 82.5 days (range 60-90). After laser treatment, topical application of MSC-CM showed greater scar volume reduction than did with the control, by $23.5 \%$ on the MSC-CM side vs. $15.0 \%$ on the control side (Park C. S. et al., 2019). Furthermore, the MSC-CM-treated side improved subjective satisfaction and clinical assessment, showing better TEWL, SCH, elasticity, roughness, and collagen density than did the controls (laser alone or DMEM). Nevertheless, laser therapy+MSC-CM showed lower clinical improvement in acne scars than the combination of laser+platelet-rich plasma (AbdelMaguid et al., 2019). Adverse events reported were erythema and edema, linked more to laser therapy than MSC-CM treatment.

\section{Inflammatory Skin Diseases Preclinical Studies}

One study evaluated the effect of CM derived from murine adipose tissue for treating atopic dermatitis (AD) (Park H. S. et al., 2019; Table 11). Mice were followed up 33 days after AD lesions had developed and treated with subcutaneous injections every 3 days with saline, MSC, MSC-CM, or 2.5\% cortisone lotion ( $n=6$ /group). A higher AD severity index decrease was observed in groups treated with MSC, MSC-CM, or cortisone, as compared with the saline group. Moreover, the severity index (assessed by SCORAD) was lower in the MSC-CM group treated with MSCs or cortisone. Skin thickness decreases were similar between MSC-CM, MSC, and cortisone, and all greater than in the saline group. Likewise, mast cell infiltration was reduced in MSC-CM, MSC, and cortisone groups. Th2 expression, measured in optical densities, was lower in the MSC-CM groups than in the MSC, cortisone, or saline group $(1.58 \pm 1.84$ vs. $3.79 \pm 2.08$ vs. $4.10 \pm 3.32$ vs. $19.19 \pm 5.54)$. Ig E levels were slightly reduced in mice that were treated with MSC, MSC-CM, or cortisone. IL-4 was also reduced in the group treated with MSC-CM (Park H. S. et al., 2019).

\section{Clinical Studies}

One study evaluated the effects of MSC-CM for treating AD (Kim Y. J. et al., 2020), and one case report showed the outcomes in a patient with scalp psoriasis treated with MSC-CM (Seetharaman et al., 2019; Table 11).

Twenty-eight patients (15 males and 13 females; mean age $24.68 \pm 4.32$ years) were treated with human UC-MSC-CM in cream bases for 4 weeks. MSC-CM was applied on both eczematous lesions and non-involved skin twice a day. After treatment, SCH increased by 15.67 arbitrary units (AU), a relative unit of measurement to show the ratio of amount of some quantities to a predetermined reference measurement, on eczematous lesions and 14.49 AU on non-involved skin. Moreover, TEWL decreased by $15.09 \mathrm{~g} \cdot \mathrm{m}^{-2} \cdot \mathrm{h}^{-1}$ AU on eczematous lesions and $3.08 \mathrm{~g} \cdot \mathrm{m}^{-2} \cdot \mathrm{h}^{-1}$ on non-involved skin (Kim Y. J. et al., 2020). In agreement with preclinical studies, these data showed that cosmetics that contained MSC-CM improved the skin barrier function and could be an effective treatment for $\mathrm{AD}$ patients.

One study also evaluated the clinical efficacy of MSC-CM derived from human adipose tissue for treating psoriasis scalp. A 38-year-old male was treated topically with MSC-CM on the lesions once a day. After 1-month follow-up, the number of psoriatic plaques was reduced and Psoriasis Scalp Severity Index (PSSI) changed from 28 to 0 . Moreover, no relapse or adverse events were observed after 6 months' follow-up (Seetharaman et al., 2019).

\section{DISCUSSION}

MSC-CM may be an alternative, safe, and easily delivered therapy for several skin conditions, but evidence in clinical studies is limited. They have been mainly tested in hair restoration (Shin et al., 2015; Lee et al., 2020; Narita et al., 2020; Oh et al., 2020) and skin rejuvenation (Abdel-Maguid et al., 2019; El-Domyati et al., 2019; Kim J. et al., 2020), with promising results. Preclinical studies are mainly focused on wound healing (Shin et al., 2015; Lee et al., 2020; Narita et al., 2020; Oh et al., 2020), showing high rates in wound closure. MSC-CM may also be an effective treatment for decreasing hypertrophic scars (Arjunan et al., 2020; $\mathrm{Hu}$ et al., 2020), improving flap reperfusion (Mirabella et al., 2012; Lee S. M. et al., 2014; Cooper et al., 2018; Pu et al., 2019), and treating psoriasis (Seetharaman et al., 2019) and AD (Park H. S. et al., 2019; Kim Y. J. et al., 2020). Nevertheless, there was significant variability between studies in the cell source, 
TABLE 10 | Studies regarding mesenchymal stromal cell-conditioned medium for skin rejuvenation in humans.

\begin{tabular}{|c|c|c|c|c|c|c|c|c|c|}
\hline & MSC source & $\begin{array}{l}\text { Method of } \\
\text { tissue } \\
\text { extraction }\end{array}$ & Type of study & $\begin{array}{l}\text { Indication and } \\
\text { population }\end{array}$ & $\begin{array}{l}\text { Groups of } \\
\text { treatments and } \\
\text { via of } \\
\text { administration }\end{array}$ & $\begin{array}{l}\text { Follow-up } \\
\text { (days) }\end{array}$ & Assessment & Main outcome & Other outcomes \\
\hline $\begin{array}{l}\text { El-Domyati } \\
\text { et al., } 2020\end{array}$ & $\begin{array}{l}\text { Human } \\
\text { amniotic fluid }\end{array}$ & - & $\begin{array}{l}\text { Prospective } \\
\text { observational } \\
\text { study }\end{array}$ & $\begin{array}{l}\text { Volunteers with } \\
\text { facial aging } \\
49.9 \pm 5.59 \text { years } \\
3: 7 \text { (M:F) }\end{array}$ & $\begin{array}{l}1 \mathrm{ml} \text { of MSC-CM } \\
\text { was topically } \\
\text { applied to the } \\
\text { treated group } \\
\text { - Skin needling } \\
\text { (control) } \\
\text { - Skin } \\
\text { needling+MSC-CM } \\
(n=10)\end{array}$ & 30 & $\begin{array}{l}\text { Clinical } \\
\text { examination, } \\
\text { photographs, } \\
\text { histology (HE, MT, } \\
\text { Orcein stains) }\end{array}$ & $\begin{array}{l}\text { The percentage of } \\
\text { improvement was } \\
\text { higher in the } \\
\text { MSC-CM group } \\
\text { compared with } \\
\text { controls } \\
(65.40 \pm 11.34 \text { vs. } \\
38.60 \pm 9.02 \\
p<0.001)\end{array}$ & $\begin{array}{l}\text { Remodeling of the dermal } \\
\text { structures was observed } \\
\text { mainly on the combined } \\
\text { side. Epidermal thickness } \\
\text { increased on both treated } \\
\text { sides }\end{array}$ \\
\hline $\begin{array}{l}\text { Kim J. et al., } \\
2020\end{array}$ & $\begin{array}{l}\text { Human } \\
\text { umbilical cord }\end{array}$ & $\begin{array}{l}\text { Umbilical cord } \\
\text { dissection }\end{array}$ & $\begin{array}{l}\text { Randomized, } \\
\text { investigator-blinded, } \\
\text { prospective, } \\
\text { split-face } \\
\text { comparison study }\end{array}$ & $\begin{array}{l}\text { Patient with large } \\
\text { pores or wrinkles } \\
\text { on the face that } \\
\text { underwent laser } \\
\text { resurfacing } \\
\text { (42.2 years, range } \\
25-56)\end{array}$ & $\begin{array}{l}\text { Topical application } \\
\text { twice a day } \\
\text { - MSC-CM cream } \\
\text { (control) } \\
\text { - MSC-CM cream } \\
\text { and serum }(n=23)\end{array}$ & 21 & $\begin{array}{l}\text { Macroscopic } \\
\text { appearance } \\
\text { (photography, area } \\
\text { of microcrusts), } \\
\text { skin biophysical } \\
\text { parameters (TEWL, } \\
\text { SCH, erythema) }\end{array}$ & $\begin{array}{l}\text { The percentage of } \\
\text { the total microcrust } \\
\text { area was } \\
\text { significantly smaller } \\
\text { in the MSC-CM } \\
\text { cream and serum } \\
\text { group than in the } \\
\text { cream group } \\
(2.70 \pm 0.56 \text { vs. } \\
3.13 \pm 0.76 \\
p<0.05)\end{array}$ & $\begin{array}{l}\text { A slight increase in } \mathrm{SCH} \\
\text { values were observed in } \\
\text { both groups without } \\
\text { changes in TEWL. Patient } \\
\text { satisfaction was similar in } \\
\text { both groups. No adverse } \\
\text { events were reported } \\
\text { related to MSC-CM } \\
\text { application }\end{array}$ \\
\hline $\begin{array}{l}\text { Abdel- } \\
\text { Maguid et al., } \\
2019\end{array}$ & $\begin{array}{l}\text { Human } \\
\text { amniotic fluid }\end{array}$ & - & $\begin{array}{l}\text { Prospective } \\
\text { randomized } \\
\text { split-face study }\end{array}$ & $\begin{array}{l}\text { Patients with } \\
\text { atrophic acne scars }\end{array}$ & $\begin{array}{l}\text { - Group I }(n=17) \text {. } \\
\text { FxCR+topical } \\
\text { MSC-CM on one } \\
\text { side of the face or } \\
\text { FxCR plus saline on } \\
\text { the other side } \\
\text { - Group II }(n=16) \text {. } \\
\text { FXCR+ topical PRP } \\
\text { on one side of the } \\
\text { face or FxCR+ } \\
\text { topical MSCs on } \\
\text { the other side }\end{array}$ & 90 & $\begin{array}{l}\text { Macroscopic } \\
\text { appearance } \\
\text { (photography), } \\
\text { histology (HE, MT), } \\
\text { qRT-PCR }\end{array}$ & $\begin{array}{l}\text { In both groups, } \\
\text { scars improved } \\
\text { after treatment. No } \\
\text { significant } \\
\text { difference in clinical } \\
\text { improvement of } \\
\text { acne scars was } \\
\text { observed between } \\
\text { the } \\
\text { FxCR+MSC-CM } \\
\text { and FxCR, while } \\
\text { better and faster } \\
\text { improvement was } \\
\text { detected on } \\
\text { FxCR+PRP side } \\
\text { compared with } \\
\text { FxCR +MSC-CM } \\
\text { side }\end{array}$ & $\begin{array}{l}\text { All patients developed } \\
\text { transient erythema and mild } \\
\text { edema without differences } \\
\text { between groups. Dermal } \\
\text { collagen was increased and } \\
\text { procollagen type I gene } \\
\text { was upregulated in both } \\
\text { FCL/PRP and FCL/SC-CM } \\
\text { sides compared with FCL } \\
\text { only sides }\end{array}$ \\
\hline
\end{tabular}


TABLE 10 | Continued

\begin{tabular}{|c|c|c|c|c|c|c|c|c|c|}
\hline & MSC source & $\begin{array}{l}\text { Method of } \\
\text { tissue } \\
\text { extraction }\end{array}$ & Type of study & $\begin{array}{l}\text { Indication and } \\
\text { population }\end{array}$ & $\begin{array}{l}\text { Groups of } \\
\text { treatments and } \\
\text { via of } \\
\text { administration }\end{array}$ & $\begin{array}{l}\text { Follow-up } \\
\text { (days) }\end{array}$ & Assessment & Main outcome & Other outcomes \\
\hline $\begin{array}{l}\text { El-Domyati } \\
\text { et al., } 2019\end{array}$ & $\begin{array}{l}\text { Human } \\
\text { amniotic fluid }\end{array}$ & - & $\begin{array}{l}\text { Prospective } \\
\text { observational } \\
\text { study }\end{array}$ & $\begin{array}{l}\text { Patients with } \\
\text { atrophic acne } \\
\text { scars. }\end{array}$ & $\begin{array}{l}\text { Topical application } \\
\text { after five sessions } \\
\text { of microneedling } \\
\text { with dermaroller } \\
-1 \text { ml of } \\
\text { MSCs-CM } \\
\text { - Non-treated } \\
(n=10)\end{array}$ & 90 & $\begin{array}{l}\text { Clinical } \\
\text { examination, } \\
\text { histology, } \\
\text { histometric analysis }\end{array}$ & $\begin{array}{l}\text { There was a } \\
\text { significant increase } \\
\text { in the improvement } \\
\text { percentage of acne } \\
\text { scars on the } \\
\text { MSC-CM-treated } \\
\text { side } \\
(65.40 \pm 11.34 \text { vs. } \\
38.60 \pm 9.02)\end{array}$ & $\begin{array}{l}\text { Improvement of character } \\
\text { of collagen and elastic } \\
\text { fibers was noticed, } \\
\text { especially on MSC-CM } \\
\text { side. Significant increase in } \\
\text { epidermal thickness on } \\
\text { both sides of face was } \\
\text { detected. Erythema and } \\
\text { slight edema appeared on } \\
\text { both cheek sides }\end{array}$ \\
\hline $\begin{array}{l}\text { Park C. S. } \\
\text { et al., } 2019\end{array}$ & $\begin{array}{l}\text { Human } \\
\text { adipose tissue }\end{array}$ & - & $\begin{array}{l}\text { Prospective } \\
\text { randomized } \\
\text { split-face study }\end{array}$ & $\begin{array}{l}\text { Patients with } \\
\text { atrophic acne scars }\end{array}$ & $\begin{array}{l}\text { Topical application } \\
\text { twice a day after } \\
\text { laser treatment } \\
-80 \% \\
\text { MSC-CM+20\% HA } \\
\text { - HA }(n=15)\end{array}$ & 60 & $\begin{array}{l}\text { Scar volume and } \\
\text { erythema were } \\
\text { objectively } \\
\text { evaluated using an } \\
\text { Antera 3DVR CS }\end{array}$ & $\begin{array}{l}\text { Scar volume was } \\
\text { reduced by } 23.5 \% \\
\text { in MSC-CM side } \\
\text { vs. } 15.0 \% \text { in control } \\
\text { side, and the } \\
\text { volume of the skin } \\
\text { pores was reduced } \\
\text { by } 37.6 \% \text { in } \\
\text { MSC-CM side vs. } \\
15.9 \% \text { in control } \\
\text { side }\end{array}$ & $\begin{array}{l}\text { The erythema increase was } \\
\text { lower in MSC-CM side } \\
(2.8 \% \text { vs. vs. } 3.1 \%)\end{array}$ \\
\hline $\begin{array}{l}\text { Prakoeswa } \\
\text { et al., } 2019\end{array}$ & $\begin{array}{l}\text { Human } \\
\text { amniotic } \\
\text { membrane }\end{array}$ & - & $\begin{array}{l}\text { Randomized, } \\
\text { matching pair, } \\
\text { clinical trial }\end{array}$ & $\begin{array}{l}\text { Healthy women } \\
\text { with clinical } \\
\text { photoageing } \\
(50.31 \pm 5.1 \text { years) }\end{array}$ & $\begin{array}{l}3 \text { ml topically } \\
\text { applied every } \\
2 \text { weeks after } \\
\text { microneedling } \\
\text { - Normal saline } \\
\text { (control) } \\
\text { - MSC-CM }(n=48)\end{array}$ & 56 & $\begin{array}{l}\text { Macroscopic } \\
\text { appearance } \\
\text { (photography, } \\
\text { Glogau scale) }\end{array}$ & $\begin{array}{l}\text { MSC-CM group } \\
\text { showed better } \\
\text { improvements in } \\
\text { pore and wrinkle }\end{array}$ & $\begin{array}{l}\text { Skin tone did not improve } \\
\text { in either of the groups }\end{array}$ \\
\hline $\begin{array}{l}\text { Kim et al., } \\
2018\end{array}$ & $\begin{array}{l}\text { Human } \\
\text { umbilical cord }\end{array}$ & - & $\begin{array}{l}\text { Prospective } \\
\text { observational } \\
\text { study }\end{array}$ & $\begin{array}{l}\text { Healthy women } \\
\text { with face wrinkles } \\
\text { (range 18-55 years) }\end{array}$ & $\begin{array}{l}10 \% \text { MSC-CMs in } \\
\text { cream base } \\
\text { topically applied } \\
\text { daily on face skin } \\
(n=22)\end{array}$ & 28 & $\begin{array}{l}\text { Macroscopic } \\
\text { appearance } \\
\text { (photography), } \\
\text { ultrasound }\end{array}$ & $\begin{array}{l}\text { Dermal density was } \\
\text { increased by } \\
2.46 \% \text { compared } \\
\text { before treatment }\end{array}$ & $\begin{array}{l}\text { Wrinkles of eye-end area } \\
\text { were decreased after the } \\
\text { treatment. No irritation, } \\
\text { stinging, or any adverse } \\
\text { reactions were observed }\end{array}$ \\
\hline
\end{tabular}


TABLE 10 | Continued

\begin{tabular}{|c|c|c|c|c|c|c|c|c|c|}
\hline & MSC source & $\begin{array}{l}\text { Method of } \\
\text { tissue } \\
\text { extraction }\end{array}$ & Type of study & $\begin{array}{l}\text { Indication and } \\
\text { population }\end{array}$ & $\begin{array}{l}\text { Groups of } \\
\text { treatments and } \\
\text { via of } \\
\text { administration }\end{array}$ & $\begin{array}{l}\text { Follow-up } \\
\text { (days) }\end{array}$ & Assessment & Main outcome & Other outcomes \\
\hline $\begin{array}{l}\text { Xu et al., } \\
2016\end{array}$ & $\begin{array}{l}\text { Human } \\
\text { adipose tissue } \\
\text { and placenta }\end{array}$ & - & $\begin{array}{l}\text { Prospective } \\
\text { randomized } \\
\text { clinical trial }\end{array}$ & Healthy volunteer & $\begin{array}{l}\text { Intradermal } \\
\text { injections } \\
\text { - AT-MSC-CM+HA } \\
\text { - P-MSC-CM+HA } \\
\text { - HA (control) } \\
(n=6 / \text { group) }\end{array}$ & 15 & $\begin{array}{l}\text { Biophysical } \\
\text { measurements }\end{array}$ & $\begin{array}{l}\text { Erythema, melanin, } \\
\text { elasticity, TEWL, } \\
\text { and hydration } \\
\text { showed } \\
\text { improvement in } \\
\text { hAD-MSC-CM and } \\
\text { hP-MSC-CM } \\
\text { compared with the } \\
\text { control group }\end{array}$ & $\begin{array}{l}\text { Only the melanin index of } \\
\text { the hAD-MSC-CM group } \\
\text { was significantly lower than } \\
\text { that of the hP-MSC-CM } \\
\text { group }\end{array}$ \\
\hline $\begin{array}{l}\text { Zhou et al., } \\
2016\end{array}$ & $\begin{array}{l}\text { Human } \\
\text { subcutaneous } \\
\text { adipose tissue }\end{array}$ & Liposuction & $\begin{array}{l}\text { Prospective } \\
\text { observational } \\
\text { study }\end{array}$ & $\begin{array}{l}\text { Patients with facial } \\
\text { wrinkles and } \\
\text { patients with } \\
\text { atrophic acne } \\
\text { scars. 36.4 years } \\
\text { (range 24-50) 5:6 } \\
\text { male:female }\end{array}$ & $\begin{array}{l}3 \mathrm{ml} \text { topical } \\
\text { application after } \\
\text { FxCR } \\
\text { - MSC-CM } \\
\text { - DMEM ( } n=9 \text { with } \\
\text { facial wrinkles } \\
n=13 \text { with atrophic } \\
\text { acne scars) }\end{array}$ & 90 & $\begin{array}{l}\text { Macroscopic } \\
\text { appearance } \\
\text { (photography), } \\
\text { subjective } \\
\text { satisfaction scale, } \\
\text { biophysical } \\
\text { measurements } \\
\text { (erythema, melanin, } \\
\text { TEWL, elasticity, } \\
\text { skin surface } \\
\text { roughness, } \\
\text { hydration), and } \\
\text { histology (HE, MT, } \\
\text { Gomori's aldehyde } \\
\text { fuchsine staining) }\end{array}$ & $\begin{array}{l}\text { Subjective } \\
\text { satisfaction } \\
(2.35 \pm 0.69 \text { vs. } \\
2.08 \pm 0.76 \text {, } \\
p<0.05) \text { and } \\
\text { objective clinical } \\
\text { assessment } \\
(2.78 \pm 0.45 \text { vs. } \\
1.89 \pm 0.60 \text {, } \\
p<0.05) \text { were } \\
\text { higher in MSC-CM } \\
\text { group than DMEM }\end{array}$ & $\begin{array}{l}\text { Elasticity and hydration } \\
\text { were significantly higher in } \\
\text { MSC-CM side, while TEWL } \\
\text { and roughness were lower. } \\
\text { Increased dermal collagen } \\
\text { and elastin density were } \\
\text { found in MSC-CM side. No } \\
\text { adverse events were } \\
\text { reported in the study }\end{array}$ \\
\hline $\begin{array}{l}\text { Lee H. J. } \\
\text { et al., } 2014\end{array}$ & $\begin{array}{l}\text { Human } \\
\text { embryo }\end{array}$ & & $\begin{array}{l}\text { Prospective } \\
\text { randomized } \\
\text { controlled } \\
\text { observer-blind } \\
\text { split face study }\end{array}$ & $\begin{array}{l}\text { Healthy individuals } \\
\text { with face wrinkles } \\
(51.6 \text { years, range } \\
41-64)\end{array}$ & $\begin{array}{l}\text { Treatment every } \\
2 \text { weeks } \\
- \text { Microneedling } \\
\text { (control) } \\
- \text { Microneedling }+ \\
1.5 \mathrm{ml} \text { of MSC-CM } \\
(n=25)\end{array}$ & 84 & $\begin{array}{l}\text { Macroscopic } \\
\text { appearance } \\
\text { (photography), } \\
\text { biophysical } \\
\text { parameters } \\
\text { (erythema, melanin, } \\
\text { elasticity) }\end{array}$ & $\begin{array}{l}\text { Overall satisfaction } \\
\text { was higher in } \\
\text { MSC-CM group } \\
\text { than in controls } \\
(3.25 \pm 1.26 \text { vs. } \\
2.72 \pm 1.45) \text { and } \\
\text { also objective } \\
\text { clinical } \\
\text { improvement } \\
(1.92 \pm 0.42 \text { vs. } \\
1.49 \pm 0.48)\end{array}$ & $\begin{array}{l}\text { Erythema, melanin, and } \\
\text { elasticity improved more in } \\
\text { MSC-CM group. No } \\
\text { serious adverse events } \\
\text { were observed; only mild } \\
\text { pain, erythema, and } \\
\text { desquamation were found }\end{array}$ \\
\hline
\end{tabular}


TABLE 10 | Continued

\begin{tabular}{|c|c|c|c|c|c|c|c|c|c|}
\hline & MSC source & $\begin{array}{l}\text { Method of } \\
\text { tissue } \\
\text { extraction }\end{array}$ & Type of study & $\begin{array}{l}\text { Indication and } \\
\text { population }\end{array}$ & $\begin{array}{l}\text { Groups of } \\
\text { treatments and } \\
\text { via of } \\
\text { administration }\end{array}$ & $\begin{array}{l}\text { Follow-up } \\
\text { (days) }\end{array}$ & Assessment & Main outcome & Other outcomes \\
\hline $\begin{array}{l}\text { Seo et al., } \\
2013\end{array}$ & $\begin{array}{l}\text { Human } \\
\text { embryo }\end{array}$ & - & $\begin{array}{l}\text { Prospective } \\
\text { randomized } \\
\text { controlled, } \\
\text { investigator- } \\
\text { blinded, split-face } \\
\text { study }\end{array}$ & $\begin{array}{l}\text { Healthy volunteers. } \\
53.8 \pm 3.21 \text { years, } \\
\text { range } 41-64\end{array}$ & $\begin{array}{l}\text { - Microneedling } \\
\text { fractional } \\
\text { radiofrequency } \\
\text { (control) } \\
\text { - Microneedling } \\
\text { fractional } \\
\text { radiofrequency+MSC- } \\
\text { CM } \\
(n=15)\end{array}$ & 28 & $\begin{array}{l}\text { Macroscopic } \\
\text { appearance } \\
\text { (photography), } \\
\text { biophysical } \\
\text { parameters (SCH, } \\
\text { erythema, melanin, } \\
\text { wrinkles, elasticity), } \\
\text { histology (HE), IHC }\end{array}$ & $\begin{array}{l}\text { More } \\
\text { improvements of } \\
\text { wrinkles and overall } \\
\text { skin appearance } \\
\text { were observed in } \\
\text { combined } \\
\text { treatment } \\
\text { compared with } \\
\text { microneedling } \\
\text { alone }(2.06 \pm 0.70 \\
\text { for radiofrequency } \\
\text { and } 2.20 \pm 0.68 \text { for } \\
\text { the combined } \\
\text { treatment, } \\
p<0.05)\end{array}$ & $\begin{array}{l}\text { Patients' overall satisfaction } \\
\text { scores were higher in } \\
\text { combined treatment } \\
(2.35 \pm 0.42 \text { vs. } \\
2.00 \pm 0.65) . \text { SCH showed } \\
\text { a greater increase in the } \\
\text { combined treatment. } \\
\text { Similar decreases in } \\
\text { erythema and melanin } \\
\text { index were observed in } \\
\text { both groups. No serious } \\
\text { adverse events were } \\
\text { reported }\end{array}$ \\
\hline $\begin{array}{l}\text { Zhou et al., } \\
2013\end{array}$ & $\begin{array}{l}\text { Human } \\
\text { subcutaneous } \\
\text { adipose tissue } \\
\text { samples }\end{array}$ & Liposuction & $\begin{array}{l}\text { Prospective } \\
\text { observational } \\
\text { study }\end{array}$ & $\begin{array}{l}\text { Healthy volunteers. } \\
24-33 \text { years 5:14 } \\
\text { male:female }\end{array}$ & $\begin{array}{l}\text { Topical application } \\
\text { after laser } \\
\text { treatment: } \\
\text { - FxCR } 8 \text { mJ, with } \\
\text { MSC-CM } \\
\text { - FxCR } 8 \text { mJ with } \\
\text { DMEM } \\
\text { - FxCR } 16 \text { mJ with } \\
\text { MSC-CM } \\
\text { - FxCR } 8 \text { mJ with } \\
\text { DMEM }(n=19)\end{array}$ & 21 & $\begin{array}{l}\text { Macroscopic } \\
\text { appearance } \\
\text { (photography), } \\
\text { biophysical } \\
\text { parameters (TEWL, } \\
\text { erythema, melanin, } \\
\text { elasticity), histology } \\
\text { (HE, MT, Gomori's } \\
\text { aldehyde fuchsine } \\
\text { staining), qT-PCR }\end{array}$ & $\begin{array}{l}\text { The } \\
\text { MSC-CM-treated } \\
\text { side shows less } \\
\text { erythema and less } \\
\text { pigmentation }\end{array}$ & $\begin{array}{l}\text { MSC-CM side also showed } \\
\text { a greater reduction of } \\
\text { TEWL. There were no } \\
\text { differences in elasticity } \\
\text { parameters. The mRNA of } \\
\text { type III procollagen in } \\
\text { MSC-CM-treated group } \\
\text { was } 2.6 \text { times that of } \\
\text { control. No adverse events } \\
\text { were reported }\end{array}$ \\
\hline
\end{tabular}

AT, adipose tissue-derived; CM, conditioned medium; DMEM, Dulbecco's modified Eagle medium; FXCR, fractional carbon dioxide laser resurfacing; HA, hyaluronic acid; HE, hematoxylin and eosin; hCB, human cord blood; hESC, human embryonic stem cell; IHC, immunohistochemistry; MSCs, mesenchymal stromal cells; MT, Masson's trichrome; P-MSCs, placenta-derived mesenchymal stromal cells; qRT-PCR, real-time quantitative polymerase chain reaction; PRP, platelet-rich plasma. 
TABLE 11 | Studies regarding mesenchymal stromal cell- conditioned medium for treating inflammatory skin diseases.

\begin{tabular}{|c|c|c|c|c|c|c|c|c|c|c|}
\hline & MSC source & $\begin{array}{l}\text { Method of } \\
\text { tissue } \\
\text { extraction }\end{array}$ & $\begin{array}{l}\text { MSC } \\
\text { characterization }\end{array}$ & $\begin{array}{l}\text { MSC } \\
\text { treatment }\end{array}$ & $\begin{array}{l}\text { Model and } \\
\text { patients }\end{array}$ & $\begin{array}{l}\text { Groups of } \\
\text { treatments } \\
\text { and via of } \\
\text { administration }\end{array}$ & $\begin{array}{l}\text { Follow-up } \\
\text { (days) }\end{array}$ & Assessment & Main outcome & Other outcomes \\
\hline \multicolumn{11}{|l|}{ Animals } \\
\hline $\begin{array}{l}\text { Park H. S. } \\
\text { et al., } 2019\end{array}$ & $\begin{array}{l}\text { Murine } \\
\text { adipose } \\
\text { tissue from } \\
\text { inguinal } \\
\text { region }\end{array}$ & $\begin{array}{l}\text { Inguinal } \\
\text { incision }\end{array}$ & $\begin{array}{l}\text { Flow cytometry } \\
\text { (CD45-, CD29+, } \\
\text { CD105+, } \\
\text { CD73+, CD34-, } \\
\text { CD44+, and } \\
\text { CD90+) }\end{array}$ & $\begin{array}{l}\text { MSCs of } \\
\text { passage } 1 \text { at } \\
70 \% \\
\text { confluence } \\
\text { were used. CM } \\
\text { was then } \\
\text { collected }\end{array}$ & $\begin{array}{l}\text { Murine. AD } \\
\text { model. 2,4- } \\
\text { dinitrochlorobenze } \\
\text { was applied on } \\
\text { the shaved } \\
\text { dorsal skin of } \\
\text { every mouse } \\
\text { for } 7.5 \text { weeks } \\
\text { to induce } \\
\text { AD-like skin } \\
\text { lesions }\end{array}$ & $\begin{array}{l}200 \mu \mathrm{l} \\
\text { subcutaneously } \\
\text { niejected every } \\
3 \text { days (on days } \\
13,16 \text {, and 19) } \\
\text { - Saline } \\
\text { - MSCs } \\
\text { - MSC-CM } \\
\text { - } 2.5 \% \\
\text { cortisone lotion } \\
\text { ( } n=6 / \text { group) }\end{array}$ & 33 & $\begin{array}{l}\text { Macroscopic } \\
\text { appearance } \\
\text { (photography, } \\
\text { SCORAD), } \\
\text { histology (HE), } \\
\text { IHC }\end{array}$ & $\begin{array}{l}\text { AD severity } \\
\text { index was } \\
\text { significantly } \\
\text { lower in groups } \\
\text { treated with } \\
\text { MSC, } \\
\text { MSC-CM, or } \\
\text { cortisone, } \\
\text { compared with } \\
\text { saline group } \\
(p<0.001)\end{array}$ & $\begin{array}{l}\text { Skin thickness decreases } \\
\text { were similar between MSC, } \\
\text { MSC-CM, and cortisone } \\
\text { and all greater than } \\
\text { placebo. Mast cell } \\
\text { infiltration was reduced in } \\
\text { the MSC-treated group } \\
\text { (40.20 } \pm 9.44 \text { cells, } \\
p<0.001) \text {, MSC-CM } \\
\text { (47.33 } \pm 13.13 \text { cells, } \\
p<0.001) \text {, or cortisone } \\
\text { (51.00 } \pm 21.46 \text { cells, } \\
p<0.001) \text { compared with } \\
\text { saline (134.00 } \pm 7.42 \text { cells) } \\
\text { Thymic stromal } \\
\text { lymphopoietin expression } \\
\text { level in saline group was } \\
\text { higher (11.7 } \pm 1.69) \text { than in } \\
\text { MSC group (5.07 } 0.76, \\
p<0.001), \text { MSC-CM } \\
\text { (4.52 } \pm 1.33, p<0.001), \\
\text { or cortisone group } \\
(6.72 \pm 1.66, p<0.001) . \\
\text { CD45 expression was } \\
\text { elevated in saline-treated } \\
\text { group (1.68 } \pm 0.29) \text {, but it } \\
\text { was reduced in MSC group } \\
\text { (0.38 } \pm 0.18, p<0.001), \\
\text { MSC-CM (0.19 } \pm 0.17, \\
p<0.001), \text { or cortisone } \\
\text { (0.37 } \pm 0.15, p<0.001) \text {. } \\
\text { Moreover, TH2 expression } \\
\text { levels were lower in } \\
\text { MSC-treated mice } \\
\text { (3.79 } \pm 2.08, p<0.001), \\
\text { MSC-CM }(1.58 \pm 1.84, \\
p<0.001), \text { or cortisone } \\
\text { (4.10 } \pm 3.32, p<0.001) \\
\text { compared with saline group } \\
\text { (19.19 } \pm 5.54) \text {. CXCL9 } \\
\text { expression levels were } \\
\text { lower in MSC group }\end{array}$ \\
\hline
\end{tabular}


TABLE 11 | Continued

MSC source

Method
tissue
extraction

MSC

MSC

Groups of

Follow-up

(days)

extraction

characterization treatment

patients

reatments

and via of

Assessment

Other outcomes

administration

$(4.49 \pm 1.25, p<0.01)$

MSC-CM $(8.78 \pm 0.51$,

$p<0.01$ ), or cortisone

$(15.83 \pm 3.94, p<0.05)$

compared with saline group

(41.2 \pm 4.15). CCL2O

expression was higher in

saline-treated group

(61.18 \pm 1.97$)$, but it was

reduced by MSCs

$(23.99 \pm 2.46, p<0.001)$,

MSC-CM (25.98 \pm 3.19 ,

$p<0.001$ ), or cortisone

$(28.87 \pm 3.1, p<0.001)$

IgE levels were slightly

reduced in mice that were

treated with MSC,

MSC-CM, or cortisone.

Tissue levels of IFN $-\gamma$ were

reduced MSCs

(66.20 $\pm 14.51 \mathrm{pg} / \mathrm{ml}$,

$p<0.001$ ) or MSC-CM

$(36.27 \pm 3.26 \mathrm{pg} / \mathrm{ml}$,

$p<0.001)$ compared with

saline

(117.14 $\pm 45.84 \mathrm{pg} / \mathrm{ml})$.

Similarly, serum levels of

$\mathrm{IL}-33$ were lower in MSC

group $(32.20 \pm 3.04 \mathrm{pg} / \mathrm{ml}$;

$p<0.001)$ and MSC-CM

group $(42.83 \pm 6.07 \mathrm{pg} / \mathrm{ml}$

$p<0.001)$ than in saline

group

(64.06 \pm 8.58 pg/ml). IL-4 level in the MSC-CM group $(30.03 \pm 8.39 \mathrm{pg} / \mathrm{ml}$,

$p<0.001)$ was decreased

compared with saline

$(51.97 \pm 2.24 \mathrm{pg} / \mathrm{ml})$.

Serum IL-13 level was

decreased in

MSCs-treated group

$(0.27 \pm 0.03 \mathrm{pg} / \mathrm{ml}$ 
TABLE 11 | Continued

\begin{tabular}{|c|c|c|c|c|c|c|c|c|c|c|}
\hline & MSC source & $\begin{array}{l}\text { Method of } \\
\text { tissue } \\
\text { extraction }\end{array}$ & $\begin{array}{l}\text { MSC } \\
\text { characterization }\end{array}$ & $\begin{array}{l}\text { MSC } \\
\text { treatment }\end{array}$ & $\begin{array}{l}\text { Model and } \\
\text { patients }\end{array}$ & $\begin{array}{l}\text { Groups of } \\
\text { treatments } \\
\text { and via of } \\
\text { administration }\end{array}$ & $\begin{array}{l}\text { Follow-up } \\
\text { (days) }\end{array}$ & Assessment & Main outcome & Other outcomes \\
\hline \multicolumn{11}{|l|}{ Human } \\
\hline $\begin{array}{l}\text { Kim Y. J. } \\
\text { et al., } 2020\end{array}$ & $\begin{array}{l}\text { Human } \\
\text { umbilical cord }\end{array}$ & $\begin{array}{l}\text { Umbilical cord } \\
\text { dissection }\end{array}$ & $\begin{array}{l}\text { Flow cytometry } \\
\text { (CD24+, CD29+, } \\
\text { CD44+, CD73+, } \\
\text { CD90+, } \\
\text { CD105+, } \\
\text { CD10-, CD14-, } \\
\text { CD31-, CD34-, } \\
\text { CD45-, CD62-, } \\
\text { CD133-, } \\
\text { HLA-DR-). } \\
\text { Osteogenic, } \\
\text { adipogenic, and } \\
\text { chondrogenic } \\
\text { differentiation }\end{array}$ & $\begin{array}{l}\text { MSCs of } \\
\text { passage } 6 \text { were } \\
\text { used. CM was } \\
\text { collected }\end{array}$ & $\begin{array}{l}\text { Prospective } \\
\text { observational } \\
\text { study Patients } \\
\text { with atopic } \\
\text { dermatitis } \\
\text { patients. Age } \\
24.68 \pm 4.32 \\
\text { Sex } 15: 13 \\
\text { male:female }\end{array}$ & $\begin{array}{l}\text { MSC-CM } \\
\text { containing } \\
\text { cream bases } \\
\text { were applied } \\
\text { twice a day to } \\
\text { patients' lesion } \\
\text { and non-lesion } \\
\text { skin }(n=28)\end{array}$ & 28 & $\begin{array}{l}\text { Skin } \\
\text { biophysical } \\
\text { parameters } \\
\text { (TEWL, SCH) }\end{array}$ & $\begin{array}{l}\text { MSC-CM } \\
\text { improved skin } \\
\text { barrier } \\
\text { functions }\end{array}$ & $\begin{array}{l}p<0.05) \text { compared with } \\
\text { saline group } \\
(3.68 \pm 1.40 \mathrm{pg} / \mathrm{ml}) \mathrm{SCH} \\
\text { increased and TEWL } \\
\text { decreased on both the } \\
\text { lesion and non-involved } \\
\text { skin after MSC-CM. SCH } \\
\text { increased by } 15.67 \text { and } \\
14.49 \mathrm{AU} \text { on the lesion and } \\
\text { non-involved skin, } \\
\text { respectively. TEWL } \\
\text { decreased } 15.09 \mathrm{AU} \text { and } \\
3.08 \mathrm{AU} \text { on the lesion and } \\
\text { non-involved skin, } \\
\text { respectively }\end{array}$ \\
\hline $\begin{array}{l}\text { Seetharaman } \\
\text { et al., } 2019\end{array}$ & $\begin{array}{l}\text { Human } \\
\text { adipose } \\
\text { tissue from } \\
\text { the waist area }\end{array}$ & Lipoaspiration & - & $\begin{array}{l}\text { MSCs of } \\
\text { passage at } \\
90 \% \\
\text { confluence } \\
\text { were used. CM } \\
\text { was then } \\
\text { collected }\end{array}$ & $\begin{array}{l}\text { Case report. } \\
\text { Patient with } \\
\text { scalp psoriasis. } \\
38 \text { years Male }\end{array}$ & $\begin{array}{l}\text { MSC-CM was } \\
\text { topically } \\
\text { applied on the } \\
\text { lesions once a } \\
\text { day }\end{array}$ & 30 & $\begin{array}{l}\text { Clinical } \\
\text { examination } \\
\text { (PSSI) }\end{array}$ & $\begin{array}{l}\text { Psoriatic } \\
\text { plaques were } \\
\text { reduced after } \\
\text { MSC-CM } \\
\text { treatment }\end{array}$ & $\begin{array}{l}\text { PSSI score reduced from } \\
28 \text { to } 0 \text { and diseases } \\
\text { regression continued for } \\
6 \text { months of follow-up }\end{array}$ \\
\hline
\end{tabular}

AD, atopic dermatitis; CM, conditioned medium; HE, hematoxylin and eosin; IHC, immunohistochemistry; MSCs, mesenchymal stromal cell; PSSI, Psoriasis Scalp Severity Index; SCORAD, SCORing Atopic Dermatitis Index; SCH, stratum corneum hydration, TEWL, transepidermal water loss. 


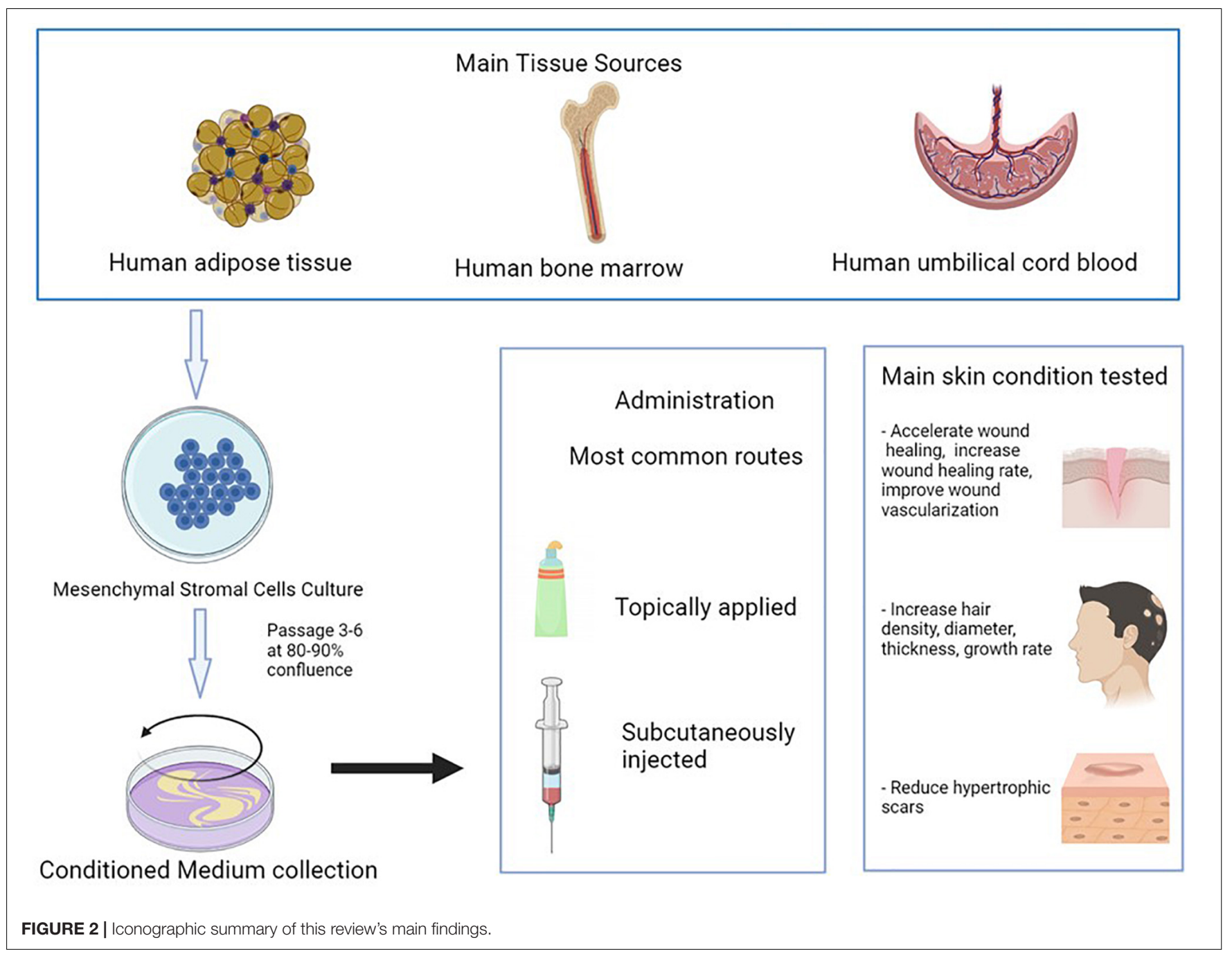

cell treatment, method of delivery, disease model used to assess efficacy, ways of assessment, and outcome evaluation. This review provides a useful summary regarding the use of MSC-CM for skin conditions and highlights the need to standardize manufacturing processes and characterize CM. The main findings of this review are summarized in Figure 2.

It is important to characterize the composition of CM, but there is a lack of evidence in this aspect. Some studies showed that CM contained high concentrations of growth factors and cytokines associated with angiogenesis and endothelial cell migration such as EGF, tissue inhibitors of metalloproteinase-1, or IGF-binding protein-7 (De Gregorio et al., 2020; Kim Y. J. et al., 2020). The properties of MSC-CM vary depending on the cell source (Sagaradze et al., 2019). More than 10 sources of MSCs were used to treat skin conditions. MSCs were mainly isolated from human adipose tissue, human bone marrow, and human umbilical cord blood. Another important aspect is the timing of the collection of CM from the cells and concentration steps carried out for obtaining CM (Im et al., 2019). Most studies used cells from passages 3 to 6 at $80-90 \%$ confluence. The secretome of cells may also vary depending on the age of the cells (Maguire,
2013). Furthermore, the same type of cells is reported to secrete different levels of paracrine factors depending on the culture condition (Park et al., 2010) (hypoxic vs. normoxic) and the scaffold type (Li T. et al., 2019) (monolayer vs. 3D cultures). Hypoxic treatment is one of the most frequently used ways to improve CM, as hypoxic stress reduces oxygen and improves cellular functions (Du et al., 2017). CM collected from MSCs cultured under hypoxic conditions improved the cells' capacities of proliferation and self-renewal (Chen et al., 2014; Jun et al., 2014; Du et al., 2016a, 2017). Determining the levels of paracrine factors secreted by MSCs at different passages with different conditions may also provide knowledge about the best stromal cell growth stage for obtaining a specific group of paracrine factors. Furthermore, MSC-CM should be considered both an alternative therapy and a synergic therapy for improving skin conditions, as MSC-CM combined with the conventional therapy has been proved to have better results than MSC-CM or the conventional therapy alone (Pouriran et al., 2016; Amini et al., 2018; Bagheri et al., 2018; Fridoni et al., 2019; Kouhkheil et al., 2019). In fact, some studies regarding wound healing in diabetic and infected wounds showed that PBM+MSC-CM application 
accelerated the process of wound healing, while it did not happen when using MSC-CM alone (Pouriran et al., 2016; Fridoni et al., 2019; Kouhkheil et al., 2019).

Several routes of administration have been also tested. Topical application and subcutaneous injection of CM were the most common routes of administration, and they are also the least invasive ways, appearing as promising routes for future research on MSC-CM.

No adverse events were reported to be related to MSC$\mathrm{CM}$ in either preclinical or clinical trials. This is one of the main advantages of using MSC-CM instead of CM, as adverse events related to cells such as hyperimmunogenicity or tumorigenicity can be avoided (Gunawardena et al., 2019b). Only three studies evaluated differences between MSCs and MSCCM, showing similar results between them (Tamari et al., 2013; Park H. S. et al., 2019; Zhang S. et al., 2020). Similar effectiveness was observed between UC-MSCs and UC-MSC-CM for accelerating wound healing rate. The wound area of UC-MSC and UC-MSC-CM was $\approx 15 \%$ reduced as compared with controls without differences in UC-MSC and UC-MSC-CM (Park H. S. et al., 2019; Zhang S. et al., 2020). Other research also showed similar epithelialization rate when using MSC or MSC-CM (Tamari et al., 2013). Moreover, it was observed that the effect of autologous AT-MSCs and AT-MSC-CM was similar for treating $\mathrm{AD}$ in mouse and higher than in the control group (Park H. S. et al., 2019).

It is also important to differentiate MSC-CM from culture media only. MSC-CM is the one in which MSCs have been grown for a period of time and with some requirements, and the culture media only is the media in which we grow the MSC-CM but has not been exposed to the cells. The culture media were used as control in some studies to prove the effectiveness of MSCCM in wound healing (Jun et al., 2014; Deng et al., 2019; Rong et al., 2019). Higher wound healing rates and faster healing were observed with MSC-CM treatment than DMEM. Moreover, it was observed that hypertrophic scar reduction was higher using MSC-CM than DMEM (Zhang et al., 2015; Liu et al., 2018; Hu et al., 2020). It was also found that the topical application of MSC-CM after laser treatment showed less erythema and less pigmentation than the application of DMEM (Zhou et al., 2013, 2016). This might mean that the effect observed of MSC-CM in these diseases is due to the secretome and is not being caused by the culture media alone.

One of the limitations of MSC-CM is that, to translate its use to patients, it is necessary to know the exact composition of each CM and that its use validation should be conducted for every disease it is to be used for. Moreover, CM needs to be given more frequently

\section{REFERENCES}

Abdel-Maguid, E. M., Awad, S. M., Hassan, Y. S., El-Mokhtar, M. A., El-Deek, H. E., and Mekkawy, M. M. (2019). Efficacy of stem cell-conditioned medium vs. platelet-rich plasma as an adjuvant to ablative fractional CO2 laser resurfacing for atrophic post-acne scars: a split-face clinical trial. J. Dermatolog. Treat. 32, 242-249. doi: 10.1080/09546634.2019.1630701

Ahangar, P., Mills, S. J., Smith, L. E., Strudwick, X. L., Ting, A. E., Vaes, B., et al. (2020). Human multipotent adult progenitor cell-conditioned medium than MSC, as the half-lives of cytokines and growth factors are mostly shorter than those of stromal cells, which may survive for rather long periods (Pawitan, 2014). Further research is needed to determine the components of MSC-CM that improves skin diseases. Moreover, regulatory requirements for manufacturing, standardization, and quality control of MSC-CM regarding MSC origin, isolation methods, and culture conditions are necessary to establish the safety and efficacy profiles of these products (Park H. S. et al., 2019).

Although there are some reviews regarding MSC-CM (Pawitan, 2014; Mizukami and Yagihashi, 2016; Bogatcheva and Coleman, 2019), they include little information about cutaneous disease. Pawitan et al. included some studies where MSC-CM was used for skin repair and alopecia. Bogatcheva and Coleman only included two articles where MSC-CM was used for skin diseases, one on treating dermatitis and the other on burns. Mizukami and Yagihashi reviewed the status of preclinical studies on stromal cell therapy for diabetic polyneuropathy, but they focused on MSCs and did not include information on other diseases. As far as we know, here, we review the use of MSC-CM in all skin conditions reported in the literature for the first time.

In conclusion, MSC-CM is a promising therapy for skin conditions. Studies on animals showed important rates of wound closure after MSC-CM treatment and clinical studies showed good results for skin rejuvenation. Further studies are needed to corroborate safety and effectiveness and to standardize CM manufacturing.

\section{AUTHOR CONTRIBUTIONS}

TM-V and SA-S contributed to conceptualization, formal analysis, investigation, and writing - original draft preparation. TM-V, ÁS-S, and SA-S contributed to methodology. AM-L contributed to software. TM-V, AM-L, and SA-S contributed to validation and visualization. MQ-V contributed to resources. TM-V, ÁS-S, MS-D, and MQ-V contributed to data curation. TM-V, SA-S, ÁS-S, and AM-L contributed to writing - review and editing. All authors have read and agreed to the published version of the manuscript.

\section{SUPPLEMENTARY MATERIAL}

The Supplementary Material for this article can be found online at: https://www.frontiersin.org/articles/10.3389/fcell.2021. 654210/full\#supplementary-material

improves wound healing through modulating inflammation and angiogenesis in mice. Stem Cell Res. Ther. 11:299. doi: 10.1186/s13287-020-01819-z

Amini, A., Pouriran, R., Abdollahifar, M. A., Abbaszadeh, H. A., Ghoreishi, S. K., Chien, S., et al. (2018). Stereological and molecular studies on the combined effects of photobiomodulation and human bone marrow mesenchymal stem cell conditioned medium on wound healing in diabetic rats. J. Photochem. Photobiol. B 182, 42-51. doi: 10.1016/j.jphotobiol.2018.03.010

Arjunan, S., Gan, S. U., Choolani, M., Raj, V., Lim, J., Biswas, A., et al. (2020). Inhibition of growth of Asian keloid cells with human umbilical cord Wharton's 
jelly stem cell-conditioned medium. Stem Cell Res. Ther. 11:78. doi: 10.1186/ s13287-020-01609-7

Aryan, A., Bayat, M., Bonakdar, S., Taheri, S., Haghparast, N., Bagheri, M., et al. (2019). Human bone marrow mesenchymal stem cell conditioned medium promotes wound healing in deep second-degree burns in male rats. Cells Tissues Organs. 206, 317-329. doi: 10.1159/000501651

Bagheri, M., Amini, A., Abdollahifar, M. A., Ghoreishi, S. K., Piryaei, A., Pouriran, R., et al. (2018). Effects of photobiomodulation on degranulation and number of mast cells and wound strength in skin wound healing of streptozotocininduced diabetic rats. Photomed Laser Surg. 36, 415-423. doi: 10.1089/pho.2018. 4453

Bian, X., Li, B., Yang, J., Ma, K., Sun, M., Zhang, C., et al. (2020). Regenerative and protective effects of dMSC-sEVs on high-glucose-induced senescent fibroblasts by suppressing RAGE pathway and activating Smad pathway. Stem Cell Res. Ther. 11:166. doi: 10.1186/s13287-020-01681-z

Bogatcheva, N. V., and Coleman, M. E. (2019). Conditioned medium of mesenchymal stromal cells: a new class of therapeutics. Biochemistry (Mosc) 84, 1375-1389. doi: 10.1134/S0006297919110129

Caplan, A. I. (2017). Mesenchymal stem cells: time to change the name! Stem Cells Transl. Med. 6, 1445-1451. doi: 10.1002/sctm.17-0051

Caplan, H., Olson, S. D., Kumar, A., George, M., Prabhakara, K. S., Wenzel, P., et al. (2019). Mesenchymal stromal cell therapeutic delivery: translational challenges to clinical application. Front. Immunol. 10:1645. doi: 10.3389/fimmu. 2019.01645

Chen, C. Y., Rao, S. S., Ren, L., Hu, X. K., Tan, Y. J., Hu, Y., et al. (2018). Exosomal DMBT1 from human urine-derived stem cells facilitates diabetic wound repair by promoting angiogenesis. Theranostics $8,1607-1623$. doi: 10 . $7150 /$ thno. 22958

Chen, L., Cheng, L., Wang, Z., Zhang, J., Mao, X., Liu, Z., et al. (2021). Conditioned medium-electrospun fiber biomaterials for skin regeneration. Bioact Mater. 6, 361-374. doi: 10.1016/j.bioactmat.2020.08.022

Chen, L., Tredget, E. E., Wu, P. Y., and Wu, Y. (2008). Paracrine factors of mesenchymal stem cells recruit macrophages and endothelial lineage cells and enhance wound healing. PLoS One 3:e1886. doi: 10.1371/journal.pone.0001886

Chen, L., Xu, Y., Zhao, J., Zhang, Z., Yang, R., Xie, J., et al. (2014). Conditioned medium from hypoxic bone marrow-derived mesenchymal stem cells enhances wound healing in mice. PLoS One 9:e96161. doi: 10.1371/journal.pone.0096161

Chen, Z., Pan, D., Hu, S., Yang, J., Zhou, L., and Shen, J. (2018). The combination of exosomes derived from umbilical cord mesenchymal stem cells and Pluronic F-127 promotes the proliferation and migration of vascular endothelial cells. Diabetes Metabolism Res. Rev. 34, 24-25. doi: 10.1002/dmrr.3079

Cho, J. W., Kang, M. C., and Lee, K. S. (2010). TGF- $\beta 1$-treated ADSCs-CM promotes expression of type I collagen and MMP-1, migration of human skin fibroblasts, and wound healing in vitro and in vivo. Int. J. Mol. Med. 26, 901-906. doi: 10.3892/ijmm_00000540

Choi, N., Kim, W. S., Oh, S. H., and Sung, J. H. (2019). HB-EGF improves the hair regenerative potential of adipose-derived stem cells via ROS Generation and Hck Phosphorylation. Int. J. Mol. Sci. 21:122. doi: 10.3390/ijms21010122

Choi, Y. J., Lee, K. S., Yeom, S. H., and Cho, Y. W. (2017). Exosomes secreted by human adipose-derived stem cells regulate the expression of collagen synthesisrelated genes in human dermal fibroblasts. J. Extracell. Vesicles 6:141. doi: 10.1080/20013078.2017.1310414

Cooper, D. R., Wang, C., Patel, R., Trujillo, A., Patel, N. A., Prather, J., et al. (2018). Human adipose-derived stem cell conditioned media and exosomes containing MALAT1 promote human dermal fibroblast migration and ischemic wound healing. Adv. Wound Care 7, 299-308. doi: 10.1089/wound.2017.0775

Dalirfardouei, R., Jamialahmadi, K., Jafarian, A. H., and Mahdipour, E. (2019). Promising effects of exosomes isolated from menstrual blood-derived mesenchymal stem cell on wound-healing process in diabetic mouse model. J. Tissue Eng. Regener. Med. 13, 555-568. doi: 10.1002/term.2799

De Gregorio, C., Contador, D., Diáz, D., Cárcamo, C., Santapau, D., LobosGonzalez, L., et al. (2020). Human adipose-derived mesenchymal stem cellconditioned medium ameliorates polyneuropathy and foot ulceration in diabetic BKS db/db mice. Stem Cell Res. Ther. 11:168. doi: 10.1186/s13287-02001680-0

Deng, C., He, Y., Feng, J., Dong, Z., Yao, Y., and Lu, F. (2019). Conditioned medium from 3D culture system of stromal vascular fraction cells accelerates wound healing in diabetic rats. Regen. Med. 14, 925-937. doi: 10.2217/rme-2018-0083
Deng, C., He, Y., Feng, J., Dong, Z., Yao, Y., Mok, H., et al. (2017). Extracellular matrix/stromal vascular fraction gel conditioned medium accelerates wound healing in a murine model. Wound Repair Regen. 25, 923-932. doi: 10.1111/ wrr. 12602

Deng, H., Sun, C., Sun, Y., Li, H., Yang, L., Wu, D., et al. (2018). Lipid, Protein, and MicroRNA composition within mesenchymal stem cell-derived exosomes. Cell Reprogram 20, 178-186. doi: 10.1089/cell.2017.0047

Dominici, M., Le Blanc, K., Mueller, I., Slaper-Cortenbach, I., Marini, F., Krause, D., et al. (2006). Minimal criteria for defining multipotent mesenchymal stromal cells. The International Society for Cellular Therapy position statement. Cytotherapy 8, 315-317. doi: 10.1080/14653240600855905

Dong, L., Hao, H., Liu, J., Ti, D., Tong, C., Hou, Q., et al. (2017). A conditioned medium of umbilical cord mesenchymal stem cells overexpressing Wnt7a promotes wound repair and regeneration of hair follicles in mice. Stem Cells Int. 2017:3738071. doi: 10.1155/2017/3738071

Dong, L., Hao, H., Xia, L., Liu, J., Ti, D., Tong, C., et al. (2014). Treatment of MSCs with Wnt1a-conditioned medium activates DP cells and promotes hair follicle regrowth. Sci. Rep. 4:5432. doi: 10.1038/srep05432

Du, H. C., Jiang, L., Geng, W. X., Li, J., Zhang, R., Dang, J. G., et al. (2017). Growth Factor-Reinforced ECM fabricated from chemically hypoxic msc sheet with improved in vivo wound repair activity. Biomed. Res. Int. 2017:2578017. doi: $10.1155 / 2017 / 2578017$

Du, L., Lv, R., Yang, X., Cheng, S., Ma, T., and Xu, J. (2016a). Hypoxic conditioned medium of placenta-derived mesenchymal stem cells protects against scar formation. Life Sci. 149, 51-57. doi: 10.1016/j.lfs.2016.02.050

Du, L., Lv, R., Yang, X., Cheng, S., Xu, J., and Ma, T. (2016b). Hypoxia enhances the protective effects of placenta-derived mesenchymal stem cells against scar formation through hypoxia-inducible factor-1 $\alpha$. Biotechnol. Lett. 38, 931-939. doi: 10.1007/s10529-016-2067-6

El-Domyati, M., Moftah, N. H., Nasif, G. A., Ameen, S. W., Ibrahim, M. R., and Ragaie, M. H. (2020). Facial rejuvenation using stem cell conditioned media combined with skin needling: a split-face comparative study. J. Cosmetic Dermatol. 19, 2404-2410. doi: 10.1111/jocd.13594

El-Domyati, M., Moftah, N. H., Nasif, G. A., Ragaie, M. H., Ibrahim, M. R., and Ameen, S. W. (2019). Amniotic fluid-derived mesenchymal stem cell products combined with microneedling for acne scars: a split-face clinical, histological, and histometric study. J. Cosmetic Dermatol. 18, 1300-1306. doi: 10.1111/jocd. 13039

Fong, C. Y., Tam, K., Cheyyatraivendran, S., Gan, S. U., Gauthaman, K., Armugam, A., et al. (2014). Human Wharton's jelly stem cells and its conditioned medium enhance healing of excisional and diabetic wounds. J. Cell Biochem. 115, 290-302. doi: $10.1002 /$ jcb. 24661

Fridoni, M., Kouhkheil, R., Abdollhifar, M. A., Amini, A., Ghatrehsamani, M., Ghoreishi, S. K., et al. (2019). Improvement in infected wound healing in type 1 diabetic rat by the synergistic effect of photobiomodulation therapy and conditioned medium. J. Cell Biochem. 120, 9906-9916. doi: 10.1002/jcb.28273

Gunawardena, T. N. A., Masoudian, Z., Rahman, M. T., Ramasamy, T. S., Ramanathan, A., and Abu Kasim, N. H. (2019a). Dental derived stem cell conditioned media for hair growth stimulation. PLoS One 14:e0216003. doi: 10.1371/journal.pone.0216003

Gunawardena, T. N. A., Rahman, M. T., Abdullah, B. J. J., and Abu Kasim, N. H. (2019b). Conditioned media derived from mesenchymal stem cell cultures: the next generation for regenerative medicine. J. Tissue Eng. Regen. Med. 13, 569-586. doi: 10.1002/term.2806

Guo, S., Wang, T., Zhang, S., Chen, P., Cao, Z., Lian, W., et al. (2020). Adipose-derived stem cell-conditioned medium protects fibroblasts at different senescent degrees from UVB irradiation damages. Mol. Cell Biochem. 463, 67-78. doi: 10.1007/s11010-019-03630-8

He, D., Zhao, F., Jiang, H., Kang, Y., Song, Y., Lin, X., et al. (2020). LOXL2 from human amniotic mesenchymal stem cells accelerates wound epithelialization by promoting differentiation and migration of keratinocytes. Aging (Albany NY) 12, 12960-12986. doi: 10.18632/aging.103384

Heo, S. C., Jeon, E. S. I, Lee, H., Kim, H. S., Kim, M. B., and Kim, J. H. (2011). Tumor necrosis factor- $\alpha$-activated human adipose tissue-derived mesenchymal stem cells accelerate cutaneous wound healing through paracrine mechanisms. J. Invest. Dermatol. 131, 1559-1567. doi: 10.1038/jid.2011.64

Hu, C. H., Tseng, Y. W., Lee, C. W., Chiou, C. Y., Chuang, S. S., Yang, J. Y., et al. (2020). Combination of mesenchymal stem cell-conditioned medium and 
botulinum toxin type A for treating human hypertrophic scars. J. Plast Reconstr. Aesthet Surg. 73, 516-527. doi: 10.1016/j.bjps.2019.07.010

Hu, L., Yin, C., Zhao, F., Ali, A., Ma, J., and Qian, A. (2018). Mesenchymal stem cells: cell fate decision to osteoblast or adipocyte and application in osteoporosis treatment. Int. J. Mol. Sci. 19:360. doi: 10.3390/ijms19020360

Im, G. B., Kim, Y. H., Kim, Y. J., Kim, S. W., Jung, E., Jeong, G. J., et al. (2019). Enhancing the wound healing effect of conditioned medium collected from mesenchymal stem cells with high passage number using bioreducible nanoparticles. Int. J. Mol. Sci. 20:4835. doi: 10.3390/ijms20194835

Irons, R. F., Cahill, K. W., Rattigan, D. A., Marcotte, J. H., Fromer, M. W., Chang, S., et al. (2018). Acceleration of diabetic wound healing with adipose-derived stem cells, endothelial-differentiated stem cells, and topical conditioned medium therapy in a swine model. J. Vasc. Surg. 68, 115s-125s. doi: 10.1016/j.jvs.2018. 01.065

Joseph, A., Baiju, I., Bhat, I. A., Pandey, S., Bharti, M., Verma, M., et al. (2020). Mesenchymal stem cell-conditioned media: a novel alternative of stem cell therapy for quality wound healing. J. Cell. Physiol. 235, 5555-5569. doi: 10.1002/ jcp. 29486

Jun, E. K., Zhang, Q., Yoon, B. S., Moon, J. H., Lee, G., Park, G., et al. (2014). Hypoxic conditioned medium from human amniotic fluid-derived mesenchymal stem cells accelerates skin wound healing through TGFß/SMAD2 and PI3K/Akt pathways. Int. J. Mol Sci. 15, 605-628. doi: 10.3390/ ijms 15010605

Kim, J., Kim, B., Kim, S., Lee, Y. I., Kim, J., and Lee, J. H. (2020). The effect of human umbilical cord blood-derived mesenchymal stem cell media containing serum on recovery after laser treatment: a double-blinded, randomized, splitface controlled study. J. Cosmetic Dermatol. 19, 651-656. doi: 10.1111/jocd. 13063

Kim, J. Y., Song, S. H., Kim, K. L., Ko, J. J., Im, J. E., Yie, S. W., et al. (2010). Human cord blood-derived endothelial progenitor cells and their conditioned media exhibit therapeutic equivalence for diabetic wound healing. Cell Transplant. 19, 1635-1644. doi: 10.3727/096368910X516637

Kim, K. H., Blasco-Morente, G., Cuende, N., and Arias-Santiago, S. (2017). Mesenchymal stromal cells: properties and role in management of cutaneous diseases. J. Eur. Acad Dermatol. Venereol. 31, 414-423. doi: 10.1111/jdv.13934

Kim, Y. J., Ahn, H. J., Lee, S. H., Lee, M. H., and Kang, K. S. (2020). Effects of conditioned media from human umbilical cord blood-derived mesenchymal stem cells in the skin immune response. Biomed. Pharmacother. 118:109131. doi: 10.1016/j.biopha.2020.110789

Kim, Y. J., Seo, D. H., Lee, S. H., Lee, S. H., An, G. H., Ahn, H. J., et al. (2018). Conditioned media from human umbilical cord blood-derived mesenchymal stem cells stimulate rejuvenation function in human skin. Biochem. Biophys. Rep. 16, 96-102. doi: 10.1016/j.bbrep.2018.10.007

Kouhkheil, R., Fridoni, M., Abdollhifar, M. A., Amini, A., Bayat, S., Ghoreishi, S. K., et al. (2019). Impact of photobiomodulation and condition medium on mast cell counts, degranulation, and wound strength in infected skin wound healing of diabetic rats. Photobiomodul Photomed Laser Surg. 37, 706-714. doi: 10.1089/photob.2019.4691

Kusindarta, D. L., Wihadmadyatami, H., Fibrianto, Y. H., Nugroho, W. S., Susetya, H., Musana, D. K., et al. (2016). Human umbilical mesenchymal stem cells conditioned medium promote primary wound healing regeneration. Vet. World 9, 605-610. doi: 10.14202/vetworld.2016.605-610

Kwon, T. R., Oh, C. T., Choi, E. J., Kim, S. R., Jang, Y. J., Ko, E. J., et al. (2016). Conditioned medium from human bone marrow-derived mesenchymal stem cells promotes skin moisturization and effacement of wrinkles in UVBirradiated SKH-1 hairless mice. Photodermatol. Photoimmunol. Photomed 32, 120-128. doi: 10.1111/phpp.12224

Lee, H. J., Lee, E. G., Kang, S., Sung, J. H., Chung, H. M., and Kim, D. H. (2014). Efficacy of microneedling plus human stem cell conditioned medium for skin rejuvenation: a randomized, controlled, blinded split-face study. Ann. Dermatol. 26, 584-591. doi: 10.5021/ad.2014.26.5.584

Lee, J. Y., Oh, N., and Park, K. S. (2017). Ell3 modulates the wound healing activity of conditioned medium of adipose-derived stem cells. Dev. Reprod. 21,335-342. doi: $10.12717 / \mathrm{dr} .2017 .21 .3 .335$

Lee, M. J., Kim, J., Lee, K. I., Shin, J. M., Chae, J. I., and Chung, H. M. (2011). Enhancement of wound healing by secretory factors of endothelial precursor cells derived from human embryonic stem cells. Cytotherapy 13, 165-178. doi: $10.3109 / 14653249.2010 .512632$
Lee, S. M., Lee, S. C., and Kim, S. J. (2014). Contribution of human adipose tissue-derived stem cells and the secretome to the skin allograft survival in mice. J. Surg. Res. 188, 280-289. doi: 10.1016/j.jss.2013. 10.063

Lee, Y. I., Kim, J., Kim, J., Park, S., and Lee, J. H. (2020). The effect of conditioned media from human adipocyte-derived mesenchymal stem cells on androgenetic alopecia after nonablative fractional laser treatment. Dermatol. Surg. 46, 16981704. doi: 10.1097/DSS.0000000000002518

Li, J. Y., Ren, K. K., Zhang, W. J., Xiao, L., Wu, H. Y., Liu, Q. Y., et al. (2019). Human amniotic mesenchymal stem cells and their paracrine factors promote wound healing by inhibiting heat stress-induced skin cell apoptosis and enhancing their proliferation through activating PI3K/AKT signaling pathway. Stem Cell Res. Ther. 10:247. doi: 10.1186/s13287-019-1366-y

Li, T., Ma, H., Ma, H., Ma, Z., Qiang, L., Yang, Z., et al. (2019). Mussel-Inspired nanostructures potentiate the immunomodulatory properties and angiogenesis of mesenchymal stem cells. ACS Appl. Mater. Interfaces 11, 17134-17146. doi: $10.1021 /$ acsami.8b22017

Li, Y., Zhang, W., Gao, J., Liu, J., Wang, H., Li, J., et al. (2016). Adipose tissuederived stem cells suppress hypertrophic scar fibrosis via the p38/MAPK signaling pathway. Stem Cell Res. Ther. 7:102. doi: 10.1186/s13287-016-0356-6

Liu, J., Ren, J., Su, L., Cheng, S., Zhou, J., Ye, X., et al. (2018). Human adipose tissuederived stem cells inhibit the activity of keloid fibroblasts and fibrosis in a keloid model by paracrine signaling. Burns 44, 370-385. doi: 10.1016/j.burns.2017.08. 017

Ma, D., Kua, J. E. H., Lim, W. K., Lee, S. T., and Chua, A. W. C. (2015). In vitro characterization of human hair follicle dermal sheath mesenchymal stromal cells and their potential in enhancing diabetic wound healing. Cytotherapy 17, 1036-1051. doi: 10.1016/j.jcyt.2015.04.001

Maguire, G. (2013). Stem cell therapy without the cells. Commun. Integr. Biol. 6:e26631. doi: 10.4161/cib.26631

Martinez-Lopez, A., Montero-Vilchez, T., Sierra-Sanchez, A., Molina-Leyva, A., and Arias-Santiago, S. (2020). Advanced medical therapies in the management of non-scarring alopecia: areata and androgenic alopecia. Int. J. Mol. Sci. 21:8390. doi: $10.3390 /$ ijms 21218390

Mehanna, R. A., Nabil, I., Attia, N., Bary, A. A., Razek, K. A., Ahmed, T. A., et al. (2015). The effect of bone marrow-derived mesenchymal stem cells and their conditioned media topically delivered in fibrin glue on chronic wound healing in rats. Biomed. Res. Int. 2015:846062. doi: 10.1155/2015/846062

Mirabella, T., Hartinger, J., Lorandi, C., Gentili, C., van Griensven, M., and Cancedda, R. (2012). Proangiogenic soluble factors from amniotic fluid stem cells mediate the recruitment of endothelial progenitors in a model of ischemic fasciocutaneous flap. Stem Cells Dev. 21, 2179-2188. doi: 10.1089/scd.2011. 0639

Mizukami, H., and Yagihashi, S. (2016). Is stem cell transplantation ready for prime time in diabetic polyneuropathy? Curr. Diab. Rep. 16:86. doi: 10.1007/s11892016-0776-9

Moll, G., Ankrum, J. A., Kamhieh-Milz, J., Bieback, K., Ringden, O., Volk, H. D., et al. (2019). Intravascular mesenchymal stromal/stem cell therapy product diversification: time for new clinical guidelines. Trends Mol. Med. 25, 149-163. doi: 10.1016/j.molmed.2018.12.006

Moll, G., Hoogduijn, M. J., and Ankrum, J. A. (2020). Editorial: safety, efficacy and mechanisms of action of mesenchymal stem cell therapies. Front. Immunol. 11:243. doi: 10.3389/fimmu.2020.00243

Montero-Vilchez, T., Segura-Fernandez-Nogueras, M. V., Perez-Rodriguez, I., Soler-Gongora, M., Martinez-Lopez, A., Fernandez-Gonzalez, A., et al. (2021). Skin barrier function in psoriasis and atopic dermatitis: transepidermal water loss and temperature as useful tools to assess disease severity. J. Clin. Med. 10:359. doi: $10.3390 /$ jcm 10020359

Narita, K., Fukuoka, H., Sekiyama, T., Suga, H., and Harii, K. (2020). Sequential scalp assessment in hair regeneration therapy using an adipose-derived stem cell-conditioned medium. Dermatol. Surg. 46, 819-825. doi: 10.1097/dss. 0000000000002128

Oh, H. A., Kwak, J., Kim, B. J., Jin, H. J., Park, W. S., Choi, S. J., et al. (2020). Migration inhibitory factor in conditioned medium from human umbilical cord blood-derived mesenchymal stromal cells stimulates hair growth. Cells 9:1344. doi: 10.3390/cells 9061344

Ou, K. L., Kuo, Y. W., Wu, C. Y., Huang, B. H., Pai, F. T., Chou, H. H., et al. (2020). The potential of a hair follicle mesenchymal stem cell-conditioned medium for 
wound healing and hair follicle regeneration. Appl. Sci. (Switzerland) 10:2646. doi: 10.3390/APP10082646

Park, B. S., Kim, W. S., Choi, J. S., Kim, H. K., Won, J. H., Ohkubo, F., et al. (2010). Hair growth stimulated by conditioned medium of adipose-derived stem cells is enhanced by hypoxia: evidence of increased growth factor secretion. Biomed. Res. 31, 27-34. doi: 10.2220/biomedres.31.27

Park, C. S., Park, J. H., Kim, C. R., and Lee, J. H. (2019). Objective analysis of volume restoration in atrophic acne scars and skin pores: a split study using human stem cell-conditioned media. J. Dermatol. Treat. 32, 73-77. doi: 10.1080/09546634. 2019.1628915

Park, H. S., Son, H. Y., Choi, M. H., Son, Y., Kim, S., Hong, H. S., et al. (2019). Adipose-derived stem cells attenuate atopic dermatitis-like skin lesions in NC/Nga mice. Exp. Dermatol. 28, 300-307. doi: 10.1111/exd.13895

Park, J., Jun, E. K., Son, D., Hong, W., Jang, J., Yun, W., et al. (2019). Overexpression of Nanog in amniotic fluid-derived mesenchymal stem cells accelerates dermal papilla cell activity and promotes hair follicle regeneration. Exp. Mol. Med. 51:72. doi: 10.1038/s12276-019-0266-7

Park, J., Lee, J. H., Yoon, B. S., Jun, E. K., Lee, G. I, Kim, Y., et al. (2018). Additive effect of bFGF and selenium on expansion and paracrine action of human amniotic fluid-derived mesenchymal stem cells. Stem Cell Res. Ther. 9:293. doi: $10.1186 /$ s13287-018-1058-z

Pawitan, J. A. (2014). Prospect of stem cell conditioned medium in regenerative medicine. Biomed. Res. Int. 2014:965849. doi: 10.1155/2014/965849

Payushina, O. V., Butorina, N. N., Sheveleva, O. N., and Domaratskaya, E. I. (2018). Effect of mesenchymal stromal cells and conditioned media on healing of skin wound. Bull. Exp. Biol. Med. 165, 572-575. doi: 10.1007/s10517-018-4215-6

Pouriran, R., Piryaei, A., Mostafavinia, A., Zandpazandi, S., Hendudari, F., Amini, A., et al. (2016). The effect of combined pulsed wave low-level laser therapy and human bone marrow mesenchymal stem cell-conditioned medium on open skin wound healing in diabetic rats. Photomed Laser Surg. 34, 345-354. doi: 10.1089/pho.2015.4020

Prakoeswa, C. R. S., Natallya, F. R., Harnindya, D., Thohiroh, A., Oktaviyanti, R. N., Pratiwi, K. D., et al. (2018). The efficacy of topical human amniotic membranemesenchymal stem cell-conditioned medium (hAMMSC-CM) and a mixture of topical hAMMSC-CM + vitamin C and hAMMSC-CM + vitamin E on chronic plantar ulcers in leprosy:a randomized control trial. J. Dermatol. Treat. 29, 835-840. doi: 10.1080/09546634.2018.1467541

Prakoeswa, C. R. S., Pratiwi, F. D., Herwanto, N., Citrashanty, I., Indramaya, D. M., Murtiastutik, D., et al. (2019). The effects of amniotic membrane stem cell-conditioned medium on photoaging. J. Dermatol. Treat. 30, 478-482. doi: 10.1080/09546634.2018.1530438

Pu, C. M., Chen, Y. C., Chen, Y. C., Lee, T. L., Peng, Y. S., Chen, S. H., et al. (2019). Interleukin-6 from adipose-derived stem cells promotes tissue repair by the increase of cell proliferation and hair follicles in ischemia/reperfusiontreated skin flaps. Mediators Inflamm. 2019:2343867. doi: 10.1155/2019/23 43867

Raj, V., Claudine, S., Subramanian, A., Tam, K., Biswas, A., Bongso, A., et al. (2019). Histological, immunohistochemical, and genomic evaluation of excisional and diabetic wounds treated with human Wharton's jelly stem cells with and without a nanocarrier. J. Cell. Biochem. 120, 11222-11240. doi: 10.1002/jcb.28398

Ratajczak, M. Z., Kucia, M., Jadczyk, T., Greco, N. J., Wojakowski, W., Tendera, M., et al. (2012). Pivotal role of paracrine effects in stem cell therapies in regenerative medicine: can we translate stem cell-secreted paracrine factors and microvesicles into better therapeutic strategies? Leukemia 26, 1166-1173. doi: 10.1038/leu.2011.389

Robert, A. W., Azevedo Gomes, F., Rode, M. P., Marques da Silva, M., Veleirinho, M., Maraschin, M., et al. (2019). The skin regeneration potential of a proangiogenic secretome from human skin-derived multipotent stromal cells. J. Tissue Eng. 10:2041731419833391. doi: 10.1177/2041731419833391

Rong, X., Chu, W., Zhang, H., Wang, Y., Qi, X., Zhang, G., et al. (2019). Antler stem cell-conditioned medium stimulates regenerative wound healing in rats. Stem Cell Res. Ther. 10:326. doi: 10.1186/s13287-019-1457-9

Sabzevari, R., Roushandeh, A. M., Mehdipour, A., Alini, M., and Roudkenar, M. H. (2020). SA/G hydrogel containing hCAP-18/LL-37-engineered WJMSCs-derived conditioned medium promoted wound healing in rat model of excision injury. Life Sci. 261:118381. doi: 10.1016/j.lfs.2020.118381

Sagaradze, G., Grigorieva, O., Nimiritsky, P., Basalova, N., Kalinina, N., Akopyan, Z., et al. (2019). Conditioned medium from human mesenchymal stromal cells: towards the clinical translation. Int. J. Mol. Sci. 20:1656. doi: 10.3390/ ijms20071656

Saheli, M., Bayat, M., Ganji, R., Hendudari, F., Kheirjou, R., Pakzad, M., et al. (2020). Human mesenchymal stem cells-conditioned medium improves diabetic wound healing mainly through modulating fibroblast behaviors. Arch. Dermatol. Res. 312, 325-336. doi: 10.1007/s00403-019-02016-6

Seetharaman, R., Mahmood, A., Kshatriya, P., Patel, D., and Srivastava, A. (2019). Mesenchymal stem cell conditioned media ameliorate psoriasis vulgaris: a case study. Case Rep. Dermatol. Med. 2019:8309103. doi: 10.1155/2019/8309103

Seo, K. Y., Kim, D. H., Lee, S. E., Yoon, M. S., and Lee, H. J. (2013). Skin rejuvenation by microneedle fractional radiofrequency and a human stem cell conditioned medium in Asian skin: a randomized controlled investigator blinded split-face study. J. Cosmet Laser Ther. 15, 25-33. doi: 10.3109/14764172. 2012.748201

Shim, J. H. (2015). Hair growth-promoting effect of human dermal stem/progenitor cell-derived conditioned medium. Tissue Eng. Regen. Med. 12, 268-275. doi: 10.1007/s13770-015-0012-8

Shin, H., Ryu, H. H., Kwon, O., Park, B. S., and Jo, S. J. (2015). Clinical use of conditioned media of adipose tissue-derived stem cells in female pattern hair loss: a retrospective case series study. Int. J. Dermatol. 54, 730-735. doi: 10.1111 ijd. 12650

Sun, B., Guo, S., Xu, F., Wang, B., Liu, X., Zhang, Y., et al. (2014). Concentrated hypoxia-preconditioned adipose mesenchymal stem cell-conditioned medium improves wounds healing in full-thickness skin defect model. Int. Sch. Res. Notices 2014:652713. doi: 10.1155/2014/652713

Sun, J., Zhang, Y., Song, X., Zhu, J., and Zhu, Q. (2019). The healing effects of conditioned medium derived from mesenchymal stem cells on radiationinduced skin wounds in rats. Cell Transplant 28, 105-115. doi: 10.1177/ 0963689718807410

Tam, K., Cheyyatraviendran, S., Venugopal, J., Biswas, A., Choolani, M., Ramakrishna, S., et al. (2014). A nanoscaffold impregnated with human wharton's jelly stem cells or its secretions improves healing of wounds. J. Cell. Biochem. 115, 794-803. doi: 10.1002/jcb.24723

Tamari, M., Nishino, Y., Yamamoto, N., and Ueda, M. (2013). Acceleration of wound healing with stem cell-derived growth factors. Int. J. Oral. Maxillofac. Implants 28, e369-e375. doi: 10.11607/jomi.te17

Tarcisia, T., Damayanti, L., Antarianto, R. D., Moenadjat, Y., and Pawitan, J. A. (2017). Adipose derived stem cell conditioned medium effect on proliferation phase of wound healing in sprague dawley rat. Med. J. Indonesia 26, 239-245. doi: 10.13181/mji.v26i4.1755

Templin, C., Grote, K., Schledzewski, K., Ghadri, J. R., Schnabel, S., Napp, L. C., et al. (2009). Ex vivo expanded haematopoietic progenitor cells improve dermal wound healing by paracrine mechanisms. Exp. Dermatol. 18, 445-453. doi: 10.1111/j.1600-0625.2008.00809.x

Ueda, M., and Nishino, Y. (2010). Cell-based cytokine therapy for skin rejuvenation. J. Craniofac. Surg. 21, 1861-1866. doi: 10.1097/SCS. 0b013e3181f43f0a

Won, C. H., Choi, S. J., Kwon, O. S., Park, W. S., Kang, Y. J., Yoo, H. G., et al. (2010). The establishment and characterization of immortalized human dermal papilla cells and their hair growth promoting effects. J. Dermatol. Sci. 60, 196-198. doi: 10.1016/j.jdermsci.2010.08.015

Won, C. H., Jeong, Y. M., Kang, S., Koo, T. S., Park, S. H., Park, K. Y., et al. (2015). Hair-growth-promoting effect of conditioned medium of high integrin $\alpha 6$ and low CD 71 ( $\alpha 6 \mathrm{bri} / \mathrm{CD} 71 \mathrm{dim})$ positive keratinocyte cells. Int. J. Mol. Sci. 16, 4379-4391. doi: 10.3390/ijms16034379

Wong, S. P., Rowley, J. E., Redpath, A. N., Tilman, J. D., Fellous, T. G., and Johnson, J. R. (2015). Pericytes, mesenchymal stem cells and their contributions to tissue repair. Pharmacol. Ther. 151, 107-120. doi: 10.1016/j.pharmthera.2015.03.006

Wu, Y., Peng, Y., Gao, D., Feng, C., Yuan, X., Li, H., et al. (2015). Mesenchymal stem cells suppress fibroblast proliferation and reduce skin fibrosis through a TGF- $\beta 3$-dependent activation. Int. J. Lower Extremity Wounds 14, 50-62. doi: $10.1177 / 1534734614568373$

Xiao, S., Deng, Y., Mo, X., Liu, Z., Wang, D., Deng, C., et al. (2020). Promotion of hair growth by conditioned medium from extracellular matrix/stromal vascular fraction gel in C57BL/6 Mice. Stem Cells Int. 2020:9054514. doi: 10.1155/2020/ 9054514

Xu, Y., Guo, S., Wei, C., Li, H., Chen, L., Yin, C., et al. (2016). The comparison of adipose stem cell and placental stem cell in secretion characteristics 
and in facial antiaging. Stem Cells Int. 2016:7315830. doi: 10.1155/2016/73 15830

Yang, C. Y., Chang, P. Y., Chen, J. Y., Wu, B. S., Yang, A. H., and Lee, O. K. (2021). Adipose-derived mesenchymal stem cells attenuate dialysis-induced peritoneal fibrosis by modulating macrophage polarization via interleukin-6. Stem Cell Res. Ther. 12:193. doi: 10.1186/s13287-021-02270-4

Yoon, B. S., Moon, J. H., Jun, E. K., Kim, J., Maeng, I., Kim, J. S., et al. (2010). Secretory profiles and wound healing effects of human amniotic fluid-derived mesenchymal stem cells. Stem Cells Dev. 19, 887-902. doi: 10.1089/scd.2009. 0138

Yuan, B., Broadbent, J. A., Huan, J., and Yang, H. (2018). The effects of adipose stem cell-conditioned media on fibrogenesis of dermal fibroblasts stimulated by transforming growth factor- $\beta 1$. J. Burn Care Res. 39, 129-140. doi: 10.1097/ bcr.0000000000000558

Zhang, K., Yu, L., Li, F. R., Li, X., Wang, Z., Zou, X., et al. (2020). Topical application of exosomes derived from human umbilical cord mesenchymal stem cells in combination with sponge spicules for treatment of photoaging. Int. J. Nanomed. 15, 2859-2872. doi: 10.2147/ijn.S249751

Zhang, Q., Liu, L. N., Yong, Q., Deng, J. C., and Cao, W. G. (2015). Intralesional injection of adipose-derived stem cells reduces hypertrophic scarring in a rabbit ear model. Stem Cell Res. Ther. 6:145. doi: 10.1186/s13287-015-0133-y

Zhang, S., Chen, L., Zhang, G., and Zhang, B. (2020). Umbilical cord-matrix stem cells induce the functional restoration of vascular endothelial cells and enhance skin wound healing in diabetic mice via the polarized macrophages. Stem Cell Res. Ther. 11:39. doi: 10.1186/s13287-020-1561-x

Zhou, B. R., Xu, Y., Guo, S. L., Xu, Y., Wang, Y., Zhu, F., et al. (2013). The effect of conditioned media of adipose-derived stem cells on wound healing after ablative fractional carbon dioxide laser resurfacing. Biomed Res. Int. 2013:519126. doi: 10.1155/2013/519126

Zhou, B. R., Zhang, T., Bin Jameel, A. A., Xu, Y., Xu, Y., Guo, S. L., et al. (2016). The efficacy of conditioned media of adipose-derived stem cells combined with ablative carbon dioxide fractional resurfacing for atrophic acne scars and skin rejuvenation. J. Cosmet Laser Ther. 18, 138-148. doi: 10.3109/14764172.2015. 1114638

Zhou, H., Li, X., Yin, Y., He, X. T., An, Y., Tian, B. M., et al. (2020). The proangiogenic effects of extracellular vesicles secreted by dental pulp stem cells derived from periodontally compromised teeth. Stem Cell Res. Ther. 11:110. doi: 10.1186/s13287-020-01614-w

Zhou, P., Li, X., Zhang, B., Shi, Q., Li, D., and Ju, X. (2019). A Human umbilical cord mesenchymal stem cell-conditioned medium/chitosan/collagen/ $\beta$ glycerophosphate thermosensitive hydrogel promotes burn injury healing in mice. Biomed Res. Int. 2019:5768285. doi: 10.1155/2019/576 8285

Conflict of Interest: The authors declare that the research was conducted in the absence of any commercial or financial relationships that could be construed as a potential conflict of interest.

Publisher's Note: All claims expressed in this article are solely those of the authors and do not necessarily represent those of their affiliated organizations, or those of the publisher, the editors and the reviewers. Any product that may be evaluated in this article, or claim that may be made by its manufacturer, is not guaranteed or endorsed by the publisher.

Copyright (C) 2021 Montero-Vilchez, Sierra-Sánchez, Sanchez-Diaz, Quiñones-Vico, Sanabria-de-la-Torre, Martinez-Lopez and Arias-Santiago. This is an open-access article distributed under the terms of the Creative Commons Attribution License (CC BY). The use, distribution or reproduction in other forums is permitted, provided the original author(s) and the copyright owner(s) are credited and that the original publication in this journal is cited, in accordance with accepted academic practice. No use, distribution or reproduction is permitted which does not comply with these terms. 